\title{
Tribology of Ti6Al4V: A review
}

\author{
Jibin T PHILIP ${ }^{1}$, Jose MATHEW ${ }^{2}$, Basil KURIACHEN ${ }^{1, *}$ \\ ${ }^{1}$ Department of Mechanical Engineering, National Institute of Technology Mizoram, Aizawl 796012, India \\ ${ }^{2}$ Department of Mechanical Engineering, National Institute of Technology Calicut, Calicut 673601, India \\ Received: 11 May 2019 / Revised: 27 September 2019 / Accepted: 21 October 2019 \\ (C) The author(s) 2019.
}

\begin{abstract}
The deleterious innate attribute of Ti6Al4V, the workhorse material among the alloy series of titanium is its incompetent tribo-behavior. Infinite surface modification techniques, viz., the accretion of adherent appendage layers, diffusion hardening, infusion of residual stresses, microstructural evolution, and phase transformations were attempted to enhance the wear resistance of the alloy. The need lies to establish a bridge between the indigenous material properties and the tribo-characteristics of Ti6Al4V so that the enforced improvement techniques can raise the barriers of its applicability. A critical review of the microstructural transitions, mechanisms governing tribo-behavior and the parametric conditions leading to material removal at dry sliding conditions of Ti6Al4V, falls under the scope of this manuscript. Hence, the prime focus of the approach is to impart a clear-cut perception of the minute variations in mechanical, metallurgical, and tribological characteristics of the alloy at interactive instances with distinct counter-body surfaces.
\end{abstract}

Keywords: Ti6Al4V; tribology; sliding behavior; microstructure

\section{Introduction}

Tribologists have shown specific interest in titanium (Ti) and its series of alloys, due to their poor wear characteristics on counter-body interaction [1]. The material owns inherent properties such as high strength, low density, corrosion resistance, and superior biocompatibility $[2,3]$. Due to such adaptive characteristics, the Ti-alloys have a cutting-edge advantage over other light-weight alloys based on aluminium (Al) and magnesium $(\mathrm{Mg})$, especially in the fields of biomedical and tribological applications. The former has elevated advantage in terms of hardness, stiffness, and corrosion resistance [4]. High priority consideration has been extended for its implementation as rotors in bearings and disk brakes, requiring dynamic wear resistance [5]. Ti is chemically reactive with the majority of the cutting tool materials. The low thermal conductivity and elastic modulus make the conventional machining of the material to be inadequate and laborious [6]. The underlying factors that contribute to poor tribological properties of $\mathrm{Ti}$ and its alloys are enormous, inclusive of low strain hardenability, low resistance to shearing by plastic deformation, and impact of the loosely bound metal oxide layers contributing to high wear rate [7]. Further, the low d-bond characteristic of Ti (27\%), makes the metal active (highly alloying nature) and more prone to friction [8]. Consequently, the interactive characteristics such as highly unstable coefficient of friction $(\mathrm{CoF})$, a strong affinity for surfaces leading to adhesion and wear, susceptibility to material loss by fretting and propensity for seizure become the natural behavioral part of the material $[9,10]$. The unique properties of the material are reported to be due to adiabatic shear banding (ASB) and shear rate response (SRR) [11-13].

The utility domains of $\mathrm{Ti}$ and its alloys are numerous. Nonetheless, from a research perspective, its employability pertinent to biomedical applications is highly sensitive and worth requiring precise attention.

* Corresponding author: Basil KURIACHEN, E-mail: basilkuriachen@gmail.com 


\begin{tabular}{|c|c|c|c|c|}
\hline ASB & Adiabatic shear banding & Ti64 & \multicolumn{2}{|c|}{ Ti6Al4V } \\
\hline $\mathrm{BCC}$ & Body centered cubic & ThO & \multicolumn{2}{|c|}{ Thermal oxidation } \\
\hline BCOR & Burgers crystallographic orientation & $\mathrm{TL}$ & \multicolumn{2}{|c|}{ Tribo-layer } \\
\hline $\mathrm{CoF}$ & Coefficient of friction & TO & \multicolumn{2}{|c|}{ Tribo-oxides } \\
\hline $\mathrm{CP}$ & Commercially pure & TOL & \multicolumn{2}{|c|}{ Tribo-oxide layer } \\
\hline DLC & Diamond-like carbon & TS & \multicolumn{2}{|c|}{ Thermal softening } \\
\hline DMM & Dynamic material modeling & U-Ti64 & \multicolumn{2}{|c|}{ Untreated Ti6Al4V } \\
\hline DRX & Dynamic recrystallization & VHN & \multicolumn{2}{|c|}{ Vickers hardness number } \\
\hline DRY & Dynamic recovery & W-H plot & \multicolumn{2}{|c|}{ Williamson-Hall plot } \\
\hline DSC & Differential scanning calorimetry & XRD & \multicolumn{2}{|c|}{ X-ray diffraction spectrosco } \\
\hline EDX & Energy dispersive X-ray spectroscopy & YSZ & \multirow{2}{*}{\multicolumn{2}{|c|}{ Yttria stabilized zirconia }} \\
\hline $\mathrm{EH}$ & External heating/heat flux & & & \\
\hline $\mathrm{E} / \mathrm{H}$ & Elastic modulus to hardness ratio & \multicolumn{3}{|l|}{ Notations } \\
\hline FB & Flow banding & \multicolumn{3}{|l|}{$\mathrm{Al}$} \\
\hline FCC & Face centered cubic & $\mathrm{C}$ & & Carbon \\
\hline FESEM & Field emission scanning electron microscopy & $c_{0}$ & & Carbon \\
\hline $\mathrm{FH}$ & Frictional heating & Ce & & Cerium \\
\hline FS & Flow stress & $\mathrm{Fe}$ & & Iron \\
\hline FWHM & Full width at half maximum & $\mathrm{Fe}_{2} \mathrm{O}_{3}$ & & Iron (III) oxide \\
\hline $\mathrm{HCP}$ & Hexagonal close-packed & $\gamma_{\mathrm{cr}}$ & & Critical plastic strain \\
\hline HRC & Rockwell hardness & $\mathrm{La}$ & & Lanthanum \\
\hline $\mathrm{HV}$ & Vickers hardness & $\mathrm{Mg}$ & & Magnesium \\
\hline m-DRX & Meta-dynamic recrystallization & $\mathrm{N}$ & & Nitrogen \\
\hline MML & Mechanically mixed layer & $\mathrm{N}_{2}$ & & Dinitrogen \\
\hline N-Ti64 & Glow discharge nitrided Ti6Al4V & $\mathrm{O}$ & & Oxygen \\
\hline $\mathrm{PB}$ ratios & Pilling Bedworth ratios & $\mathrm{SiC}$ & & Silicon carbide \\
\hline SAE & Society of Automotive Engineers & $\mathrm{TaC}$ & & Tantalum carbide \\
\hline SEM & Scanning electron microscopy & $\mathrm{Ti}$ & & Titanium \\
\hline SG & Space group & $\mathrm{Ti}_{3} \mathrm{Al}$ & & Titanium aluminide \\
\hline SMT & Surface modification techniques & TNZT/TNZ & IZTO & $\mathrm{Ti}-35 \mathrm{Nb}-8 \mathrm{Zr}-5 \mathrm{Ta}$ \\
\hline SRR & Shear rate response & $\mathrm{TiO}$ & & Titanium oxide \\
\hline SRS & Shear rate sensitivity & $\mathrm{TiO}_{2}$ & & Titanium dioxide \\
\hline SS & Stainless steel & $\mathrm{Ti}_{8} \mathrm{O}_{15}$ & & Titanium suboxide \\
\hline $21 \mathrm{SRX}$ & Metastable $\beta$ & $\mathrm{V}$ & & Vanadium \\
\hline ST & Solution treatment & $\mathrm{V}_{2} \mathrm{O}_{3}$ & & Vanadium(III) oxide \\
\hline
\end{tabular}

Hussein et al. [14] conducted a review on the wear behavior of metallic-based bio-materials. The fundamental attributes of Ti-alloys which make them a potential candidate for biomedical applications include excellent biocompatibility, good mechanical strength, high resistance to corrosion, non-magnetic characteristics, lightweight, and relatively low modulus of elasticity. Nevertheless, the high CoF leading to the reduced wear resistance of the material can cause degrading effects. Various surface coating/treatment methodologies such as ion implantation, nitriding, carburization, boriding, and plasma spray coatings have got recommended as preventive measures against material failure due to wear of Ti-alloys [14]. In the 
context of bio-implants, the formation of wear debris at the interactive interface of the joints can result in inflammation, toxicity, and severe pain. Moreover, the shear strength of $\mathrm{Ti}$ is less competent for implementation as a base material for bone screws and plates [10]. To mitigate such adverse effects, distinctive methods are advisable, viz., heat treatment, surface coating, induction of compressive stresses, and as such [3]. The martensitic transformation of $\mathrm{Ti}$ achieved through water quenching from high temperatures (near to $\beta$-transus) has been reported to enhance the hardness of the material and thereby assist in the improvement of implant wear resistance [15]. Development of protective coatings and surface modification techniques (SMT) are the primary solutions that have been developed and found to fetch convincing results for reduction in wear of Ti and its alloys $[16,17]$. The implementation of yttria-stabilized zirconia (YSZ) coatings doped with lanthanum (La) and cerium (Ce) has been observed to be common practice to enhance the abrasive and erosive wear resistance of the material. Unfortunately, YSZ appendage layers are identified to get spalled off at tribo-interactive sliding conditions of long duration [18]. The recognized practical incompetency of coatings has led the focus on the structural modification of material to minimize imposed damage/material loss due to the impinging wear mechanisms [19-21]. The SMT has been implemented in the past to improve the friction and wear characteristics of $\mathrm{Ti}$ and its alloys through laser surface treatment [7], nitriding [22], and ion implantation [23]. The wear resistance of the material is also found to be enhanced by nitriding (glow-discharge) methods. Nonetheless, at high speed and load conditions, spalling assisted fragmentation leads to the generation of debris particles at the interface resulting in severe wear by third body abrasion [24, 25]. Furthermore, the highly reactive nature of $\mathrm{Ti}$ with carbon, oxygen, and nitrogen has enhanced the possibility for surface modification of the functional material through diffusion-based techniques. The improvement in tribo-properties of the materials (inclusive of $\mathrm{Ti}$ and its alloys) is reported to be achievable by a simplified, economical, and eco-friendly method of thermal oxidation [26].

Ti6Al4V (henceforth referred to as "Ti64", grade 5), is a multi-phase alloy $(\alpha+\beta)$ of Ti with substantial utility in various domains of the engineering, medicine, and research. Apart from the alloying elements, viz., aluminum (Al, $6 \%, \alpha$-stabilizer) and vanadium $(\mathrm{V}, 4 \%$, $\beta$-stabilizer), it consists of components such as iron $(\mathrm{Fe}, 0.25 \%)$ and oxygen $(\mathrm{O}, 0.2 \%)$, in trace quantities. The application base of the alloy is vast, encapsulating the fields of aerospace industry (turbine blades, structural parts), biomedicine (osseointegration, orthopaedic, dental implants and wheelchairs), sporting equipment (golf club bats, bicycle frames) [1, 27], and chemical process industries (valves and pipe fittings) [9]. The material possesses extensive capabilities such as strength to density ratio, low elastic modulus, absolute inertness to in-vivo environments, corrosion resistance, the capacity to be knit with bones and tissues, and as such $[1,4]$. On the downside, the Ti64 alloy also has several indigenous behavioral characteristics that delimitate its scope of applicability. The alloy is known for its higher strength than commercially pure (CP) Ti. Nonetheless, its thermal conductivity is nearly $60 \%$ lower than the latter [28]. Above all, the poor tribo-properties of the material leads to severe friction and wear conditions during body to counterbody interactions, resulting in material removal and seizure [7,9]. At critical sliding conditions of high speed and load, the wear mechanism in Ti64 favors the transfer of material to the counter-face [29-31]. Lin et al. [32] reviewed the possibility of improving the tribo-behavior of Ti64 alloy through surface alloying by employing double glow plasma discharge process. A considerably hard and low friction alloyed layer got developed using the technique which possesses strong metallurgical bonding with the substrate. Later, Lepika and Dahlke [33] conducted a review of various surface modification techniques to develop triboadaptive Ti64 surfaces for biomedical applications. Superior anti-wear properties were found to be achievable by deposition of carbon layers (amorphous) in the form of diamond-like carbon (DLC) or tantalum carbide $(\mathrm{TaC})$ coatings. The sliding behavior of steel and aluminum (at low velocities below $1 \mathrm{~m} \cdot \mathrm{s}^{-1}$ ) has got governed by the wear mechanisms, viz., oxidation, and delamination [34]. Their oxidative wear behavior is at close similitude to that in the case of Ti64, at low 
load conditions [35]. The oxidation of metallic regions combined with mechanical action leads to the formation of surface oxide layers in the form of islands. They are highly unstable and get continuously formed and worn off, simultaneously [36]. Among the various parameters monitoring the material sliding characteristics of the Ti64 alloy, the velocity and load retain a significant role. At low and high sliding velocities, T1-Welsh transition (mild to severe wear) and Quinn's-type wear (oxidative), respectively, are the dominant material removal mechanisms, influenced by the applied load [37, 38]. Whereas, the dynamic recrystallization (DRX) assisted thermal softening (TS) active in specific materials (at chosen temperature conditions) can hinder the occurrence of the Quinn'stype wear (mild) at peak velocities, leading to severe metallic wear through delamination [39].

Finally, the tribo-behavior of Ti-alloys (esp. Ti64) in the subject context) remains ambiguous due to its dependency on various factors, viz., thermal oxidation (ThO), tribo-oxidation/oxides (TO), tribo-oxide layer (TOL), mechanically mixed layer (MML), adiabatic shear banding (ASB), shear rate sensitivity/response (SRS/SRR), dynamic recrystallization (DRX), flow stress (FS), external heating/heat flux (EH), frictional heating (FH), and thermal softening (TS). From the applicability standpoint (to modify/enhance the surface/material properties), it is essential to elucidate the frictional and wear characteristics of the alloy based on sound concepts. Additionally, the influence of the process sliding conditions (velocity, load, and temperature), counter-body material, and the presence of foreign particles/materials can significantly influence the process. Henceforth, the focal point of this paper was to review, investigate, and consolidate the known facets pertinent to the tribo-behavior of Ti64 with precise emphasis to the below detailed:

- Microstructural transformations in terms of structure (body centered cubic (BCC)/face centered cubic (FCC)), composition (percentage of $\alpha$ and $\beta$ stabilizers) and phases $\left(\alpha, \beta, \alpha^{\prime \prime}, \alpha^{\prime \prime \prime}\right.$, and $\left.\omega\right)$.

- Factors affecting tribo-behavior (ThO, TO, MML, ASB, SRS/SRR, DRX, FS, EH, FH, and TS).

- Variations in friction and wear characteristicsof the alloy during dry interactive sliding against distinct counter-body surfaces (behavioral plots, SEM metallographic images (worn-pin and wear debris)).

\section{Microstructural evolution}

The superiority of the Ti-alloys lies vis a vis to the fact that a broad spectrum of microstructures is achievable based on the alloy chemistry and the thermal/mechanical processing methods. Hence, the desired properties can be activated based on specific application requirements. The microstructure and phases of the material at room temperature are governed majorly by the chemical composition (percentage of $\alpha$ and $\beta$-stabilizers) and its processing history (thermal/mechanical). The alloy is categorized to have grouped into distinct grades based on the microstructural orientation/phases $(\alpha, \beta, \alpha+\beta)$ and the range of added stabilizers. Three types of stabilizers are used to be alloyed with Ti to enhance its indigenous capabilities, viz., $\alpha$-stabilizers (aluminum, carbon, nitrogen, oxygen), $\beta$-stabilizers (vanadium, molybdenum, tantalum, niobium) and $\alpha-\beta$ stabilizers (zirconium, tin) [40]. During plastic deformation and phase transition/ recrystallization, the $\mathrm{HCP}$ structured $\mathrm{Ti}$, zirconium, and its alloys, develop crystallographic textures causing the material to be anisotropic [27, 41-43]. Moreover, the microstructure has a principal role in controlling/ monitoring the mechanical properties of $\mathrm{Ti}$ and its alloys [44, 45]. The distinction in the imposed thermal processing methods can lead to the development of structurally diverse phase orientations of the material, namely lamellar, bi-model, and equiaxed [46]. The SEM metallographic images of the specified phase orientations are as depicted in Fig. 1. Enormous counts of unique properties associated with the material having different structural characteristics, aid in the selection of the alloy for practical applications. The heavily utilized category is that of the bi-modal microstructure (considered to be a blend of lamellar and equiaxed structures), implemented majorly for industrial applications in the fabrication of components for machinery [45, 47]. Accordingly, the combined advantages of both the lamellar and equiaxed phase orientations are reported to be owned by the bi-modal microstructure [47]. The competent properties of the microstructure are in terms of ductility, yield strength, tensile strength, and fatigue strength, which has imparted a cutting edge for the same over their counterparts [48]. The fully lamellar and equiaxed microstructures of the material are identified to have 
(a)

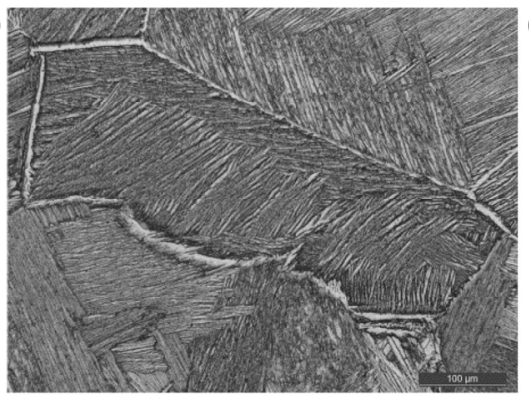

(b)

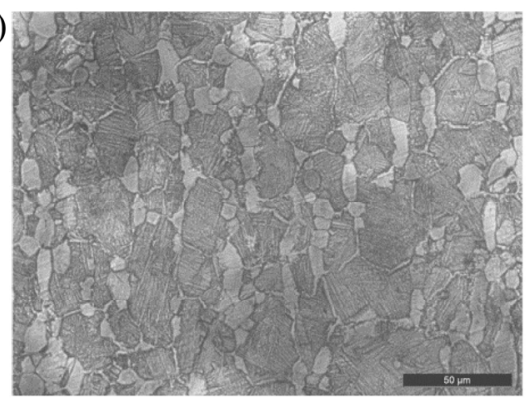

(c)

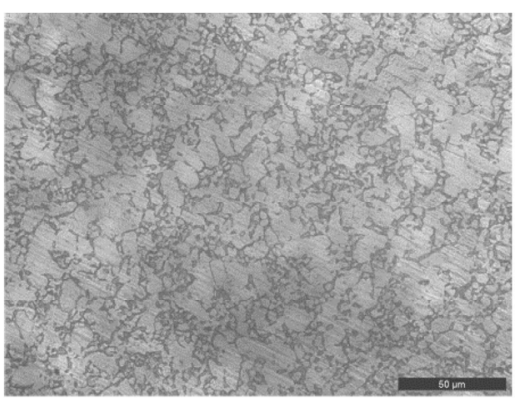

Fig. 1 Microstructures of Ti and its alloys developed at various heat treatment conditions: (a) lamellar; (b) bi-modal; (c) equiaxed. Reproduced with permission from Ref. [50]. Copyright Springer Nature, 2014.

superior properties such as fracture toughness, resistance to fatigue crack propagation, creep resistance for the former, and fatigue strength, ductility, preferability for superplastic deformation associated with the latter, respectively $[47,48]$. The Ti64 $(\alpha+\beta$ phase $)$ alloy is generally utilized in "mill annealed condition" to achieve enhanced mechanical properties, viz., tensile, yield and fatigue strengths when subject to solution treatment (ST), quenching and aging. The method of quenching in metals (e.g., steels) by water/oil was found to enhance the hardness of the material and thereby wear resistance [49]. The microstructural transformations undergone by the Ti64 alloy subject to various heat treatment conditions and thermally influential environments are significant to have elucidated. An overall understanding of phase transformations pertinent to the material $\left(\alpha, \beta, \alpha^{\prime}, \alpha^{\prime \prime}\right)$, morphological (shape, size, orientation) and quantitative (percentage distribution, uniformity) levels of the distinct phases, and recrystallization is essential for productive utilization of the material. Consequently, from an applicability standpoint, these characteristics will govern the mechanical, metallurgical, and tribological competency of the alloy for operational conditions.

In Ti64 ( $\alpha+\beta$ alloy), both the phases $\alpha$ and $\beta$ are reportedly stable at room/ambient temperature conditions [51]. The $\alpha$-phase (hexagonal close-packed (HCP), SG: P63/mmc) is the major, which will get transformed progressively to $\beta$-phase (minor, bodycentered cubic (BCC)) with increment in temperature on ST. The transition gets completed once the $\beta$-transus temperature $\left(\approx 980{ }^{\circ} \mathrm{C}\right)$ has been attained [52]. The $\beta$-treated structure, generally in the form of acicular or lamellar orientations is achieved through processing/ heat treatment of the alloy above the transformation temperature. The mechanical processing and heat treatment below the transformation temperature in the $\alpha+\beta$ phase-field develops a combination of equiaxed $\alpha$ and $\beta$-phases [4]. The final volume fraction and morphology of the respective phases $(\alpha$ and $\beta$ ), is governed by ST temperature, rate of cooling, and the aging temperature [44]. The microstructural evolutions in terms of controlling and optimization of the type, morphology [53, 54], percentage/amount of the $\alpha$ and $\beta$-phases [55-57] are achievable by the aid of thermal treatment processing methods. The transformation of $\beta$ to $\alpha^{\prime}$ (martensite) or much finer counter-parts of the phases $(\alpha$ or $\beta$ ) themselves is found to enhance the mechanical properties of the Ti64 alloy through ST methods, succeeded by quenching and aging. The shift can be achieved basically by two distinct routines: (i) martensitic transformation and (ii) controlled diffusion methods [51]. Then, the microstructure of the material consequently will be monitored by the morphology and diversity of the developed $\alpha^{\prime}$ phase. Nevertheless, to achieve the required structural efficiency of the alloy, extremely meticulous procedural routines are essential to diversify the phase transitions $(\alpha-\alpha$ or $\left.\beta-\alpha^{\prime}\right)$ and operate within the curbs of the heat treatment process possibilities [58]. The rapid quenching/cooling of the alloy from high temperatures of the order of $1,050{ }^{\circ} \mathrm{C}, 800{ }^{\circ} \mathrm{C}$ and $650{ }^{\circ} \mathrm{C}$ has resulted in the transformation of $\beta$-phase to the $\alpha^{\prime}$-phase, characterized by the formation of fine-needle like structures [47, 55]. Moreover, the latter phase was identified to undergo vanadium ( $\beta$-stabilizer) segregation and aluminium ( $\alpha$-stabilizer) curtailment [59]. Further, the decomposition of $\beta$-phase through martensitic transformation by quenching/quenching and aging leads to the develo- 
pment of acicular (plate-like) structures. Possibilities also do exist for the formation of other acicular and lenticular (plate-like structures), even without the martensitic transformation. The $\alpha^{\prime}$-phase developed through the $\beta$-phase transition will unquestionably be acicular with variability in the fineness of structure. The two primary martensitic phase structures are $\alpha^{\prime}$ (alpha prime) and $\alpha^{\prime \prime}$ (alpha double-prime) having crystal lattice structure of hexagonal and supersaturated orthorhombic, respectively. The $\alpha^{\prime}$ is identified to be an acicular phase similar in appearance of microstructural orientation to acicular $\alpha$ (alpha). The formations of both $\alpha^{\prime}$ and $\alpha^{\prime \prime}$ is through quenching/ cooling subsequently undergoing decomposition during the process of aging to get transformed to $\alpha$ and $\beta$-phases. The primary $\alpha$ (alpha) remains equiaxed (globular), but the $\alpha$ and $\alpha^{\prime}$ (transformed $\beta$-phases) take the form of acicular or elongated structures. The percentage of primary $\alpha$ and the fineness of the developed martensitic phases can govern the properties of the alloy [40]. The phase transition diagram of Ti64 based on various rates of cooling is as shown in Fig. 2. The formation of $\alpha^{\prime \prime}, \alpha^{\prime \prime \prime}$ and meta-stable $\beta$-phase (sometimes inclusive of $\omega$-phase) can happen based on the percentage of $\beta$-stabilizers, with its increased solute content [60]. Since the amount of vanadium ( $\beta$-stabilizer) is limited in case of Ti64, the possibility is only for the formation of $\alpha^{\prime}$-phase through transformation ensuing quenching [61]. Based on the cooling rate, the homogenization of the $\beta$-phase can lead to

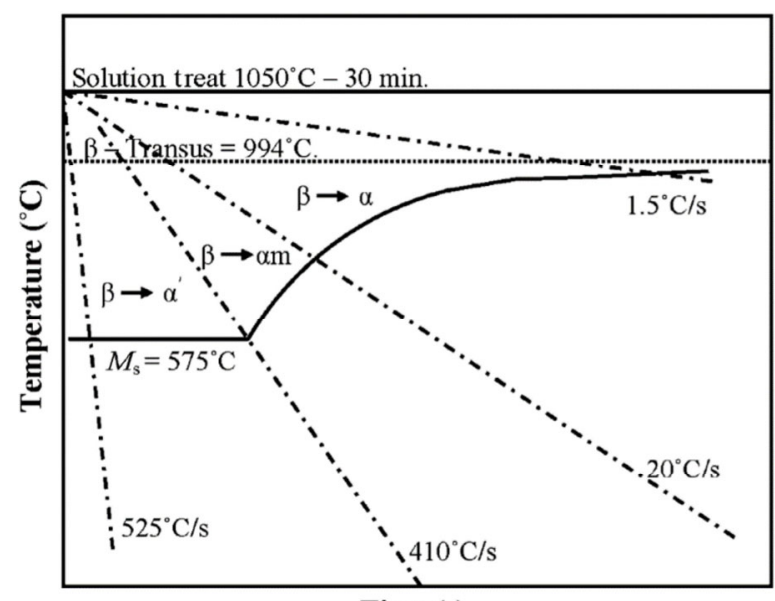

Time (s)

Fig. 2 The phase transition diagram of Ti64 based on the rate of cooling. Reproduced with permission from Ref. [55]. Copyright Elsevier, 1998. the development of colonized plate-like $\alpha$-phase (at slow cooling), basket-weave or fully lamellar structure (at medium cooling) and Widmanstätten (at rapid cooling), respectively [43, 62]. Significance of cooling rate lies in the fact that it governs the structure of the transformed lamellas and the response to precipitation during aging [44]. At the enhanced cooling rate, the size of the $\alpha$-phase lamellar structures gets minimized, and with further increment to higher rates of cooling, the size of the lamellas accordingly reduces to form a single plate structure of martensite [45]. The $\beta$-phase transformation to the acicular $\alpha$ and $\alpha^{\prime}$ phases can impart high hardness and tensile strength to the material surfaces. It is possibly aided by the quenching induced phase transition to $\alpha^{\prime}$-structure (HCP, SG: P63 $/ \mathrm{mmc}, a=b=0.2946 \mathrm{~nm}, c=0.29525 \mathrm{~nm})[63,64]$ and the subsequent aging, resulting in the formation of the acicular $\alpha$ and fine $\beta$-phases, respectively [65, 66]. In quenched Ti64 specimens, the visible platelet like structures are acicular $\alpha^{\prime}$-phase (HCP) which may undergo twinning. During the aging process, the martensitic phase $\left(\alpha^{\prime}\right)$ supersaturated in $\beta$-stabilizers will get decomposed to $\alpha$ and $\beta$-phases. Moreover, the development of intermetallic compounds such as $\mathrm{Ti}_{3} \mathrm{Al}$ or precipitation of $\beta$-phases may occur during aging at low temperatures [51]. The precipitation of the fine $\beta$-particles will occur along the plate boundaries (having $\beta$-phase layers) and at the regions of dislocations [67-69].

The martensitic transformation in Ti64 is associated with the existence of peak dislocation densities and transition-infused stresses [51, 70]. The reduction in dislocation densities may occur ensuing aging, but it would be large enough to be more prominent in comparison to the as-received samples. The presence of dislocation results in the development of micro-strain, which can lead to the broadening of peaks in XRD patterns, generally measured in terms of the full width at half maximum (FWHM) [71, 72]. Thereby induced lattice strain due to quenching and aging, also contributes significantly to the enhanced hardness and reduced ductility of the samples [61]. Besides, phase transitional strains also get imposed on the material during martensitic transformations [51, 70]. The same can be quantified using the typical Williamson-Hall (W-H) plot, which is generally used 
for randomly textured or powered specimens and does not account for the peak broadening due to anisotropy [73, 74]. The $\beta$-phase transformation in Ti64 or any other HCP structures to martensitic phases, through annealing, will obey the relationship of Burgers crystallographic orientation (BCOR) [75].

$$
\{0001\}_{\alpha} / /\{110\}_{\beta} \text { and }<11-20>_{\alpha} / /<111>_{\beta}
$$

According to BCOR, the formation of minimum dislocation density interfaces is observable in multiphase systems involving combined BCC-HCP structural orientations (as in Ti64) and their corresponding transformations [43]. Moreover, at various cooling rates, the $\beta$-phase can get transformed into 12 distinct variants of the $\alpha$-phases [76, 77]. The formation of respective phases got governed by the enforced state and processing conditions, instigating the $\beta$-transition. Nevertheless, a maximum number of 6 variants consists of $\beta$-grains. The evaluation of $\beta$-phase transformation assisted modification of textures, suggests that the variant selection does not occur during quenching in CP Ti. The same happens when $\beta$-phase will get subjected to substantial deformation above the level of transformation [77]. Furthermore, if the interacting counter-body possesses larger abrasive grains in contrast to the precipitated fine $\beta$-phase, or if the debris particles generated are geometrically larger, it results in the easy removal of the precipitates along with its associated volumes from the substrate surface. Consequently, the enhancement in hardness achieved by ST and quench-aging does not have a precise role in improving the abrasive wear resistance of the material [78]. Besides, since the elastic modulus is relatively independent of the structural variations, the value maintains its constancy, regardless of the increment in hardness ensuing heat treatment. Accordingly, the elastic modulus to hardness ratio $(E / H)$ declines, favoring abrasive wear assisted material removal by micro-cutting in case of quench-aged samples having higher hardness than the as-received Ti64 material [79]. The spatial orientation of the $\alpha / \beta$ phases and the crystallographic textures ( $\alpha$-phase) predominantly govern the mechanical behavioral responses of the $\mathrm{Ti}$ and its series of alloys [61].

$\mathrm{Xu}$ and Kriegel [80] investigated the martensitic transformation of the Ti64 alloy ensuing ST, quenching, and water cooling. Rapid quenching aided in the martensitic transformation of the $\beta$-phase. The phase transformation got instigated at a temperature lower than $850{ }^{\circ} \mathrm{C}$, and the $\beta$-transus temperature is within the range of $900-950{ }^{\circ} \mathrm{C}$. The quenching from $850{ }^{\circ} \mathrm{C}$ developed trace quantities of $\alpha^{\prime}$-prime at random regions with broad spacing between the primary $\alpha$-phase and the grain boundaries possessing a zig-zag geometry (irregular). Further, quenching from a higher temperature of $900{ }^{\circ} \mathrm{C}$ resulted in the formation of enhanced $\alpha^{\prime}$ and its primary counter-part shifting to an equiaxed geometric state. Increment in grain size of $\beta$-phase and its corresponding volume fraction occurred at high-temperature quenching from $950{ }^{\circ} \mathrm{C}$. The microstructure consisted majorly of the primary $\alpha$ and the $\alpha^{\prime}$ (wide and coarse needle-like structures), and increased precipitation of more martensite occurred with water cooling. From the differential scanning calorimetry (DSC) and x-ray diffractogram (XRD) analyses, it became evident that with rapid quenching, $\alpha^{\prime}$ and $\alpha^{\prime \prime}$ phases were developed and both get decomposed with aging. With a rise in quenching temperature, the lattice constants also showed increment, except for the decline identified at $950{ }^{\circ} \mathrm{C}$. This can be attributed to as since the peak temperature considered was higher than the $\beta$-transus and hence complete transformation to $\beta$-phase takes place during quenching from $950{ }^{\circ} \mathrm{C}$. Moreover, the said phase supports diffusion, thereby causing an increment in lattice distortion due to solidification. The step-wise transformation takes place in $\alpha^{\prime}$, firstly from body-centered cubic (BCC) to face-centered cubic (FCC) and then to hexagonal closed packed structure $(\mathrm{HCP})$. The cooling rate governs the $\beta$-phase transformation to various martensitic phases, hence the variation in properties of the material processed at distinct cooling rates resulting in the development of discrete microstructures [80].

Feng and Khan [19], elucidated the influence of distinct quenching mediums on the wear characteristics of Ti64 alloy. The alloy was heat-treated to temperatures of $750{ }^{\circ} \mathrm{C}$ and $1,000{ }^{\circ} \mathrm{C}$ (below and above the $\beta$-transus). The material was then quenched separately in a different fluid medium of oil, water and liquid 
nitrogen for $24 \mathrm{~h}$. For the sample subjected to ST at $750{ }^{\circ} \mathrm{C}$ followed by quenching using liquid nitrogen $\left(\mathrm{N}_{2}\right)$, was found to undergo negligible variation in its microstructure. The primary $\alpha$ and $\beta$ phases were easily distinguishable as in the case of the bare Ti64 specimen surface. The characteristic equiaxed structure of $\alpha$-phase can be easily identified from the metallography images of the as-received and the ST to be quenched (with $\mathrm{N}_{2}$ ) Ti64, as shown in Fig. 3. As the imposed heat treatment temperature $\left(750{ }^{\circ} \mathrm{C}\right)$ was much lower than the $\beta$-transus temperature, the possibility does not exist for martensitic ( $\alpha^{\prime}$ or $\left.\alpha^{\prime \prime}\right)$ transitions during quenching. The ST (at $1,000{ }^{\circ} \mathrm{C}$ ) Ti64 quenched using disparate fluid mediums such as oil, water, and $\mathrm{N}_{2}$ was observed to undergo distinguishable microstructural transformations, in comparison to that of the as-received Ti64 surfaces (Fig. 4). It is significant to note that the imposed ST temperature was higher than that of $\beta$-transus pertinent to Ti64 alloys. The formation of $\alpha^{\prime}$-phase (martensite) with its characteristic needle-like structure got formed in the case of all the samples quenched in different mediums, but with slight variation in fineness of their respective structures. The oil and water quenched
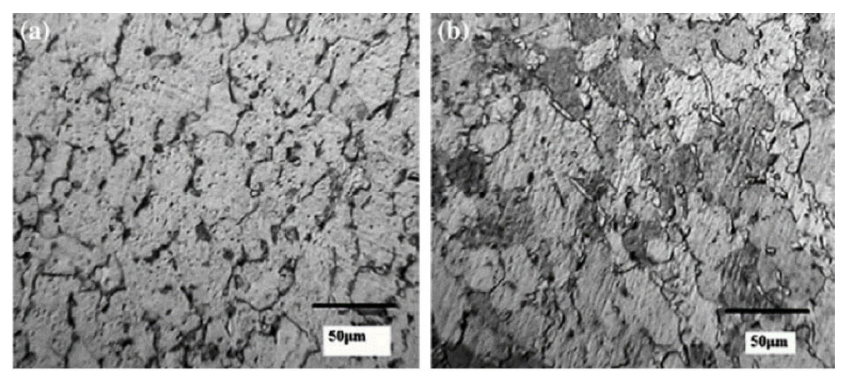

Fig. 3 Metallography images of Ti64 surfaces: (a) as received; (b) ST at $750{ }^{\circ} \mathrm{C}$ (30 min) and quenched in $\mathrm{N}_{2}$. Reproduced with permission from Ref. [19]. Copyright Springer Nature, 2007. samples have primary $\alpha$-phases scattered to be present at discrete positions identifiable from their microstructural images. The $\alpha$-phase transformation (caused by slow cooling rate) and better cooling characteristics of $\mathrm{N}_{2}$, aided for the same. Further, the subsequently developed $\alpha$-lamellas do not vary significantly in their sizes. The needle-like structures corresponding to $\alpha^{\prime}$-phase were non-uniformly distributed and scattered [19].

Hadke et al. [61] investigated on the microstructural transformations and the abrasive characteristics of Ti64 sliding against a silicon carbide abrasive counterface (150 grit). The specimens were subjected to ST at $1,339 \mathrm{~K}$ for an hour with subsequent quenching in oil, followed by aging (at $823 \mathrm{~K}$ ) and air-cooled to ambient temperature at inert conditions. The XRD patterns of the as-received and quench-aged Ti64 samples are as shown in Fig. 5. The primary $\alpha$ and $\beta$-phases were observable from the phase patterns of the former. The peaks representing the $\alpha$-phase were extremely narrow, guaranteeing the fact that the as-received Ti64 samples were in a stress-free state. As confirmed from the SEM and EDX analyses, the $\beta$-phase particles got uniformly distributed in the $\alpha$-matrix with a higher percentage of vanadium ( $\beta$-stabilizer) concentration. The volume fraction of the $\beta$-phase was $2 \%$ (approx.), and the average grain size of $\alpha$-phase was $2 \mu \mathrm{m}$ (approx.). Nonetheless, in the case of quench-aged Ti64 sample, only the $\alpha$-phases could be identified from the XRD patterns (Fig. 5(b)). Although the characteristic peak of $\alpha$-phase Ti64 (\{002\}) might have been over-lapped by the $\beta$-phase (\{101\}) as they occurred significantly close to each other, it was not the actual case as the peaks were found to be narrow at the quench-aged state as well.
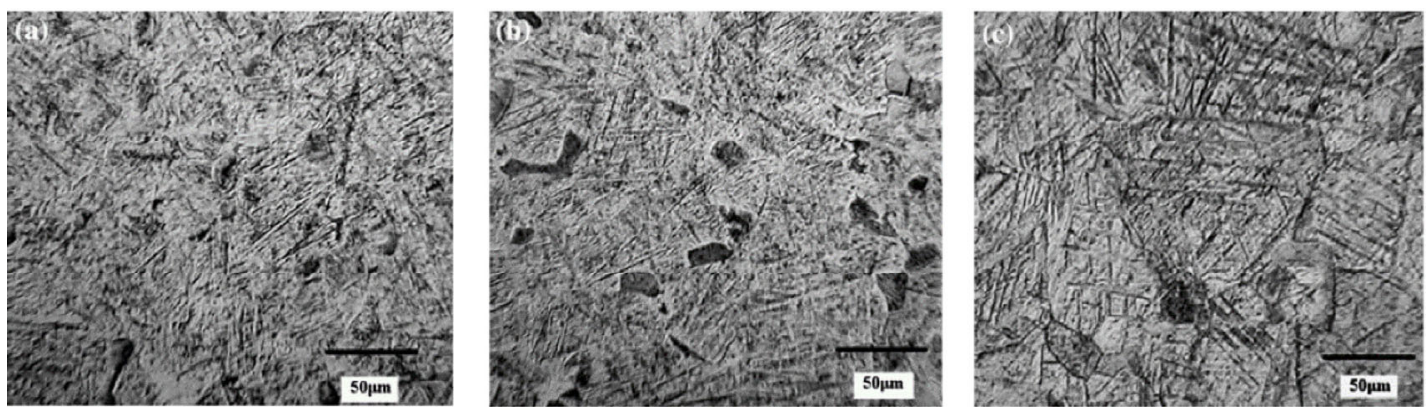

Fig. 4 Metallography images of Ti64 surfaces ST at 1,000 ${ }^{\circ} \mathrm{C}$ (30 min) and quenched: (a) oil; (b) water; (c) N2. Reproduced with permission from Ref. [19]. Copyright Springer Nature, 2014. 

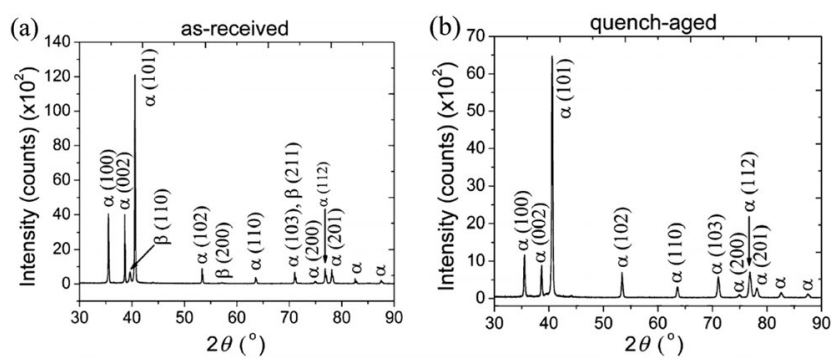

Fig. 5 XRD patterns of the characterized Ti64 surfaces: (a) as-received; (b) quenched-aged. Reproduced with permission from Ref. [61]. Copyright Springer Nature, 2015.

The crystallographic texture of the test sample was identified to own a significant role in the observed deviation. Among the quench-aged samples, the perpendicular nature of $\alpha$-platelets demonstrates the transformation of $\beta$-phase to $\alpha^{\prime}$ (martensite) and $\alpha$ states. The characteristic acicular structure of the $\alpha$-phase is identifiable from the metallographic images. Such a morphology imparts high hardness and high tensile strength to the substrate material surfaces [61].

The quench-aged Ti64 samples were found to impart better properties in terms of strength and hardness when compared to the as-received specimens. The precipitation of the fine $\beta$-phase was suggested to have majorly contributed towards the same. Contrarily, the softer nature of $\beta$-precipitates has led to its shearing while undergoing plastic deformation. Hence, the improved properties do not contribute to enhancing the wear resistance of the substrate surfaces. Moreover, the size and hardness of the $\mathrm{SiC}$ abrasive particles were nearly quintuple times higher than the test materials, which also had a dominant role in the specified scenario. Although $\alpha$ (acicular) and fine $\beta$-phases got developed ensuing quench-aging, the softer $\beta$-phase is effortlessly plowed off by the abrasive action of the counter-body surface. The possible constructive advantage associated with the increment in hardness got downgraded by microstructural changes in the substrate. From the XRD results corresponding to the wear debris, the peaks corresponding to the $\alpha$-phase and the SiC were identified to be dominating. Further, the FWHM values of wear debris related to as-received specimens were found to be higher than the corresponding values of the quench-aged samples. Hence, the maxim that the former has undergone larger deformation during abrasive wear conditions was confirmed. The differences in average FWHM of the as-received and quench-aged specimens at mild and severe wear conditions were determined to be $0.3737^{\circ}$ and $0.1421^{\circ}$, respectively. Hence, similar material removal mechanisms dominated at severe wear than at mild wear conditions [61].

\section{Mechanisms governing tribo-behavior}

Rigney [81] has reported (based on his experimental findings) that the sliding of metals is governed by multiple mechanisms, viz., plastic deformation (due to interlocking of asperities and adhesion), development of wear debris (through interfacial material removal), material transfer/migration (through free electron transfer, diffusion), reaction with environment (oxidation), MML formation and development of TOL. In work by Raj et al. [1], the tribo-characteristics of Ti64 sliding against SS316L steel disk got evaluated. The wear resistance was reported to be governed by TO, SRR, MML, and the conditions of heat flux (caused by external heating ( $\mathrm{EH})$ or $\mathrm{FH}$ ) at the interface. Budinski [9] notified that the wear resistance of $\mathrm{CP} \mathrm{Ti}$ (with lower hardness) is superior to Ti64 alloy (with higher hardness), which contradicts the Archard's law. Moreover, the Ti64 alloy exhibits inefficient abrasive wear in comparison to stainless steel (300 series) of low relative hardness, hence has got practically disregarded from systems involved with high abrasion rate. Generally speaking (as per Archard's law), the hardness of the material is the single most significant parameter which governs the abrasive wear behavior. Based on experimental observations in the past [9], it got inferred that the role played by hardness may be significant in specific cases but, other factors such as mechanical, microstructural and surface characteristics of the sliding material and the counter-face also have an influential role. Hence, Archard's law can give only a first-hand estimate regarding the cause and occurrence of the abrasive phenomenon [79]. Similar behavior was notified at distinct conditions by Hadke [61], Feng and Khan [19] in the context of the asreceived and quench-aged Ti64 surfaces. The latter was found to have suffered a higher wear rate at similar dry sliding conditions to that of the as-received Ti64 samples (which were comparatively less hard). The underlying reason behind such discrepancy in behavior can be explained based on the microstructural 
transformations and shift in wear mechanisms of the various materials [61]. Although hardness plays a significant role, it can only impart a limited knowledge in the prediction of the friction and wear responses of the material surfaces.

Wang et al. [82] suggested two distinct mechanisms of deformation for CP Ti and Ti64 (at low temperatures), viz., slip and twinning, respectively. The existence of ambiguity in the mechanisms associated with plastic deformation in $\mathrm{Ti}$ and its alloys throw light to the fact that in-depth microstructural analysis has to be carried out. The former has a significant role in the wear mechanisms of the material during counter-body interactions [1]. The rise in interfacial temperature (by frictional heating or external aid) can promote the transition in the microstructure of the tribo-pair surfaces. Moreover, the shift in wear mechanisms at the interface (mild to severe or viceversa) got controlled by the contact temperatures [83, 84]. Therefore, the sliding speed has a predominant role in such a transformation as there will be a drastic increment in interfacial temperature with the rise in intensity of asperity interactions $[85,86]$. The microstructural changes associated with severe interacting conditions of peak contact temperature, high speed, and load can take place by the mechanisms, viz. plastic deformation, loss of resistivity, phase transformation, recrystallization and even by a shift to the molten state through melting $[87,88]$. These alterations can assist in the activation of thermal softening (TS) behavior in many materials. Hence, it is evident that the variation enforced on the surface/structural integrity of the substrate involuntarily contributes considerably towards the low tribo-characteristics of the Ti-alloys.

Hsu et al. [89] notified that at slow sliding speed and ambient conditions, wear process got regulated by the contact stress enforced plastic deformation and its resultant influence on the interacting asperity projections. With the increment in speed, the temporal effect takes over, dominantly controlling the wear mechanisms. The variation in temperature can control the increment or decrement in the intensity of interaction associated with the interface and emanating wear debris, with the environment. Hence, the same will govern the surface/structural integrity, thickness, and strength of the developed tribo-layer (TL). Ohidul Alam and Haseeb [90] studied the dry sliding wear behavior of Ti64 and Ti-24Al-11Nb alloys sliding against hardened steel. The MML formed in case of Ti64 was a sintered mix of fragments from the sliding material, counter-body, and the byproducts of the reaction with the environment. Moreover, the developed MML was not protective in nature. Hence, the surfaces have undergone delamination and oxidative wear under severe conditions, advocating for the poor tribocharacteristics of Ti64 alloys. The wear resistance of Ti-24Al-11Nb got more highly inflated than Ti64, due to the development of $\mathrm{Ti}-\mathrm{Nb}$ oxide-based shielding layer over the substrate material ensuing tribo-interactive sliding with the counter-face. Adhesion and abrasion were the dominant wear mechanisms that govern the interaction assisted material removal, and the corresponding influences of tribo-oxides were left unmentioned.

The presence of nanoparticles at the sliding interface and its corresponding impact to act as a third body got evaluated by Ghaednia and Jackson [91]. The distinction in modes of contact are developed primarily by interaction due to the presence of nanoparticles at the interface, and secondarily, by the micromorphological undulations of the surfaces. The model evaluated the corresponding impact at the real area of contact, and thereby developed tribo-characteristics of the mating surfaces. The existence of nano-particles as the third body at the mating interface can separate the surfaces locally and hence reduce friction (as the real area of contact got minimized). The size of the particles was found to get chosen as a variable model parameter, which can be used to monitor the development of various friction and wear mechanisms. Moreover, if the particles are innately harder than the interacting interfaces, this can lead to abrasive wear conditions leading to material removal. Hence, the various process mechanisms monitoring the tribobehavior of Ti64 alloy at dry sliding conditions is worth elucidating and got discussed below. There exists a correlation between few of the factors; nonetheless, the manuscript addresses them individually for a comprehensive understanding of their respective causes and effects.

\subsection{Thermal oxidation (ThO)}

Thermal oxidation (ThO) is a simple and economical processing technique for the formation of a relatively 
hard and thick oxide film on material surfaces [92]. The surface modification of Ti64 was found to enhance the tribo-behavior of the alloy to a greater extent. Among the various techniques, ThO stands apart to impart better wear resistance, as the method has been previously utilized to improve the tribo-behavior of $\mathrm{Ti}$ and its alloys $[30,93,94]$. The role played by the ThO and tribo-oxidation (TO) during the counter-body interactions is distinctly unique to be compared [9]. The exposure of $\mathrm{Ti}$ to the atmosphere at elevated temperatures has been identified to promote rapid oxidation of the material, resulting in the formation of a non-adherent and thick oxide layer on a diffusion hardened subsurface of the substrate $[95,96]$. Moreover, the ThO process can produce hard surface layers on Ti64 surfaces [97]. The wear resistance of the material components was reported to be enhanced consequently by the technique [98]. However, the treatment has to be parametrically controlled to develop the required microstructure. The prolonged high-temperature application can lead to stratification and interface debonding, while the formation of discontinuous oxide layers is the consequence of insufficient temperature conditions applied for long durations [92, 99, 100]. The surface roughness of the ThO treated surfaces is found to have got enhanced in comparison to the as-received specimens, attributed to the oxide layer growth mechanism. It is the resultant of the formation of a porous and stratified structure, developed overtime under the enforced treatment conditions [99, 101]. Generally, the ThO process gets performed in the air within a temperature range of $873-923 \mathrm{~K}$ for a period of $60-65 \mathrm{~h}[101,102]$. As a result, thin oxide scales $(2-3 \mu \mathrm{m})$ are developed over the functional material surface with a diffused subsurface zone $(20 \mu \mathrm{m})$ beneath it. The development of the secondary hard phase $\mathrm{TiO}_{2}$ coupled with the oxygen diffused sub-zone imparts high hardness to the material surface, leading to a subsequent reduction in wear. Moreover, the innate corrosion-resistant characteristic of the functional material is retained ensuing ThO process [101, 103].

Borgioli et al. [26] investigated the effect of thermal oxidation on the wear behavior of Ti64 alloy. The annealed Ti64 disks (dia. ( $\varnothing$ ): $50 \mathrm{~mm}$, thick: $8 \mathrm{~mm}$ ) were subject to ThO in an air circulating furnace at a temperature of $1,173 \mathrm{~K}(2 \mathrm{~h})$ and pressure $\left(10^{5} \mathrm{~Pa}\right)$. The weak surface oxide scale was removed by quenching in compressed air. The resultant surface was assessed to have developed a topmost compound layer and a subsurface diffused layer. After the removal of the weakly bound appendage oxide layer, the substrate was identified to possess $\alpha$-phase $\mathrm{Ti}(\mathrm{HCP}), \mathrm{TiO}_{2}$ (tetragonal, rutile), $\mathrm{TiN}_{x} \mathrm{O}_{y}$ (FCC, traces), forming a continuous layer. Moreover, $\mathrm{Ti}_{3} \mathrm{Al}$ (hexagonal, intermetallic phase) was also identified to have formed at the interface, generally associated with the $\alpha$-phase $\mathrm{Ti}$ (solid solution). Moreover, for a case depth of $35 \mu \mathrm{m}$ (approx.), a decrement in hardness was observed from the interface $\left(970 \mathrm{HK}_{0.025}\right)$ to the base material matrix $\left(380 \mathrm{HK}_{0.025}\right)$. The wear volume loss suffered by the thermally oxidized Ti64 (ThO-Ti64) in comparison to the untreated Ti64 (U-Ti64) and glow discharge nitrided Ti64 (N-Ti64) specimens on counter-body interaction is as shown in Fig. 6. Moreover, the metallographic images of the wear debris emanated from the Ti64 alloy samples at distinct sliding conditions of $0.4 \mathrm{~m} \cdot \mathrm{s}^{-1}$ and $1.6 \mathrm{~m} \cdot \mathrm{s}^{-1}$ are as shown in Fig. 7. Comparatively, low wear occurred at an intermediate sliding speed of $0.8 \mathrm{~m} \cdot \mathrm{s}^{-1}$ for both categories of U-Ti64 and ThO-Ti64. Further, the wear debris comprised of metallic plates (Ti) and $\mathrm{TiO}$ (FCC, fine powders). With the increment in sliding velocity, the volume fraction of the oxides keeps on decreasing. For ThO-Ti64, an only trace amount of oxides was identified at a peak sliding speed of $1.6 \mathrm{~m} \cdot \mathrm{s}^{-1}$, while for U-Ti64, the same was observed to be absent. The shift in wear mechanism was from oxidative to delamination with increment in sliding velocity; similar results were obtained for other researchers in the past $[25,34]$. The formation of metallic plate-like structured wear debris at peak sliding speeds occurs, due to the fracturing of the material layers adjacent to the interacting zone $[25,29]$. Further, the ThO-Ti64 samples displayed superior wear resistance than N-Ti64, as the nitride layers underwent micro-fragmentation leading to abrasion and severe wear [26].

Yazdanian et al. [94] investigated on the sliding wear behavior of ThO-Ti64 under vacuum conditions. The Ti64 disks (dia. $(\emptyset): 25 \mathrm{~mm}$, thick: $5 \mathrm{~mm}$ ) were cut to have processed from annealed rods of the alloy. The ThO treatment got performed at a temperature of $873 \mathrm{~K}(60 \mathrm{~h})$. The formation of hard $\mathrm{TiO}_{2}$ (rutile and anatase) occurred over the material surface. The appendage oxide layer was comparatively thin $(1-4 \mu \mathrm{m})$ 

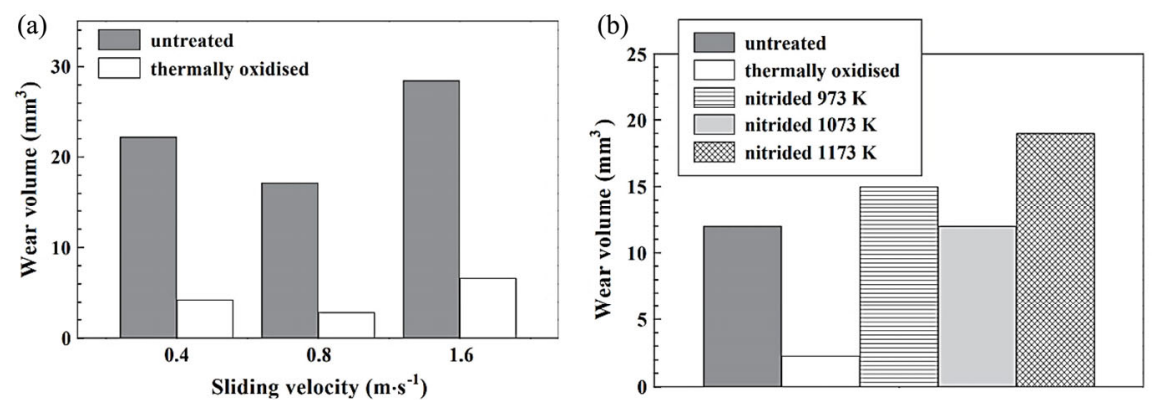

Fig. 6 Wear behavior of processed Ti64 specimens (U-Ti64, ThO-Ti64, N-Ti64) at different block-sliding conditions: (a) coupling load $=50 \mathrm{~N}$ and sliding distance $=3,000 \mathrm{~m}$; (b) coupling load $=50 \mathrm{~N}$, sliding velocity $=0.8 \mathrm{~m} \cdot \mathrm{s}^{-1}$, and sliding distance $=1,700 \mathrm{~m}$. Reproduced with permission from Ref. [26]. Copyright Elsevier, 2005.
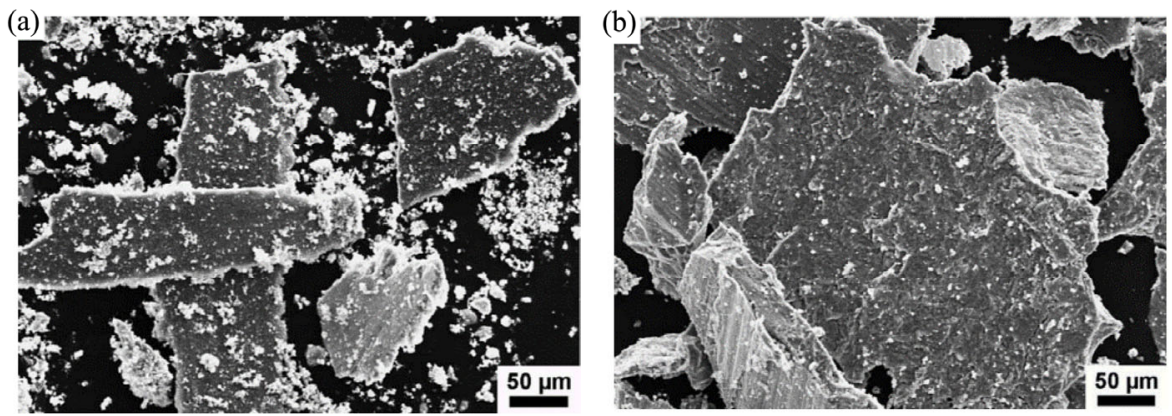

Fig. 7 Wear debris emanated from ThO-Ti64 alloy specimen at distinct sliding conditions (coupling load $=50 \mathrm{~N}$, sliding distance $=$ $3,000 \mathrm{~m}$ ): (a) sliding speed $=0.4 \mathrm{~m} \cdot \mathrm{s}^{-1}$; (b) sliding speed $=1.6 \mathrm{~m} \cdot \mathrm{s}^{-1}$. Reproduced with permission from Ref. [26]. Copyright Elsevier, 2005.

with a measured micro-hardness of $1,631 \pm 240 \mathrm{HV}$. The wear tests were carried out using a tribometer (ball-on-disk) under ambient and vacuum conditions. Experiments got conducted with steel balls (SAE 52100, dia. $(\varnothing): 6 \mathrm{~mm}$ ) as the counter-body, at constant load and sliding speed of $2 \mathrm{~N}$ and $0.05 \mathrm{~m} \cdot \mathrm{s}^{-1}$, respectively. The SEM metallographic images of the worn-pin surfaces developed under ambient air and vacuum conditions are as shown in Fig. 8. In ambient air testing, the dominant wear mechanism was identified to be governed by oxidation. The worn-pin surfaces consisted of scratches which are the characteristic feature of the abrasive wear. Contrarily, for ThO-Ti64 the damage was associated only with the oxide layer; the substrate remained unaffected. Another significant observation was the presence of oxidized iron patches. The ThO-Ti64 samples were associated with a wear resistance of $90 \%$, in comparison to the untreated counterpart. During vacuum testing, the un-treated Ti64 surfaces were observed to undergo severe plastic deformation governed by the "stick-slip" phenomenon; similar cases of which have been notified in the past for metals at comparable conditions [104, 105]. A negligible amount of material transfer was identified with the test surface from the counter-face, as observed in the case of ambient air testing. In the case of ThO-Ti64 specimens, the surface does not undergo plastic deformation. The mass loss suffered by the material was reported to be negligible whereas material was removed from the counter-face (through abrasion) to get transferred. The argument got confirmed through the presence of iron and chromium on the test material surface. The replacement of the steel ball counter-face with the same material as that of the ThO-Ti64 was found to alleviate the condition of counter-face wear. Henceforth, the mild wear controlled the material removal mechanism caused by the fracture and flattening of asperities associated with the oxide appendage layer.

\subsection{Tribo-layer (TL) and tribo-oxidation/oxides (TO)/ tribo-oxide layer (TOL)}

Micro-structurally and tribo-behaviorally different layers were identified to have formed during dry sliding interaction of Ti64 with various counter-bodies. Li et al. [106] reported that three distinct zones got 


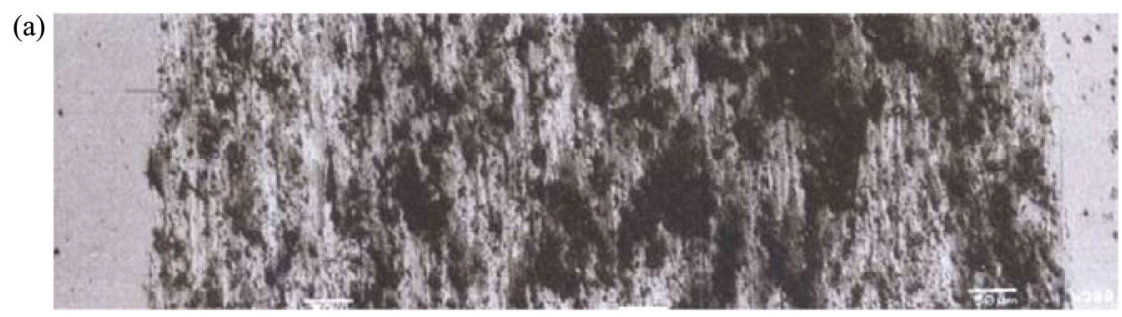

(b)

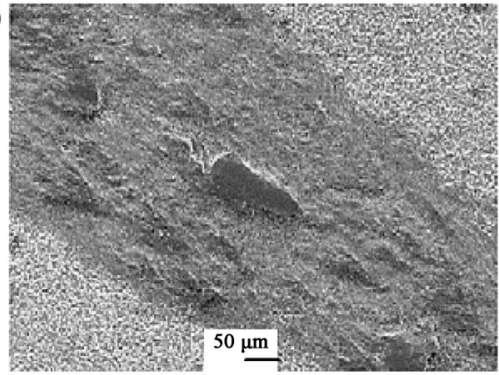

(d)

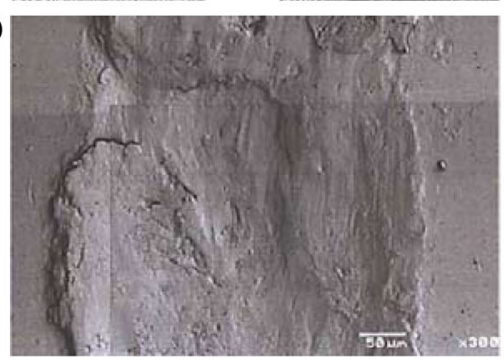

(c)

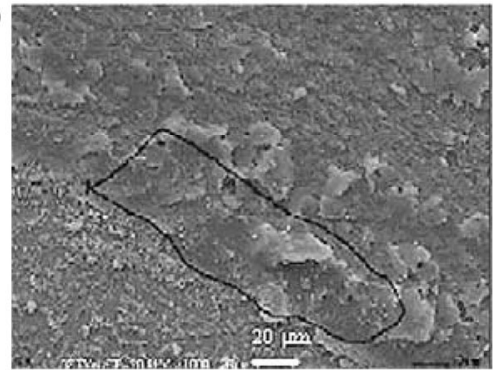

(e)

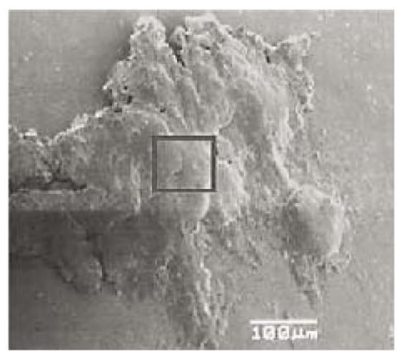

Fig. 8 SEM micrographs of worn-pin Ti64 surfaces and the counter-face tested at distinct conditions: (a) untreated (tested in ambient air); (b) ThO-Ti64 (tested in ambient air); (c) ThO-Ti64 (tested in vacuum); (d) untreated Ti64 (tested in vacuum); (e) steel counter-face with transfer material (tested in vacuum against untreated Ti64). Reproduced with permission from Ref. [94]. Copyright Elsevier, 2007.

developed on the substrate surface during tribointeraction of Ti64 with AISI 52100 steel. The top, intermediate, and bottom layers are (i) tribo-layer (TL), (ii) plastically deformed layer (PDL), (iii) base material matrix, respectively. The morphology of the layers varied with increment in sliding velocities such that the TL and PDL were associated with unique characteristics. At sliding speeds of $0.75,2.68$ and $4 \mathrm{~m} \cdot \mathrm{s}^{-1}$, the former demonstrated uncompacted (for low and medium speed) and compacted forms (for high speed), respectively. However, the size of the latter varied from being thick to thicker and then to be thin, with increment in velocity.

Pauschitz [107] notified that the wear characteristic pertinent to dry sliding in metals varies with the stability and existence of TL. Its formation depends upon multiple factors such as the type, nature, and state of the sliding contact, characteristics of the base material and the counter-face. The TL has been classified broadly into three categories: (i) material migration layer, with a low percentage of oxygen content, developed when the counter-face is softer than the test material. The migration layer possesses a similar composition as that of the counter-face and generally forms at room temperature; (ii) mechanically mixed layer (MML), having lower levels of oxygen content with improved hardness characteristics. The MML develops at relatively peak temperatures during interaction of tribo-pairs having moderate hardness; (iii) composite layer, with high levels of oxygen content. The nature of the formation is hard and brittle, developed at high temperatures and susceptible to material loss by wear [107].

Generally, TO or TOL assist in the development of a protective film on the substrate against sliding wear. Nevertheless, such appendage layers are found to be unstable and non-adherent for $\mathrm{Ti}$ and its alloys, due to the in-competent Pilling Bedworth ratios (P-B ratios). Moreover, the discrepancy in the thermal expansion coefficient of the developed oxide layers with that of the substrate material infuses internal stresses that aid in the failure of the TOL, progressively [108]. The 
propensity to form oxides is active in the case of the rotating specimen (among the tribo-pair), during the periods of non-contact $[109,110]$. The argument still holds about the diffusivity of oxygen being less efficient for stationary counterpart, which maintains a continuous contact [29]. In the case of Ti64, this mechanism is absent at vacuum test conditions and found to dominate in the context of ambient and high-temperature environments. Moreover, the thickness of the oxide layer is governed by two factors: (i) rate of oxidation which depends upon the temperature conditions (imposed externally by the environment or internally by the frictional heating at high speeds); and (ii) the time-lapse available for the repair of the failed oxide films, which generally becomes negligible at high speed [111]. Nonetheless, the formation of loosely bound oxide layers improves the material loss due to wearing associated with the alloy [9]. The rate of oxidation in simple terms gets regulated by two factors: (i) the amount of wear debris emanating from the interacting surfaces; and (ii) the temperature of the tribo-pair and the environment. The freely moving particles along the wear track have greater accessibility to react with the atmosphere than the material surfaces. Thereby the interaction can improve the hardness of the interfacial debris particles instigating third body abrasion and plowing. Further, the rise in temperature of the material and the environment will weaken the surficial molecular forces, to make them more vulnerable and reactive to get oxidized.

In work by Mao et al. [2], no oxide layer was confirmed to have formed over the Ti64 surface during dry sliding at $25^{\circ} \mathrm{C}$. The presence of Ti ( $\alpha$-phase) got identified on the worn-pin surface through XRD analysis. Contrarily, trace amounts of TOL developed on the pin slid under an applied load of 50-200 N, at a temperature of $200{ }^{\circ} \mathrm{C}$. Further, with increment in temperature up to a range of $400-500{ }^{\circ} \mathrm{C}$, the TOLs were stable enough to provide a protective coating at a pin load condition of 100-200 N. Thereby formed layers over the substrate were identified to be dominated by $\mathrm{TiO}_{2}$ and $\mathrm{Ti}_{8} \mathrm{O}_{15}$. The wear rate reached the lowest minimum at this state of sliding condition, due to the influence of the existence of TL and TOL. The cross-sectional SEM images gave an insight into the formation of such layers at discrete conditions of load and temperature. Further, TL was not a unique characteristic ascribed to a particular state of sliding contact and got developed at all circumstances of counter body interaction, although in varying thicknesses (Table 1). Nevertheless, a distinctive characteristic that separates such layers formed at differing parametric conditions is the amount to oxygen content present. At low-temperature sliding $\left(25-200{ }^{\circ} \mathrm{C}\right)$ only trace amount of oxygen was identified, contrarily to its high percentage at peak temperature conditions $\left(400-500{ }^{\circ} \mathrm{C}\right)$. The same got confirmed from the XRD and EDS line analysis techniques conducted on the worn-pin surfaces. The hardness difference of TL with the substrate at 25 and $200{ }^{\circ} \mathrm{C}$ was $45-100 \mathrm{HV}$, compared to $200-210 \mathrm{HV}$ and $150-265 \mathrm{HV}$ at 400 and $500{ }^{\circ} \mathrm{C}$, respectively, under applied normal load conditions of 100-200 N. The low hardness value identified at $500{ }^{\circ} \mathrm{C}$, was attributed to as due to the reduction in yield strength (950 to 650 to $450 \mathrm{MPa}$ ) of Ti64 with increment in temperature (ambient to 200 to $500{ }^{\circ} \mathrm{C}$ ), respectively [112]. A notable characteristic that correlates the work of Raj et al. [1] and Mao et al. [2] is that the respective hardness of MML and TL increases with increment in oxygen content, which invariably was found to reach the peak maximum at high temperatures of the interacting interface (achieved by frictional heating or external supply).

Cui et al. [113] studied the wear behavior of Ti64 interacting with GCr15 steel counter-body. The sliding material was solid dissolved at a temperature of $955^{\circ} \mathrm{C}$ (2 h) and quenched in water followed by aging at $540{ }^{\circ} \mathrm{C}$ $(4 \mathrm{~h})$ to be air-cooled. The disk was austenitized (at $850^{\circ} \mathrm{C}$ ), and quenched, then the material got tempered at $400{ }^{\circ} \mathrm{C}(2 \mathrm{~h})$. The wear loss was identified to follow a

Table 1 Variation in TL thickness with load and temperature [2].

\begin{tabular}{ccccc}
\hline S1. No. & $\begin{array}{c}\text { Temperature } \\
\left({ }^{\circ} \mathrm{C}\right)\end{array}$ & Load $(\mathrm{N})$ & $\begin{array}{c}\text { TL thickness } \\
(\mu \mathrm{m})\end{array}$ & TOL \\
\hline 1 & 25 & 50 & $3-6$ & Nil \\
2 & 25 & $100-250$ & $20-25$ & Nil \\
3 & 200 & 50 & $5-8$ & Trace \\
4 & 200 & $100-250$ & $20-25$ & Trace \\
5 & 400 & 50 & $15-20$ & Nil \\
6 & 400 & $100-250$ & $20-35$ & More \\
7 & 500 & 50 & $10-15$ & Trace \\
8 & 500 & $100-250$ & $10-15$ & More \\
\hline
\end{tabular}


similar incremental trend under an applied load range of $50-250 \mathrm{~N}$ at $20^{\circ} \mathrm{C}$ and $200{ }^{\circ} \mathrm{C}$, with the exception that it was slightly higher for the latter. Contrasting wear behavior was obtained at $400{ }^{\circ} \mathrm{C}$ with low, medium, and high wear at 50-100 N, 100-200 N and above $200 \mathrm{~N}$, respectively. This was attributed to as due to the action of TL (Fig. 9), the thickness of which was reported to has reached $20 \mu \mathrm{m}$. Moreover, the hardness of the appendage oxide layer (HV562) was determined to be higher than that of the substrate (HV368). The EDX analysis results of the worn-pin Ti64 surfaces at varying load and temperature conditions, in terms of elemental composition, are as shown in Fig. 10. The variational regularity in the subject context of the surfaces at $20^{\circ} \mathrm{C}$ and $200{ }^{\circ} \mathrm{C}$, at applied load conditions of 50-250 N, portrayed similar trends. The primary elements of the alloy (titanium (Ti), aluminium $(\mathrm{Al})$, and vanadium $(\mathrm{V})$ ) at the surface zone got reduced with increment in load. Conversely, the iron (Fe) concentration was enhanced, whereas the oxygen (O) percentage remained zero. Hence, the possibility for TOL formation or the resultant oxide wear at $20-200{ }^{\circ} \mathrm{C}$ was assumed to be negligible. At $400{ }^{\circ} \mathrm{C}$, unique trends were observed with a comparable higher concentration of $\mathrm{O}$ and Fe within a load variation of 50-200 N, with a stark decline of the respective percentages at $250 \mathrm{~N}$. Accordingly, the dominant wear mechanisms at varying temperature range of $20-200{ }^{\circ} \mathrm{C}$, were adhesion leading to abrasion resulting in material removal. Further,

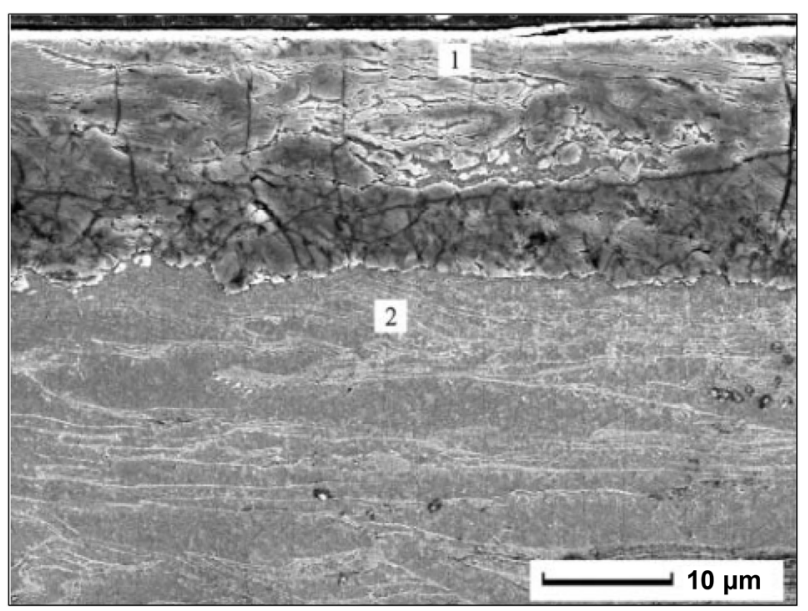

Fig. 9 Cross-sectional metallography image of worn-pinTi64 surface with TL, formed at an applied load $=200 \mathrm{~N}$ and temperature $=400{ }^{\circ} \mathrm{C}((1) \mathrm{TL}$ and (2) substrate matrix, i.e., Ti64). Reproduced with permission from Ref. [113]. Copyright Taylor \& Francis, 2012.
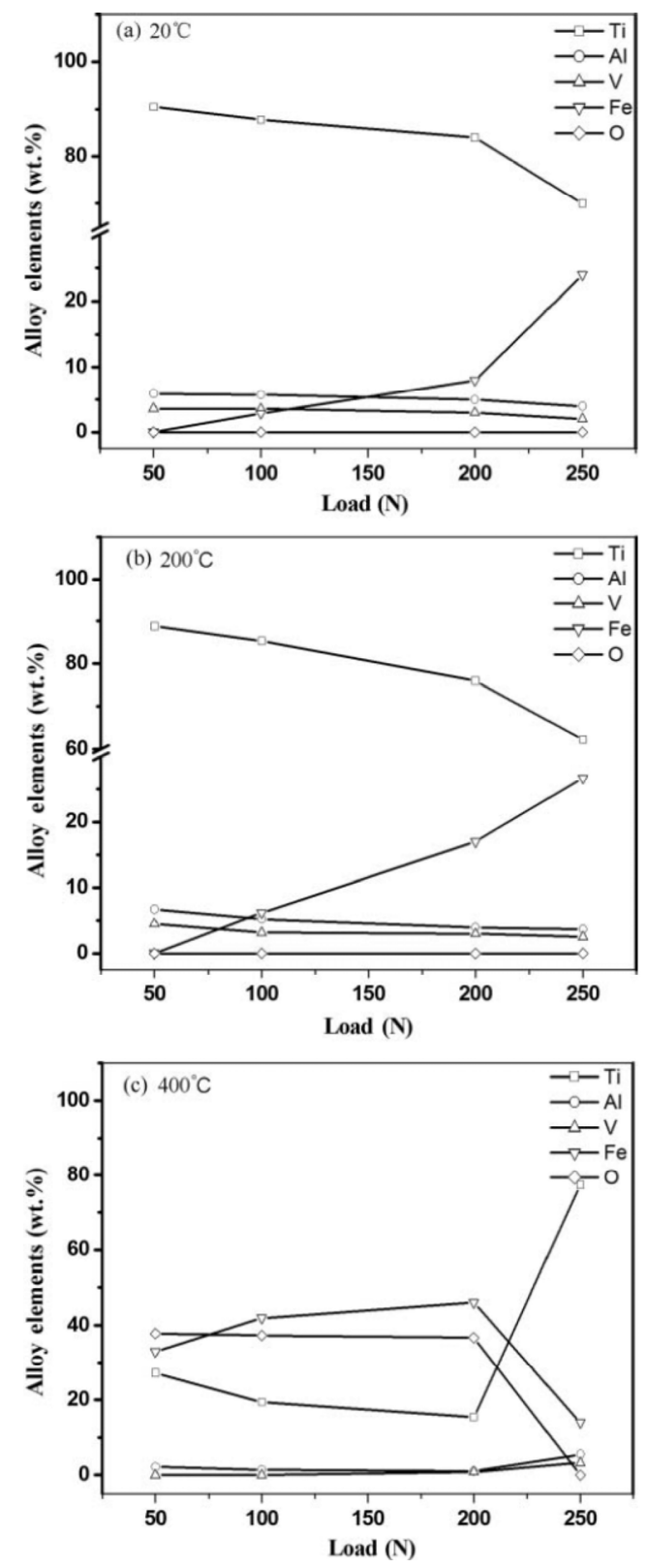

Fig. 10 EDX results of worn-pin Ti64 surfaces slid under various loads $(50-250 \mathrm{~N})$ at distinct temperature conditions: (a) $20{ }^{\circ} \mathrm{C}$; (b) $200{ }^{\circ} \mathrm{C}$; (c) $400{ }^{\circ} \mathrm{C}$. Reproduced with permission from Ref. [113]. Copyright Taylor \& Francis, 2012.

the Fe concentration was observed to increase with increment in applied load [113].

It is significant to note that at $400{ }^{\circ} \mathrm{C}$, the concentration of oxygen on the surface remained nearly uniform at varying loads of 50-200 N. Hence the low wear rate observed at this state of sliding is justified and is due to the protective action of the TOL formed over the substrate at high temperatures. The increment in hardness and the considerable thickness of the 
developed layers (as observable from Fig. 9) has contributed extensively towards resisting the external forces. Further, it got recommended that the significant number of researchers who have argued about the low protective action of the TOL pertinent to $\mathrm{Ti}$ and its alloys have performed their experimentation at ambient conditions. Conversely, at elevated temperatures, the appendage oxide layers are more compact, comparatively to extend persistent protective action. Further, with increment in load (up to $250 \mathrm{~N}$ ) at $400{ }^{\circ} \mathrm{C}$, the adhesive quality of the TOL is lost to get fragmented, resulting in severe wear. This argument is supported by the EDX plots as shown in Fig. 10(c). A drastic reduction in the percentage of $\mathrm{O}$ and $\mathrm{Fe}$ is identified, exposing the substrate surface to the environment (hence the increased concentration of $\mathrm{Ti}, \mathrm{Al}$, and V) [113].

The dry sliding wear behavior of Ti64 running against similar counter-body and AISI M2 steel got evaluated by Straffelini [29] and Molinari et al. [25] at distinct sliding velocities and normal loads. The formation of a brittle, non-adherent, and un-stable TOL has occurred over the functional material. The paucity of such layers developed by TO has caused them to get spalled off at severe conditions. Contrarily, in the case of Ti64 sliding against itself, the wear rate reached the least minimum and then shifted to cause catastrophic damage with increment in sliding velocity. The reduction in wear was due to the decline in the rate of oxidative wear. The hardness of the surface scale and plastically deformed substrates were 1,000 HV and 400-500 HV, respectively. Mao et al. [2] commented that the specified contradiction was due to the formation of TOL in MML. Further, they ruled out the argument that the TOL of Ti64 does not impart protective characteristics to the surface. They also pointed out the need for carrying out advanced characterization such as X-ray diffractogram (XRD) analysis, to distinctly identify the oxide layers.

Ming et al. [114] investigated the effect of FH on the tribological performance of Ti64 interacting with GCr15 steel counter-face at peak sliding speeds. The subsequent increment in the interface temperatures led to the formation of distinctive oxides of $\mathrm{Ti}(\mathrm{TiO}$ and $\left.\mathrm{TiO}_{2}\right)$ and vanadium $\left(\mathrm{V}_{2} \mathrm{O}_{3}\right)$. The XRD spectral analysis carried out on the worn-pin surfaces of Ti64 interacting against GCr15 steel counter-face at various stages of sliding $\left(30,50\right.$ and $\left.70 \mathrm{~m} \cdot \mathrm{s}^{-1}\right)$, was identified with enhanced TOL formation. The surface appendage layer got dominated by a high percentage of $\mathrm{Ti}$ at $30 \mathrm{~m} \cdot \mathrm{s}^{-1}, \mathrm{TiO}$ at $50 \mathrm{~m} \cdot \mathrm{s}^{-1}, \mathrm{TiO}_{2}$, and $\mathrm{V}_{2} \mathrm{O}_{3}$ at $70 \mathrm{~m} \cdot \mathrm{s}^{-1}$, respectively. The wear resistance of Ti64 underwent a continuous decline with increment in sliding speed. The development of un-stable and loosely bound oxides over the substrate surface contributed to this downside. With the increase in sliding velocity, frictional heating caused the rise in temperatures resulting in the development of more oxide scales over the substrate surface. Moreover, the formation temperatures of $\mathrm{TiO}_{2}$ and $\mathrm{V}_{2} \mathrm{O}_{3}$ are higher than that of $\mathrm{TiO}$, hence they were found to be absent at a sliding speed of $50 \mathrm{~m} \cdot \mathrm{s}^{-1}$. The incapability in the development of aluminium oxides or its absence was due to the longer time lapse required for its formation [115]. Low adherence of the developed oxide layers, with the substrate material, was notified to have resulted in the poor tribocharacteristics of the alloy [114].

During tribo-interaction, the stresses at the contact zone due to external load and the retainment of debris particles emanating from the mating surfaces contribute to the formation of MML $[12,13]$. The establishment of such a layer gets assisted by extreme mating conditions of load, speed, and temperature, the excess of which thereby leads to its failure [81]. The existence of MML was confirmed only for bigger pins (6.6 $\mathrm{mm}$ $\emptyset$ and $4.6 \mathrm{~mm} \emptyset)$, in contrast to smaller pins $(2.1 \mathrm{~mm} \emptyset)$. This is due to the capability of the former in retaining the debris particles within the sliding zone of the wear track, although wear gets instigated at same contact pressure. Using nanoindentation testing, an increment in hardness got confirmed for the layer, with a gain in oxygen content [2]. Moreover, the formation of MML is favored for bigger pins at vacuum conditions (at a sliding speed of $0.5 \mathrm{~m} \cdot \mathrm{s}^{-1}$ (approx.)) [1]. The stability of the layer depends on various factors, viz., the existence of favorable contact stresses at the interface, compatibility of the elements that constitute the MML, and the bond strength of the layer to remain intact with the substrate at severe conditions. Hence it was suggested that the sliding speed which governs the frictional heating, can control the capability of the MML to remain steadfast with the substrate $[2,81]$. 
Straffelini and Molinari [29] performed tribo-tests under disk on disk arrangement with Ti64 running against AISI M2 steel. The wear mechanism of Ti64 primarily favors two distinct modes of material removal, viz., oxidative wear and delamination. The former is associated with low-speed sliding $\left(0.3-0.5 \mathrm{~m} \cdot \mathrm{s}^{-1}\right)$ while the latter at considerably higher speeds $\left(0.6-0.8 \mathrm{~m} \cdot \mathrm{s}^{-1}\right)$. Besides, the frictional heating experienced by the tribopairs at the specified peak sliding speeds instigated plastic strains at the contact zone of the asperities. This led to the subsequent increment in wear causing the development of debris particles, contributing to the formation of MML. The layer was found to be a compaction of succumbed obsolete specks emanating from the mating surfaces, consisting of oxides and metallic constituents. Such oxide scales there so formed were frail in nature with improper bonding with the substrate inflicted upon by strain hardening. Hence, low adherence has forced them to be brittle to get continuously fragmented under the imposed stress conditions. This has led to the shift in wear mechanisms contributing to enhanced removal of material, thereby imparting negligible protective action against wear [29].

The TL is reported [106] to be formed and exist at all sliding conditions of load $(10-50 \mathrm{~N})$ and speed $\left(0.5-4 \mathrm{~m} \cdot \mathrm{s}^{-1}\right)$, with distinguishable microstructure as compared to the parent matrix material. Moreover, the thickness, composition, phases, and oxygen content of the TL varied at distinct sliding conditions with the counter-face. The layer recognized at all situations is the MML consisting of migrated material from the parent material and the counter-body, reaction by-products of the debris and surfaces with the environment, and oxygen. The distinguish ability of the TL and TOL is a questionable concept requiring in-depth understanding to elucidate the sliding behavior of the mating surfaces. It is valid to suggest that among the three types of TL notified by Pauschitz [107], the second (MML) and the third (composite layer) are the mixed layers and TOL referred to in the above subject context, respectively. Hence, TOL should always be considered as a subset of the TL as the same is also developing through tribo-interaction. While TOL is a cluster of various oxides formed by the interaction of the wear debris with the environment, MML can be a merger of TOL and metal debris particles
$[2,113,116,117]$. Consequently, the degree of influence the MML has on the dry sliding wear behavior of the sliding components gets controlled by the existence of TOL, duration of its retainment over the subject surface and the percentage of oxygen content. Besides, the disposition, compactness, and thickness of the latter can get altered with the sliding velocity, sliding load, and temperature. The formation of TO drastically increases with sliding speed, due to frictional heating (FH). However, the TO developed over the substrate will be stable enough to undergo accretion to form TOL, imparting protective action is governed by the presence of movable oxides, the impact of centrifugal forced clearance of the wear track and retainment of debris oxides by the effect of elevated temperature and pressures. The presence of loose oxide particles can promote abrasive wear, serving as hard fragments between the sliding surfaces. This leads to a significant reduction in $\mathrm{CoF}$ through rolling action of the wear debris. Contrarily, the presence of stable TOL can restrain material adhesion by limiting the direct metal to metal contact. The non-metallic nature of the oxides also restricts the free electron transfer, which actuates bond formation. Moreover, the combined presence of TOL and MML can modify the sliding characteristics of the mating surfaces. Hence, the metal alloy surfaces with the appendage layers may function like ceramics resulting in anomalous tribo-behavior. Such a feature exhibited by the TL has been reported to act as a high hardness protective layer guarding the metallic substrate against wear [24]. Further, the formation and integrity of the TL govern the material deformation, and transfer behavior of the sliding pair surfaces thereby governs the dynamic friction behavior $[118,119]$.

\subsection{Strain rate response/sensitivity (SRR/SRS)}

The enforced strain rate and temperature conditions govern the microstructural evolution of a given material/alloy, hence the significance of SRR/SRS. Rigney [120] has notified that the microstructure of the nearsurface regions can monitor the sliding wear of the materials. A drastic shift in wear mechanisms can occur due to the change in microstructure induced by $\mathrm{FH}$ or the variation in the applied strain rate. The SRR approach has been previously tried to evaluate the 
wear phenomenon, based on the changes in microstructure under the applied strain, strain rate, and temperature conditions [121-123]. The microstructural response to strain has been quantified using the dynamic material modeling (DMM), where the power dissipated by the material instigates/monitors the pertinent change. The power demonstrated with plastic deformation, $P=\sigma$, where $P$ and $\sigma$ are the flow stress and the applied strain, respectively. The SRR controls the partitioning of this power to be utilized for heat dissipation or microstructural modifications. A wide range of microstructural possibilities exist based on the applied strain and temperature conditions. Based on the utilization of the available power, the microstructural responses, viz., ASB, flow banding (FB), dynamic recovery (DRY), DRX, and superplasticity can occur [124, 125]. During sliding, strain gradients will develop at the surface and sub-surface regions due to plastic deformation. On achieving that state where the existent strain rate and temperature conditions will favor the nucleation and propagation of cracks, the material gets removed in the form of debris [121-123]. Hence the SRR approach could develop a reasonable correlation between the wear and the microstructural responses of the material on valid grounds. Finally, the TO, tribo-chemistry, and SRR at the near-surface region govern the wear rate [126].

\subsection{Adiabatic shear banding (ASB)}

ASB can occur at high and low strain conditions of temperature. The low thermal conductivity of the material leads to the formation of shear bands along with the neighborhood of the grain boundaries [127]. It got observed at flash temperatures in a standard tribological test [128]. At a strain rate of $0.001 \mathrm{~s}^{-1}$, the Ti64 specimens were found to form ASB, with temperature rise (up to $523 \mathrm{~K}$ ). Moreover, there exists a possibility for fracture along the ASB at low flow stress and high tensile circumferential stresses in a narrow zone and the bulge surface equator, respectively [129]. In work by Chelliah and Kailas [126], the dominant mechanisms governing the tribo-behavior of CP Ti were suggested to be TO, SRR and ASB. Further, the potency of ASB was significantly high at low sliding speeds and got reduced with increment in the latter. Hence, it can govern the resultant high and low wear rates of the material at the abovespecified conditions. In the case of Ti64, the formation of ASB can get pronounced at a strain rate corresponding to the sliding speed of the pin at $0.1 \mathrm{~m} \cdot \mathrm{s}^{-1}[1]$. It is resultant of the fact that at the specified low speed, the variation in wear rate is governed mainly by the correspondingly imposed strain rate instigated microstructural changes, undergone by the alloy. The same was caused, by the phenomenon of ASB and the associated mechanisms which led to the softening of the material [121, 122, 130, 131]. Besides, the above argument is conceivable, as in a similar case presented for Ti pins [126], the wear mechanisms associated with low flash temperatures were attributed to as governed by ASB [122, 132]. The proclivity in favoring ASB formation at ranges of temperatures below $700{ }^{\circ} \mathrm{C}$, is conspicuously causing the subsequent loss in strength of the alloy through the decline in surface integrity [127]. Moreover, at low sliding speeds of the pin (nearly $0.1 \mathrm{~m} \cdot \mathrm{s}^{-1}$ ), the specified temperature ranges were achieved, which instigated the ASB and the resultant material softening leading to wear [1].

\subsection{Dynamic recrystallization (DRX)}

Ding et al. [56] reported that the driving force required for the phase transition is considerably higher than that essential for the occurrence of DRX. Hence, for Ti-alloys, it is the former that is comparatively very difficult to happen than the latter. Moreover, phase transformation should happen before or after the completion of DRX during hot working processes. Even at a high temperature of $1,050{ }^{\circ} \mathrm{C}$ above the $\beta$-transus, only scarce level of DRX does occur. In the $\alpha+\beta$ phase field, the phase transformation will happen concurrently with the mechanical transformation. Nevertheless, the DRX remained inactive in the specified temperature range during hot working. Further, for metallic materials, the stored energy due to dislocation density contributes to the driving forces essential for recrystallization, which has a value range between $0.01-0.1 \mathrm{~kJ} \cdot \mathrm{mol}^{-1}$. Comparatively, the distinction in free energy of about $1 \mathrm{~kJ} \cdot \mathrm{mol}^{-1}$ of the distinct phases, contributes to the driving forces which activate the solid phase transformation [42]. When the temperature was in the $\alpha+\beta$ phase-field (850$\left.950{ }^{\circ} \mathrm{C}\right)$, the occurrence of DRX or meta-dynamic 
recrystallization (m-DRX) has found to be absent. Whereas, in the $\beta$-phase-field, the rise in temperature from $1,000-1,050{ }^{\circ} \mathrm{C}$, led to enhancement in DRX and $\mathrm{m}$-DRX percentage resulting in large areas of recrystallized regions, at strain rates of 0.5 and $1 \mathrm{~s}^{-1}$. Nevertheless, the DRX effect leading to localized softening of microstructure can assist in dynamic shear failure, resulting in catastrophic damage [133].

\subsection{Flow stress (FS)}

FS of the material is reported to be principally governed by the temperature than the strain rate [126]. In the past, a decremental trend was observed pertinent to the FS of Ti64 alloy with the rise in temperature [128, 133, 134]. The work by Long and Rack [31], studied the influence of FS characteristic on the frictional behavior related to distinct Ti-alloys, viz., Ti-35Nb8Zr-5Ta (TNZT and TNZTO), metastable- $\beta$ (21 SRX) and Ti64, were compared. During reciprocated sliding cycles, the variation in velocity monitors the strain rate experienced by the mating surfaces. Moreover, at rapidity interactions, the tested surfaces undergo strain deformation and material damage. Subsequently, the variation in frictional behavior depends on the corresponding deformation and fracture response of the alloys. The dynamic friction coefficient of Ti64 was suggested to be independent of the effect of change in sliding velocities, attributed to the reduced FS sensitivity of the alloy with the imposed strain rate [135]. Whereas for the reminder, the initial decrease in dynamic frictional coefficient was due to the increase in sensitivity of the FS and fracture strength at low contact stress. The increment in SRS has been previously notified to be the indigenous behavior of the low strength alloys (BCC) [106, 136].

\subsection{External heating/heat flux (EH)}

According to Mao et al. [2], the wear behaviors of Ti64 alloy at elevated temperatures remain influenced by the loading conditions. Superior tribological characteristics got reported at $400-500{ }^{\circ} \mathrm{C}$; nonetheless, material removal increased rapidly above $200 \mathrm{~N}$. Besides, low temperature $\left(25-200{ }^{\circ} \mathrm{C}\right)$ behavior of the alloy begets peak wear with increment in the applied load $(50-250 \mathrm{~N})$. The protective action imparted by the development and existence of TL (MML) depends on the presence/absence of more oxides. The propensity for the formation of oxides/oxide layers got enhanced with the rise in temperature. Hence, in the presence of $\mathrm{EH}, \mathrm{FH}$ should be considered to have a negligible role or its corresponding influence is not highly manifested (engulfed by the former). Hager Jr. et al. [137] compared the propensity for the occurrence of various fretting wear regimes during counter-body interaction of Ti64 alloys, at room temperature and $450{ }^{\circ} \mathrm{C}$. A drastic shift from mixed to gross fretting wear through slip occurred at room temperature, whereas at high temperature, the transition was gradual. In the case of the latter, the material underwent TS under the applied temperature-load conditions and does not promote strain hardening that leads to brittle fracture. Moreover, the effect of surface oxidation also got identified at high temperatures. Wang et al. [116] investigated the critical transition temperature (severe to mild wear) of a Ti64-steel tribo-system. The alloy demonstrated excellent tribo-behavior above the critical temperature of $400{ }^{\circ} \mathrm{C}$, dominated by mild oxidative wear. The TL formed was continuous, consisting of various oxides (inclusive of $\mathrm{Fe}_{2} \mathrm{O}_{3}$ ), extending protective action against wear. Abrasion and adhesion were the primary material removal mechanisms for dry sliding at low temperatures, promoting severe wear.

\subsection{Frictional heating $(\mathrm{FH})$}

The tribological response of Ti64 alloy is influenced by $\mathrm{FH}$, as it affects the various mechanisms, viz., TO, SRS, MML, and as such [1]. The major process parameters that influence the variation in $\mathrm{FH}$ are sliding velocity and normal load [113, 138]. Consequently, they govern the dry sliding wear behavior of the materials at room temperature. The propensity to form $\mathrm{TO}$ is increased with sliding velocity due to the consequent $\mathrm{FH}$ induced rise in temperature by surface asperity interaction [106]. The Ti64 alloy has been previously reported to possess high temperature wear resistance $[2,113,116]$. The reduction in wear attributes to the existence of TL with trace oxides, the formation of which got aided by the increment in temperature. Comparably, the temperature rise induced by the FH is suggested to produce similar results at peak sliding speeds [106]. 


\subsection{Thermal softening (TS)}

The inherent characteristic of Ti-alloys to undergo thermal softening (TS) at high temperatures is there in the findings of the previous researchers [1]. For the Ti64 specimen slid against similar counter-body (elevated velocities), the TS behavior of the alloy majorly contributed to the enhanced wear rate. The underlying reason is that the yield strength of the alloy decreases at the rate of 950 to 650 to $450 \mathrm{MPa}$ with an increase in temperature from room condition to 200 to $500{ }^{\circ} \mathrm{C}$, respectively [112]. Hence, at the increased interfacial temperature of the mating surfaces due to $\mathrm{FH}$ or rise in ambient temperature, the TS is considered to assist the material removal through the mechanism of delamination. According to the delamination theory proposed by Suh [139], the continuous interaction at the contact interface during sliding leads to severe plastic deformation enforcing accretion effect. Subsequently, as the accumulated strain approaches a value beyond the critical plastic strain $\left(\gamma_{\mathrm{cr}}\right)$, the nucleation and propagation of cracks from the subsurface regions may get instigated and continue parallel to the surface resulting in the formation of wear debris in the form of plate-like structures. Hence, the ductility of the alloy that depends on the presence of secondary phases/hindrances, which cannot be directly overcome by the thermal effects, governs the threshold value of $\gamma_{\mathrm{cr}}$. Moreover, the formation of MML was notified to occur once the surface plastic strain reaches the limiting point of $\gamma_{\mathrm{cr}}$ [140]. The dynamic fracturing of the material at high strain rates was observed by Ramirez [130] and, it was suggested to have occurred due to TS. Dynamic shear failure at high strain rates was as also recognized when the material was subject to ballistic impacts [133]. Nevertheless, arguments exist regarding the inactive nature of TS in Ti64 [128]. The Johnson-cook model has got widely utilized for material modeling of the alloy with a thermal softening exponent defined to govern the corresponding behavior at elevated temperatures. Presently, multiple opinions exist regarding the selection of values for the same and the related constants associated with the specified model [134].

\section{Friction and wear characteristics}

The tribo-characteristics of Ti64 sliding against distinct counter-body material surfaces has been collected to be combined and presented. The friction and wear behavior of the interfaces and the underlying mechanisms have been the focus of this section. Table 2

Table 2 Distinction in tribo-behavior of Ti64 sliding against discrete counter-body surfaces.

\begin{tabular}{|c|c|c|c|c|c|}
\hline $\begin{array}{l}\text { Sl. } \\
\text { No. }\end{array}$ & $\begin{array}{c}\text { Test } \\
\text { material }\end{array}$ & Counter-body & Conditions & Outcome & Ref \\
\hline 1 & $\begin{array}{l}\text { Ti6Al4V } \\
\text { (Pin) }\end{array}$ & $\begin{array}{c}\text { SS316L Steel } \\
\text { (Disk) }\end{array}$ & $\begin{array}{l}\text { Dry sliding, Ambient \& Vacuum } \\
\text { Pressure: } 2.8 \mathrm{MPa}, \pm 2 \% \\
\text { Pin }(\varnothing): 2.1,4.6 \text { and } 6.6 \mathrm{~mm} \\
\text { Disk }(\varnothing): 110 \mathrm{~mm} \text {, Thick: } 8 \mathrm{~mm} \\
\text { (Amp) } \\
\text { Disk }(\varnothing): 85 \mathrm{~mm}, \text { Thick: } 5 \mathrm{~mm} \\
\text { (Vacuum) } \\
\text { Speed: } 0.01-1.5 \mathrm{~m} \cdot \mathrm{s}^{-1}\end{array}$ & $\begin{array}{l}\text { - The wear resistance of Ti64 was influenced by MML, } \\
\text { SRR and TO and the frictional heating at the interacting } \\
\text { interface. } \\
\text { - Particularly at a speed of } 0.5 \mathrm{~m} \cdot \mathrm{s}^{-1} \text {, wear rate was } \\
\text { reduced slightly due to the decrement in shear band } \\
\text { intensity. } \\
\text { - The proclivity for formation of MML was governed } \\
\text { by the retainment of wear debris and diameter of the } \\
\text { sliding pins. }\end{array}$ & [1] \\
\hline 2 (a) & $\begin{array}{c}\text { Ti6Al4V } \\
\text { (Pin, } 40 \\
\text { HRC) }\end{array}$ & $\begin{array}{c}\text { GCr15 Steel } \\
\text { (Disk, } 50 \\
\text { HRC) }\end{array}$ & $\begin{array}{l}\text { Dry sliding, Pin type: Hot } \\
\text { extruded rod } \\
\text { Pin }(\emptyset): 6 \mathrm{~mm} \text {, Length: } 12 \mathrm{~mm} \\
\text { Load: } 50-250 \mathrm{~N} \text {, Temp: } 25-500{ }^{\circ} \mathrm{C}\end{array}$ & $\begin{array}{l}\text { - The Ti64 was identified to impart acceptable wear } \\
\text { resistance at peak elevated temperatures. } \\
\text { - Although MML was developed at various sliding } \\
\text { conditions, its protective role depended on the intensity } \\
\text { of oxide layers accumulated over the substrate. } \\
\text { - The dominant wear mechanisms at low and high } \\
\text { temperature sliding were adhesive wear assisted } \\
\text { delamination leading to abrasion for the former and } \\
\text { oxidative wear for the latter. }\end{array}$ & [2] \\
\hline
\end{tabular}


(Continued)

\begin{tabular}{|c|c|c|c|c|c|}
\hline $\begin{array}{l}\text { Sl. } \\
\text { No. }\end{array}$ & $\begin{array}{c}\text { Test } \\
\text { material }\end{array}$ & Counter-body & Conditions & Outcome & Ref. \\
\hline 2 (b) & $\begin{array}{l}\text { Ti6Al4V } \\
\text { (Pin, } \\
40 \mathrm{HRC})\end{array}$ & $\begin{array}{c}\text { GCr15 Steel } \\
\text { (Disk, } \\
60 \text { HRC) }\end{array}$ & $\begin{array}{l}\text { Dry sliding, Pin type: Hot } \\
\text { extruded rod } \\
\text { Pin }(\varnothing): 14 \mathrm{~mm} \text {, Length: } 42 \mathrm{~mm} \\
\text { Disk }(\varnothing): 160 \mathrm{~mm} \text { (outer) Thick: } \\
\quad 30 \mathrm{~mm} \\
\text { Pressure: } 0.33,0.67,1 \\
\text { and } 1.33 \mathrm{MPa} \\
\text { Sliding velocity: } 0.01-1.530 \text { to } \\
\quad 70 \mathrm{~m} \cdot \mathrm{s}^{-1} \\
\text { Sliding time: } 100 \mathrm{~s}\end{array}$ & $\begin{array}{l}\text { - As the temperature developed due to frictional heating } \\
\text { exceeds the } \beta \text {-transis temperature, } \beta \text {-crystals grow } \\
\text { swiftly causing reduction in plastic deformability of } \\
\text { Ti64. } \\
\text { - The loosened oxide scales formed on the substrate } \\
\text { surface such as } \mathrm{TiO}, \mathrm{TiO}_{2} \text { and } \mathrm{V}_{2} \mathrm{O}_{3} \text {, decrease the } \\
\text { wear resistance of the } \mathrm{Ti}^{6} 6 \text { surface. }\end{array}$ & [114] \\
\hline 3 & $\begin{array}{l}\text { Ti6Al4V } \\
\text { (Plate, } \\
400 \mathrm{VHN})\end{array}$ & $\begin{array}{l}\text { Diamond Tip } \\
\text { (Pin) }\end{array}$ & $\begin{array}{c}\text { Dry sliding, Pin-on-plate } \\
\text { (reciprocated) } \\
\text { Load: } 5 \mathrm{~N} \text {, Speed: } 50 \mathrm{rpm} \\
\text { Plate size: } 20 \mathrm{~mm} \times 10 \mathrm{~mm} \times \\
10 \mathrm{~mm}\end{array}$ & $\begin{array}{l}\text { - The use of distinct quenching mediums (oil, water } \\
\text { and } \mathrm{N}_{2} \text { ) can enhance the hardness of the as-received } \\
\text { Ti64 samples from } 400 \mathrm{VHN} \text { to } 750-800 \mathrm{VHN} \text {. } \\
\text { - The wear behavior of the Ti64 surfaces was observed } \\
\text { to be independent of their respective hardness and } \\
\text { does not obey the Archard's law. This was attributed } \\
\text { to as due to the shift in surface nature of the test } \\
\text { specimen from plastic to brittle during quenching } \\
\text { process, resulting from phase transformation. }\end{array}$ & [19] \\
\hline 4 & $\begin{array}{l}\text { Ti6Al4V } \\
\text { (Pin, } \\
443 \text { HV) }\end{array}$ & $\begin{array}{l}\text { Silicon } \\
\text { carbide } \\
\text { abrasive } \\
\text { paper } \\
(150 \text { grit, } \\
2,200 \mathrm{HV})\end{array}$ & $\begin{array}{l}\text { Dry sliding, Two-body abrasive } \\
\text { wear test } \\
\text { Hard abrasion, } H_{\mathrm{a}} / H_{\mathrm{v}}>1.2 \\
\text { Pin }(\varnothing) \text { : } 10 \mathrm{~mm} \text {, Length: } 25 \mathrm{~mm} \\
\text { Abrasive: Silicon carbide } \\
\quad \text { ( } 150 \text { grit) } \\
\text { Disk: Steel, } 120 \mathrm{~mm} \emptyset \text {, Load = } \\
\quad 10-40 \mathrm{~N} \\
\text { Sliding velocity: } 200-800 \mathrm{rpm} \\
\text { Sliding time: } 1,200 \mathrm{~s}\end{array}$ & $\begin{array}{l}\text { The microstructure of the as-received Ti64 comprised } \\
\text { of primary } \alpha \text {-phase with uniformly dispersed } \beta \text {-phase. } \\
\text { The quench-aged specimen consisted of } \alpha \text {-plates and } \\
\text { precipitated } \beta \text {-phase formed by decomposition of the } \\
\alpha \text {-phase. } \\
\text { - The wear resistance of the material was significantly } \\
\text { governed by the microstructural transformations than } \\
\text { the mechanical properties alone such as hardness. }\end{array}$ & [61] \\
\hline 5 (a) & $\begin{array}{l}\text { Ti6Al4V } \\
\text { (Block) }\end{array}$ & $\begin{array}{c}\text { EN } 31 \\
\text { (Disk, } \\
50 \text { HRC) }\end{array}$ & $\begin{array}{c}\text { Dry sliding, Block-on-disk, } \\
\text { Room Temp } \\
\text { Experimental design: } \mathrm{L}_{9} \\
\text { orthogonal array } \\
\text { Block dimensions: } 6.35 \mathrm{~mm} \\
\times 6.35 \mathrm{~mm} \times 9 \mathrm{~mm} \\
\text { Type: Lamellar, Bimodal and } \\
\text { Equiaxed } \\
\text { Disk }(\varnothing): 60 \mathrm{~mm}, \text { Thick: } 20 \mathrm{~mm} \\
\text { Load }=50,100,150 \mathrm{~N} \\
\text { Speed }=0.3,0.6,0.9 \mathrm{~m} \cdot \mathrm{s}^{-1} \\
\text { Time }=30,45,60 \mathrm{~min}\end{array}$ & $\begin{array}{l}\text { - Applied normal load is the most dominant factor } \\
\text { influencing dry sliding mechanism, followed by } \\
\text { sliding velocity, sliding time and microstructural } \\
\text { characteristics. } \\
\text { - The dry-sliding behavior of the Ti64 alloy is directly } \\
\text { associated with the hardness. The lamellar (low } \\
\text { hardness) and equiaxed (high hardness) micro- } \\
\text { structured specimens were identified to have low } \\
\text { and high wear resistance, respectively. The bi-modal } \\
\text { structure stays as the intermediate. }\end{array}$ & [50] \\
\hline 5 (b) & $\begin{array}{l}\text { Ti6Al4V } \\
\text { (Block, } \\
27 \text { HRC) }\end{array}$ & $\begin{array}{l}\text { EN } 31 \\
\text { (Disk, } \\
50 \text { HRC) }\end{array}$ & $\begin{array}{l}\text { Dry sliding, Block-on-disk } \\
\text { Block dimensions: } 6.35 \mathrm{~mm} \\
\quad \times 6.35 \mathrm{~mm} \times 9 \mathrm{~mm} \\
\text { Disk }(\varnothing): 60 \mathrm{~mm} \text {, Thick: } 20 \mathrm{~mm} \\
\text { Load }=60,80,100 \mathrm{~N} \\
\text { Speed }=0.3,0.6,0.9 \mathrm{~m} \cdot \mathrm{s}^{-1}\end{array}$ & $\begin{array}{l}\text { - The wear mechanism of the Ti64 (bi-modal) is } \\
\text { governed by thermal oxidation and delamination at } \\
\text { low }\left(0.3 \mathrm{~m} \cdot \mathrm{s}^{-1}\right) \text { and high sliding speeds }\left(0.9 \mathrm{~m} \cdot \mathrm{s}^{-1}\right) \text {. } \\
\text { - It was reported that the sliding speed significantly } \\
\text { governs the wear mechanisms of Ti64, whereas the } \\
\text { effect of normal load was observed to be negligible. }\end{array}$ & [21] \\
\hline
\end{tabular}


(Continued)

\begin{tabular}{|c|c|c|c|}
\hline $\begin{array}{l}\text { Sl. } \\
\text { No. }\end{array}$ & $\begin{array}{c}\text { Test } \\
\text { material }\end{array}$ & Counter-body & Conditions \\
\hline 6 & $\begin{array}{l}\text { Ti6Al4V } \\
\text { (Pin, } \\
311 \mathrm{VHN})\end{array}$ & $\begin{array}{c}\text { Hardened } \\
\text { chromium } \\
\text { steel } \\
\text { (Disk, } \\
60 \mathrm{HRC})\end{array}$ & $\begin{array}{l}\text { Dry sliding, Pin }(\varnothing): 10 \mathrm{~mm} \\
\text { Specimens: Bare Ti64, heat } \\
\text { treated and quenched (water, air, } \\
\text { furnace cooled), shot peened } \\
\quad \text { (at } 3.5 \text { and } 4.5 \text { bar) } \\
\text { Load }=50 \mathrm{~N}, \text { Pressure }=0.7 \mathrm{MPa}\end{array}$ \\
\hline
\end{tabular}

- The low wear rates of the quenched Ti64 (air cooledaged and water quench-aged) specimens were reported to be due to the existence of retained oxide layer on the substrate surface and the existence of transformed $\beta$-phase.

- Shot peening has led to the development of considerably hard surfaces suitable for osseointegration.

- The dominant material removal mechanisms identified with Ti64 at the chosen sliding conditions were oxidation and delamination.

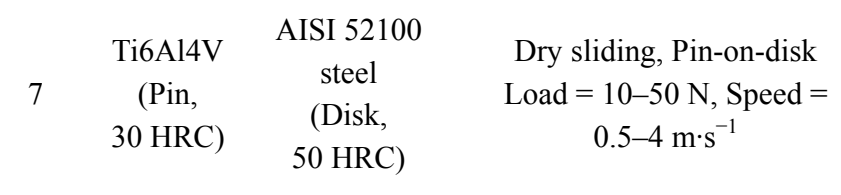

- The variation in tribo-behavior of the alloy at distinct sliding conditions was identified to vary based on the stability of the TO. Thereby formed TOL was observed to impart protective action, contradicting the conventional views.

- Two distinct wear characteristics reported during dry sliding of Ti64/Ti64 and Ti64/AISI M2 steel, varied distinctively. For the former, the wear rate reached a minimum and then increased to become severe whereas, the wear behavior of the latter followed a continuous decremental trend.

AISI M2
steel $\quad$ Dry sliding, Disk-on-disk

Ti6Al4V (Disk,

8 (Disk, $65 \mathrm{HRC})$

$\left.350 \mathrm{HV}_{10}\right) \quad \& \mathrm{Ti} 6 \mathrm{Al} 4 \mathrm{~V}$

(Disk, $350 \mathrm{HV}_{10}$ )

Load $=50-200 \mathrm{~N}$, Speed $=$ $0.3-0.8 \mathrm{~m} \cdot \mathrm{s}^{-1}$

Disk $(\varnothing): 40 \mathrm{~mm}$, Thick: $10 \mathrm{~mm}$ Sliding distance: $1,770 \mathrm{~m}$

- At a sliding velocity of $0.8 \mathrm{~m} \cdot \mathrm{s}^{-1}$, the increment in interfacial temperature due to increase in load or decrease in thermal conductivity led to enhanced plastic strain and hence higher wear rate.

- With the increment in sliding velocities from low to high, a shift in wear mechanism takes place from being due to oxidation to delamination.

- Oxidative and delamination wear dominated the wear mechanism within the chosen test conditions. Plastic deformation of subsurface regions was identified to occur during surface oxidation.

- It was recommended that the mechanical properties

Disk $(\varnothing): 40 \mathrm{~mm}$, Thick: $10 \mathrm{~mm}$ Sliding distance: $1,770 \mathrm{~m}$ of the surface must be enhanced to limit the tendency for plastic shearing, thermal softening and mechanical instability.

Dry reciprocated sliding,

\section{Pin-on-flat}

Pin $(\varnothing): 9 \mathrm{~mm}$, Chamfer $=80^{\circ}$, electropolished in a solution containing methanol $(300 \mathrm{~mL})$,

$$
\text { n-butanol }(180 \mathrm{~mL}) \text { and }
$$

perchloric acid $(30 \mathrm{ml})$ at $0-5{ }^{\circ} \mathrm{C}$ and $20 \mathrm{~V}$ for $90 \mathrm{~s}$; $\operatorname{Load}=75 \&$ $250 \mathrm{~N}$

Block dimensions: $40 \mathrm{~mm} \times$ $12 \mathrm{~mm} \times 12.5 \mathrm{~mm}$
- The dynamic friction coefficient of 21 SRX showed a decremental behavior in contrast to Ti64 having a reverse trend, due to the low shear resistance aided material migration.

- The frictional behavior of the materials was governed by the mechanisms, viz., plastic deformation and fracture, micro plowing, adhesive wear, material transfer and alloying, controlled by the TL formation. 
includes the details about the test-material, counterbody, experimental conditions and the major outcomes of the distinct investigations carried out previously by various researchers, in the subject context. The detailed discussion that follows sticks to the same sequence depicted in Table 2.

\subsection{SS316L stainless steel}

Raj et al. [1] conducted dry sliding wear test of Ti64 interacting with SS316L stainless steel disk, at ambient and vacuum conditions. The wear rate marginally got reduced at a pin sliding speed of $0.5 \mathrm{~m} \cdot \mathrm{s}^{-1}$, suggested to be due to the transition from mild (equiaxed debris) to severe wear (laminate debris). The magnitude of the material removal due to wear was identified to be much higher at vacuum than ambient conditions. Moreover, the smaller pin $(2.1 \mathrm{~mm} \emptyset)$ showed a higher wear rate for experimentations at ambient temperature; a similar trend was not observed under vacuum conditions. Further, the mechanisms of TO and MML dominate the wear mechanism at ambient condition, as they both impart a protective layer, which minimizes the direct body to counter-body interactions (the same got confirmed from the SEM and XRD spectral analyses). Nonetheless, the formation of the oxide layer was absent from the tests under vacuum conditions.

Another observation of phenomenal significance is the fact that the wear rate of the alloy is nearly independent of the heat flux at the interface (pin heating) during the low sliding speed of the pin and the reverse effect happens with its increment. Further, the possibility for third body abrasion due to debris entrapment can occur at low sliding speeds. The evaluation of frictional curves points to the fact that there was a characteristic difference in the trend for the smaller pin $(2.1 \mathrm{~mm} \varnothing)$ compared to that of larger pins (4.6 and $6.6 \mathrm{~mm} \emptyset$ ), at both ambient and vacuum conditions. This was aided by excessive heating [134, 141] and, many tests got discarded due to severe damage to the pin (at a sliding speed of $1.5 \mathrm{~m} \cdot \mathrm{s}^{-1}$ ). Since the microstructural instability of the alloy got instigated by the energy dissipation in the form of heat, the thermal properties of the material would play a significant role in governing the interactive mechanisms. Improving the thermal transport pro- perties, viz., thermal diffusivity and thermal conductivity through surface or structural modification can enhance the tribological behavior of the alloy [121, 142].

\subsection{GCr15 steel}

Mao et al. [2] investigated the dry sliding behavior of Ti64 pins, slid against GCr15 steel counter-body. The commercially available hot extruded Ti64 rods were cross-sectionally cut (with dimensional accuracies) to form the required samples (dia. $(\varnothing): 6 \mathrm{~mm}$, length: $12 \mathrm{~mm}$ ). Further, the material when subjected to solid dissolving (at $955^{\circ} \mathrm{C}, 2 \mathrm{~h}$ ), water quenching, aging (at $540{ }^{\circ} \mathrm{C}, 4 \mathrm{~h}$ ) and air cooling, high hardness (40 HRC) characteristics got achieved. The peak wear trend was identified with at a temperature range of $25-200{ }^{\circ} \mathrm{C}$ compared to the lowest at $400-500{ }^{\circ} \mathrm{C}$. It was suggested based on the obtained results that Ti64 does not exhibit poor tribo-properties at all interactive conditions of load, speed, and temperature. Under an applied load of $100-200 \mathrm{~N}$ on the pin at $400-500{ }^{\circ} \mathrm{C}$, the alloy was observed to impart high wear resistance due to the formation of tribo-oxide layers. Variation in wear rate with the applied load on the pin at various temperatures is as shown in Fig. 11.

The dominant wear mechanisms at different stages of sliding were recognized to vary with temperature and applied load on the pin. At $25-200{ }^{\circ} \mathrm{C}$ (at low load condition), adhesive wear was the typical case of material removal, characterized by plastic deformation

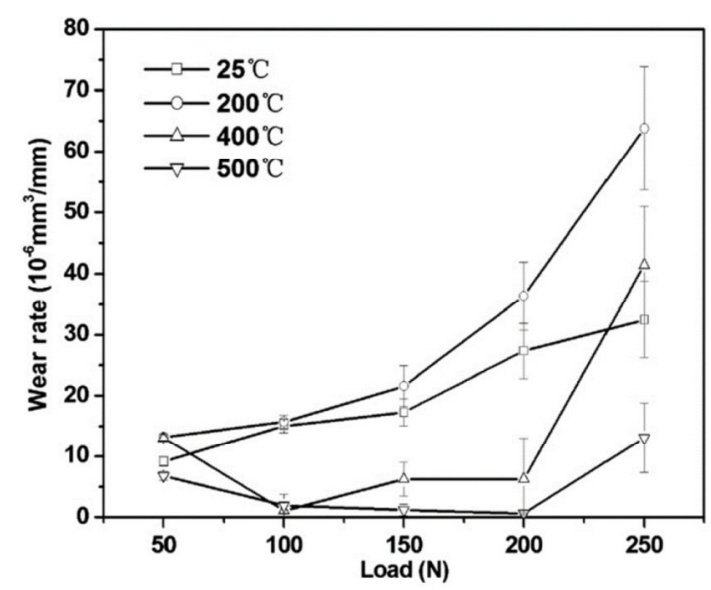

Fig. 11 Variation in wear rate with normal load on the pin at various temperatures. Reproduced with permission from Ref. [2]. Copyright Elsevier, 2013. 
and fracture leading to the formation of furrows and ridges at distinct regions along the sliding direction on the pin surface (Figs. 12(a) and 12(b)). The percentage of oxygen content identified with the surface at this state of sliding was either negligible or in trace quantities, with strength comparable to that of the substrate material. The tribo-behavior exhibited by the TOL and the Ti64 are similar in nature such that the distinction in the rate of deformation and fracture was minimal. Progressive increment in temperature $\left(400-500{ }^{\circ} \mathrm{C}\right)$ at high loads $(100-200 \mathrm{~N})$, activated the oxidative wear mechanism recognized by the formation of TOL (Figs. 12(c) and 12(e)). Nonetheless, the impinging high loads over the material surface have led to spalling and delamination with progressive sliding (Figs. 12(d) and 12(f)). The subsurface regions were subject to plastic deformation and fracture. It is significant to note that the shift in wear characteristics at $400-500{ }^{\circ} \mathrm{C}$ during varying load conditions was similar in nature producing comparable worn-pin surface characteristics. Moreover, the TOL imparted protective behavior to the surface as it possesses higher strength and hardness than the substrate material, hence the reduction in wear. Low load sliding against the counter-face at similar temperature conditions demonstrated comparable wear characteristics, as that at ambient and low-temperature tribo-interactive conditions [2].
Ming et al. [114] conducted experiments at highspeed dry sliding conditions of the Ti64 pins interacting with GCr15 steel counter-face. The increment in contact pressure led to the rise in surface contact temperatures, as identifiable from Fig. 13(a). Moreover, at a high contact pressure of $1.33 \mathrm{MPa}$, the frictional system attained the state of dynamic equilibrium, reaching the peak interfacial temperature value of $1,000{ }^{\circ} \mathrm{C}$ (approx.). The variation in $\mathrm{CoF}$ and wear rate of Ti64 with increment in contact temperature is as shown in Fig. 13(b). The characteristics identified with the mentioned tribo-properties were distinctly different in their respective propositions. The CoF increased to a peak value and then decreased with increment in contact temperature, whereas the wear rate depicted a continuous up-rise with a shift in the slope of the characteristic curve from medium to low. The critical temperature of $\mathrm{CoF}$ corresponds to the $\beta$-phase transformation temperature of Ti64, which as per the considerations would be above $800{ }^{\circ} \mathrm{C}$ and below $882^{\circ} \mathrm{C}$. The upper-limit temperature corresponds to the $\beta$-phase transformation temperature of CP Ti [143], and the lower-limit temperature value was derived from the plot (Fig. 13(b)), after rendering due consideration for possibility of error which may occur from calculations performed using neural network (NN) and genetic algorithm (GA). Further, the interfacial temperature developed due to frictional heating exceeds
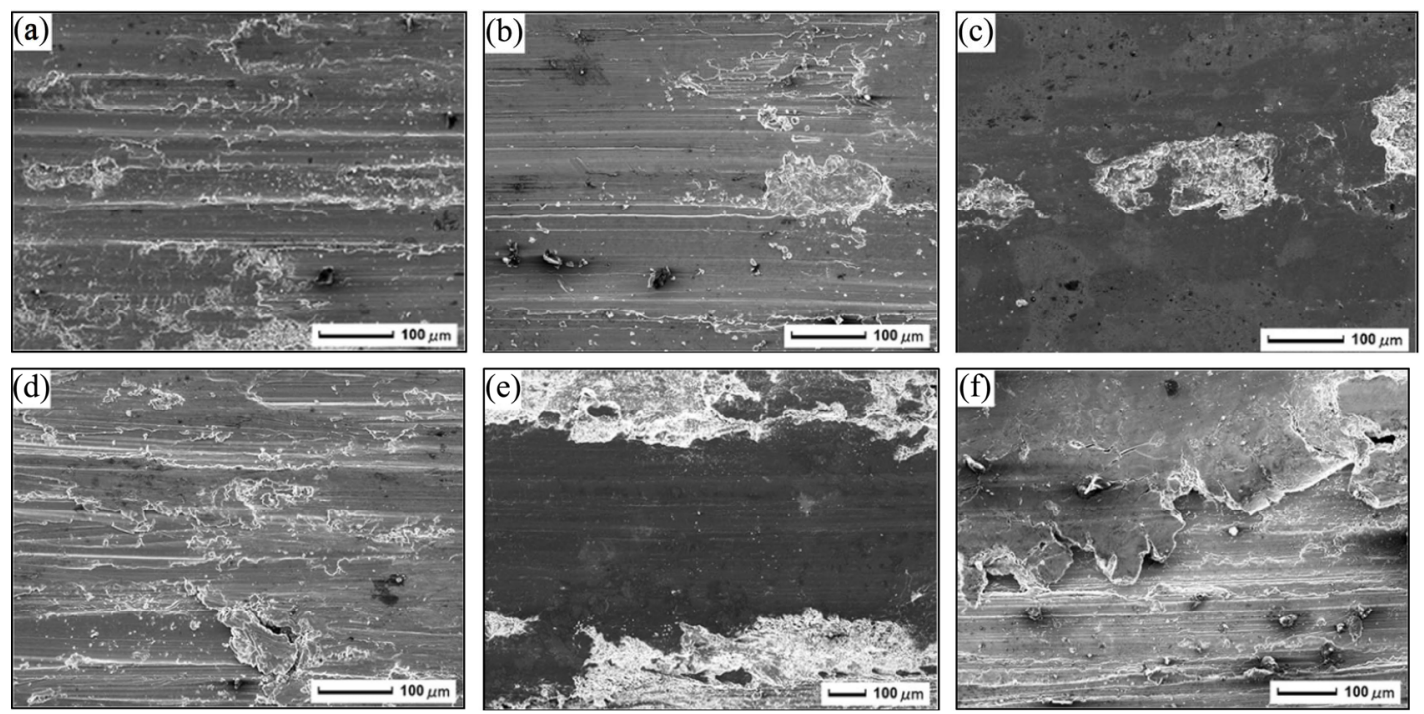

Fig. 12 Morphology of Ti64 worn pin surfaces ensuing counter-body interaction under various sliding conditions: (a) temp $=25^{\circ} \mathrm{C}$, load $=100 \mathrm{~N}$; (b) temp $=200{ }^{\circ} \mathrm{C}$, load $=100 \mathrm{~N}$; (c) temp $=400{ }^{\circ} \mathrm{C}$, load $=100 \mathrm{~N}$; (d) temp $=400{ }^{\circ} \mathrm{C}$, load $=250 \mathrm{~N}$; (e) temp $=500{ }^{\circ} \mathrm{C}$, load $=100 \mathrm{~N}$; (f) temp $=500^{\circ} \mathrm{C}$, load $=250 \mathrm{~N}$. Reproduced with permission from Ref. [2]. Copyright Elsevier, 2013. 

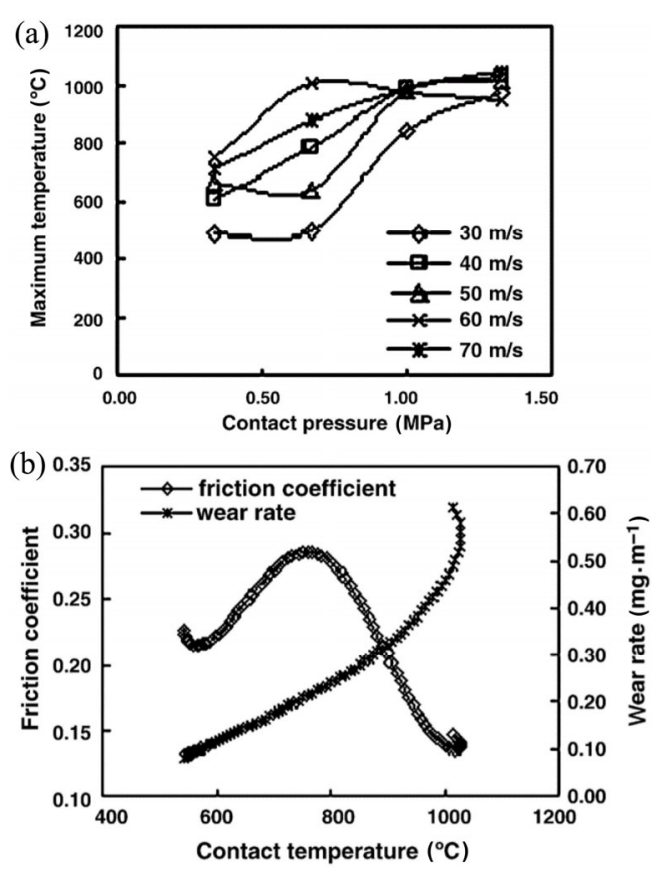

Fig. 13 Significance of contact temperature: (a) variation in maximum contact temperature with increment in contact pressure at discrete sliding speeds; (b)variation in $\mathrm{CoF}$ and wear rate with increment in contact temperature. Reproduced with permission from Ref. [114]. Copyright Elsevier, 2006.

than that of $\beta$-phase transformation temperature of Ti64, correspondingly the $\beta$-crystals will grow swiftly, reducing the plastic deformability of the material $[114,143]$.

The SEM cross-sectional micrograph of the Ti64 worn-pin sample is as shown in Fig. 14. The microstructural analysis of the surface/sub-surface layers, identified three distinct regions that differ in their structural orientation such as (a) melted and re-solidified layer (wear debris material); having fine grain structure (b) transition layer; composed of larger crystals (c) base material (Ti64). The temperature rises above $1,000{ }^{\circ} \mathrm{C}$ during sliding assisted frictional heating; the subsequent cooling in the air will force the $\alpha$-phase to get accumulated along the boundary of the early $\alpha$-grains, and the $\alpha$-crystals get enlarged [55]. With the increment in temperature $\left(550-600{ }^{\circ} \mathrm{C}\right)$, the elements such as $\mathrm{C}, \mathrm{O}$, and $\mathrm{N}$ in the air permeate into the surface and sub-surface regions of the base material. Large amounts of $\mathrm{TiO}$ and trace amounts of $\mathrm{TiO}_{2}$ got identified on the worn-pin surface, with a large percentage of $\mathrm{VN}$ formed at the subsurface region. It signified the higher penetrability of $\mathrm{N}$ over other elements, and the layer was associated with the

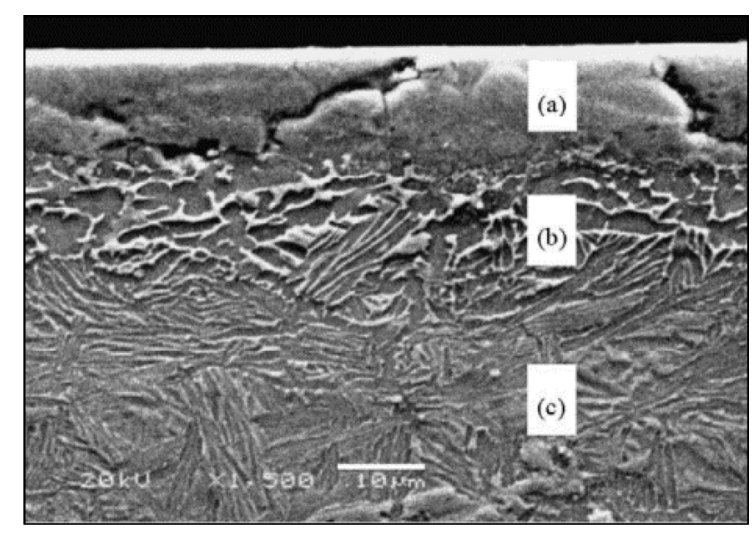

Fig. 14 SEM cross-sectional micrograph of the worn-pin Ti64 surface and sub-surface layers ((a) re-solidified layer; (b) transition layer; (c) base material). Reproduced with permission from Ref. [114]. Copyright Elsevier, 2006.

development of cracks due to the brittle nature of $\mathrm{VN}$ $[25,114]$.

\subsection{Diamond tip}

Feng and Khan [19] conducted a dry sliding wear test on a reciprocating wear tester (pin-on-plate). A diamond tip got chosen as the cutting edge (counterface) and the sliding material (Ti64) plates subjected to $\mathrm{ST}$ at $750{ }^{\circ} \mathrm{C}$ and $1,000{ }^{\circ} \mathrm{C}$, separately and quenched using distinct dielectrics (oil, water, and $\mathrm{N}_{2}$ ). Initially hardness of the quenched specimens was tested, to be found that compared to the as-received Ti64 (400 VHN), the decline in hardness of the samples, was in the order: (i) ST at $1,000{ }^{\circ} \mathrm{C}$ and water quenched (883 VHN), (ii) ST at $1,000{ }^{\circ} \mathrm{C}$ and oil quenched (802 VHN), (iii) $\mathrm{ST}$ at $750{ }^{\circ} \mathrm{C}$ and $\mathrm{N}_{2}$ quenched (746 VHN). Although quenching with $\mathrm{N}_{2}$ is a recent development, competent characteristics got were developed on the surface. The highest wear loss was identified to be for the specimen quenched in $\mathrm{N}_{2}$ and the lowest for the as-received Ti64 sample. The results when correlated with the hardness values of the surfaces contradict the Archard's law, according to which the wear resistance of the surface should increase with improvement in hardness. Nevertheless, the reverse trend was obtained, as per the results. To elucidate the underlying mechanisms, SEM micrographs of the wear tracks (Fig. 15) were subject to assessment. Micro-cutting and plowing were the dominant surface damage mechanisms resulting in material removal. Considerable plastic deformation occurred with the as-received 

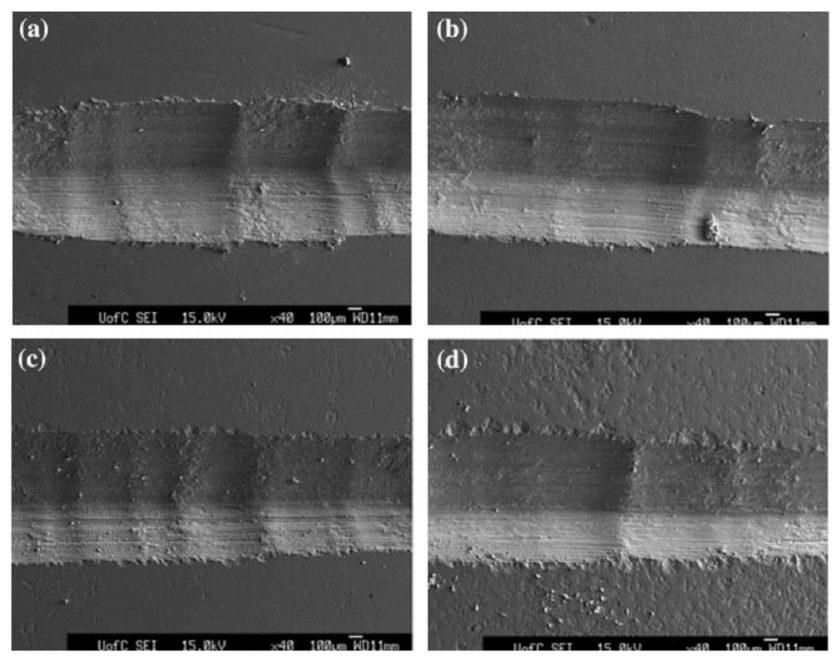

Fig. 15 Metallographic images of the wear tracks developed on the Ti64 test plate surface ST at $1,000{ }^{\circ} \mathrm{C}$ (for $30 \mathrm{~min}$ ): (a) as received Ti64 specimen; (b) quenched in oil; (c) quenched in water; (d) quenched in $\mathrm{N}_{2}$. Reproduced with permission from Ref. [19]. Copyright Springer Nature, 2007.

Ti64 worn surface, with the formation of "deformation lip" along the edges of the wear track. Comparatively, for quenched samples, continuous "chipping" effect occurred at the edges (specifically for samples quenched in water and $\mathrm{N}_{2}$ ). A shift in nature of the surface is suggested to have occurred due to phase transformation, from being more ductile (for as-received sample) to brittle (for quenched sample). The highest roughness value obtained for the wear track of the $\mathrm{N}_{2}$ quenched sample (as a result of brittle fracture), supported the above argument [19].

To investigate the strain hardening effect, the micro-hardness of worn surfaces of as-received and $\mathrm{N}_{2}$ quenched samples got evaluated at two positions: (i) at the region just below the wear track and (ii) at the region $40 \mu \mathrm{m}$ below the wear track. The hardness level obtained for the former: $550 \mathrm{VHN}$ and $381 \mathrm{VHN}$ and the latter: $407 \mathrm{VHN}$ and $391 \mathrm{VHN}$, in the order of the specified test positions. It is interesting to note that the as-received sample was strain hardened due to its plasticity. Contrarily, the quench-aged specimens have demonstrated reduced plastic behavior, and the oxygen diffusion was identified to play a significant role in the improved hardness of the substrate. Hence, it got confirmed that the quenching of Ti alloys reduces the wear resistance of the material, transforming the surface to be more brittle, thereby promoting brittle fracture during surface interactions [19].

\subsection{Silicon carbide abrasive paper}

Hadke et al. [61] evaluated the abrasive wear characteristics of Ti64 sliding against silicon carbide abrasive counter-face (150 grit). The Ti64 samples were quenchaged at $1,339 \mathrm{~K}(1 \mathrm{~h})$ and $823 \mathrm{~K}(4 \mathrm{~h})$, respectively. Cooling got performed as intermediate steps using oil and air at room temperatures in an inert atmosphere. The hardness of the samples was determined to be $321 \mathrm{HV}$ (as-received) and $433 \mathrm{HV}$ (quench-aged) compared to that of the silicon carbide abrasive ( $\mathrm{SiC}$ ) counter-body $(2,200 \mathrm{HV})$. The mass loss of both the categories of samples was found to increase linearly with load and speed. This was notified to be in contradiction to the general wear behavior of metals and alloys (e.g., steels), which decrease with increase in wear due to plastic deformation assisted work hardening. This anomaly has resulted from the characteristically lower work hardening tendency of HCP structured materials [41, 144].

It was reported that two distinct wear characteristics were noted with as-received and quench-aged samples such as micro-plowing and micro-cutting, respectively (Fig. 16). Abrasion was also identified to take place at some angle to the sliding direction (observable at random regions). This was due to the debris particles leaving the wear track ensuing centrifugal action, during rotational interaction of the mating surfaces. Another distinctive observation in case of quench-aged
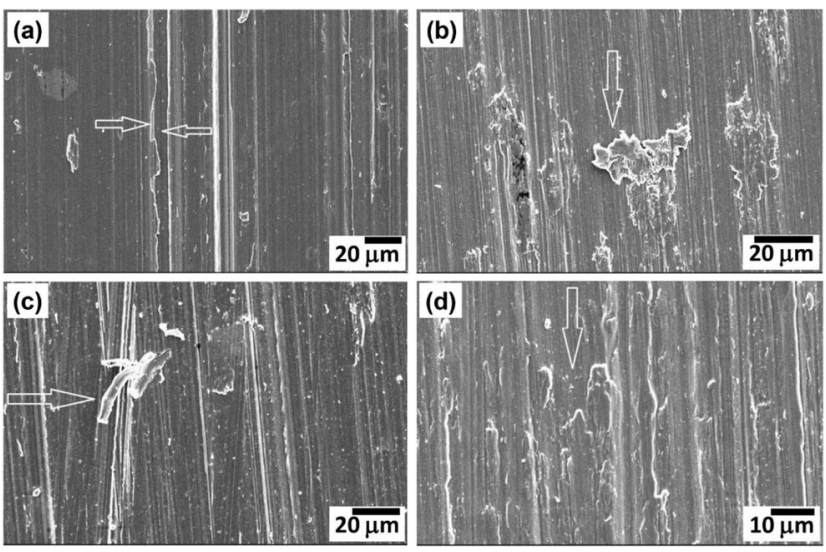

Fig. 16 SEM images of the worn-pin Ti64 surfaces: (a) as-received $($ load $=100 \mathrm{~N}$, speed $=200 \mathrm{rpm}$, time $=300 \mathrm{~s})$; (b) as-received (load $=40 \mathrm{~N}$, speed $=800 \mathrm{rpm}$, time $=1,200 \mathrm{~s})$; (c) quench-aged $($ load $=100 \mathrm{~N}$, speed $=200 \mathrm{rpm}$, time $=300 \mathrm{~s}) ;(\mathrm{d})$ quench-aged (load $=100 \mathrm{~N}$, speed $=200 \mathrm{rpm}$, time $=1,200 \mathrm{~s})$. Reproduced with permission from Ref. [61]. Copyright Elsevier, 2015. 
samples is the formation of microchips, with its traces found along the wear track. The developments of wedges and grooves were the characteristic feature of the wear mechanism associated with the as-received sample surfaces (attributed to low hardness and high ductility of the material). At mild processing conditions $($ soad $=100 \mathrm{~N}$, speed $=200 \mathrm{rpm}$, time $=300 \mathrm{~s})$, the wear behavior of the as-received and the quench-aged specimens was characteristically discrete. Contradictorily, comparable surface features have got achieved at severe conditions (load $=100 \mathrm{~N}$, speed $=200 \mathrm{rpm}$, time $=1,200 \mathrm{~s}$ ) for both the sample types, confirming the occurrence of similar wear mechanisms [61].

\subsection{EN 31 Steel}

Sahoo et al. [50] evaluated the effect of discrete microstructures on the wear behavior of Ti64. The lamellar (transformed $\beta$-phase), bi-modal (primary $\alpha$ and transformed $\beta$-phases) and the equiaxed ( $\alpha$-phase in $\beta$-matrix) structural orientations were developed by quench-air cooled-aging at $1,025^{\circ} \mathrm{C}$ and $750{ }^{\circ} \mathrm{C}$, $950{ }^{\circ} \mathrm{C}$ and $675{ }^{\circ} \mathrm{C}$, solution annealing at $850{ }^{\circ} \mathrm{C}$, respectively.

The variation in hardness of the distinct phases of the material was determined to be in the increasing order, viz., equiaxed (70\% $\alpha$-phase), bi-modal (25\% $\alpha$-phase) and lamellar (fully transformed $\beta$-phase). This got attributed to the fact that for Ti alloys, $\alpha$ and $\beta$-phases are soft and hard, respectively [145-147]. Further, the wear characteristic of the alloy was found to contradict the Archard's law. The highest wear resistance was associated with the specimen having equiaxed microstructure (with the lowest hardness), followed by bi-modal and fully-lamellar orientations. With decrement in the hardness of substrate, the wear resistance of Ti64 increases. Further, from the XRD spectra, the presence of $\mathrm{Ti}(\alpha$-phase) and TiO occurred with both lamellar and bi-modal microstructures while for equiaxed, only Ti ( $\alpha$-phase) got recognized. For lamellar micro-structured Ti64 specimen, the wear debris constitutes of $\mathrm{TiO}$ (loose and fine powder form) and metallic $\alpha$-Ti phase (plate-like). Moreover, the worn pin surface consisted of smooth compact layers, which has undergone brittle fracture along the direction of sliding. The wear debris associated with bi-modal microstructure consisted of large metallic fragments (plate-like) and trace amounts of $\mathrm{TiO}$ (fine powder); the proportion of pieces increased with the rise in sliding velocity. The dominant material removal mechanism identified with the corresponding surface was metallic delamination and fracture. Further, for equiaxed microstructure, the wear debris particles were observed to be in the form of large metallic plates, subject to plastic deformation at high-velocity sliding. The surface underwent plastic deformation with abrasive grooves developed at distinct positions. The specimens with diverse microstructures do not experience any transformation during dry sliding. Hence, the microstructure of the Ti64 had a predominant role in the wear behavior at various conditions of sliding. The shift in wear mechanisms observed at different sliding velocities was consistent, regardless of the distinction in the microstructural variation of the specimens considered [50].

Sahoo et al. [21] investigated the dry sliding wear behavior of bi-modal micro-structured Ti64 surfaces. The cylindrical specimens (dia. $(\varnothing): 20 \mathrm{~mm}$, length = $150 \mathrm{~mm}$ ) have been subjected to solution treatment (at $965^{\circ} \mathrm{C}$ ) with subsequent air-cooling and aging (at $675{ }^{\circ} \mathrm{C}$ ). The basis of the chosen conditions was to develop bi-model micro-structured Ti64 specimens which can be formed by heat treatment below $\beta$-transus followed by air-cooling to get aged at a temperature below $700{ }^{\circ} \mathrm{C}$ [46]. The volume fractions of the primary $\alpha$-phase and the transformed $\beta$-phase were $20 \%$ and $80 \%$, respectively. The FESEM images of the worn-pin and wear debris developed from the Ti64 specimens at a load of $60 \mathrm{~N}$ and varying sliding velocities (0.3, 0.6 and $0.9 \mathrm{~m} \cdot \mathrm{s}^{-1}$ ) are as shown in Fig. 17. Based on the characterization results of the worn-pin surfaces, the low, medium, and high-velocity sliding, led to the variation in surface characteristics. At $0.3 \mathrm{~m} \cdot \mathrm{s}^{-1}$, the surface features demonstrated layers which are smooth and compact, damaged by brittle fracture. Presence of plastically deformed layers and abrasive grooves was the identity of the pin slid at $0.9 \mathrm{~m} \cdot \mathrm{s}^{-1}$. It is significant to note that the reduction in oxidative wear is a behavioral characteristic of Ti64 identified at varying sliding velocities [29]. Besides, Molinari et al. [25] have confirmed (previously) the occurrence of oxidative and delamination wear at low and high sliding speeds, respectively. Consequently, at a medium 

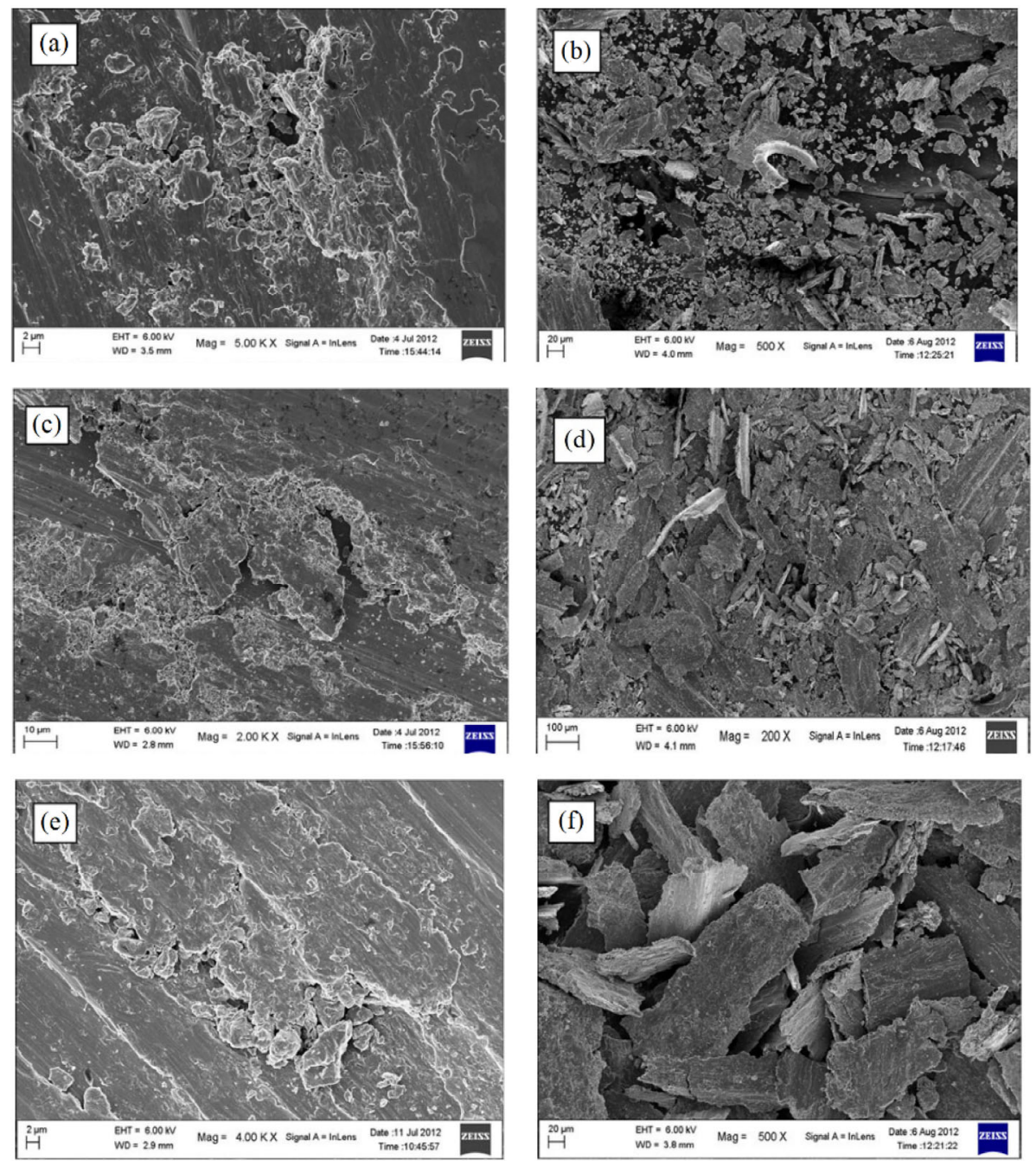

Fig. 17 FESEM metallographic images of worn-pin surface and wear debris developed from Ti64 specimen (bi-modal microstructured) at distinct sliding conditions: (a) and (b) load $=60 \mathrm{~N}$, speed $=0.3 \mathrm{~m} \cdot \mathrm{s}^{-1}$; (c) and (d) load $=60 \mathrm{~N}$, speed $=0.6 \mathrm{~m} \cdot \mathrm{s}^{-1} ;(\mathrm{e})$ and (f) load $=60 \mathrm{~N}$, speed $=0.9 \mathrm{~m} \cdot \mathrm{s}^{-1}$. Reproduced with permission from Ref. [21]. Copyright Springer Nature, 2013.

speed condition of $0.6 \mathrm{~m} \cdot \mathrm{s}^{-1}$, the associated wear mechanism demonstrates itself to that of a cusp; whereas the simultaneous occurrence of oxidative and delamination wear occurs (hence, the minimum wear). This was the underlying reason for high wear resistance of the material at intermediate sliding velocities. Moreover, at comparatively low/medium sliding speeds of 0.3 and $0.6 \mathrm{~m} \cdot \mathrm{s}^{-1}$, the wear debris consisted of $\mathrm{Ti}$ ( $\alpha$-phase, metallic fragments) and $\mathrm{TiO}$ (loose and powdered form), in varying percentages. Contrarily, the presence of the oxide does not occur at the high-velocity sliding of $0.9 \mathrm{~m} \cdot \mathrm{s}^{-1}$, and the debris morphology resembled that of plastically deformed metallic plates (large-sized). The formation of platelike metallic fragments was previously reported to signify the happening of delamination wear [148]. The results got confirmed from the XRD patterns. Similar characteristics were reported at diverse load conditions $(60,80$ and $100 \mathrm{~N})$ when the sliding velocities are varied from low to medium to high $\left(0.3-0.6-0.9 \mathrm{~m} \cdot \mathrm{s}^{-1}\right)$. Hence, it got inferred that the wear characteristics of the bi-modal Ti64 surfaces primarily depend on the variation in sliding velocities (recognized by the shift in wear mechanism and morphology of the wear debris) and insensitive to the applied load [21].

\subsection{Hardened chromium steel}

Ganesh et al. [3] investigated the sliding wear characteristics of Ti64 interacting with hard chromium steel. 
The test specimens include processed Ti64 at various states/levels namely as-received, heat-treated $\left(950{ }^{\circ} \mathrm{C}\right.$, $1 \mathrm{~h}$ ) and quenched (air, water, and furnace) and shotpeened (3.5 and 4.5 bar). It was reported that the as-received, furnace quenched and aged, air quenched and aged, water quenched and aged Ti64 specimens possess equiaxed $\alpha$-phase in $\alpha$ - $\beta$ matrix, fully lamellar $\alpha$-phase surrounded by $\beta$-grain boundary (due to slow cooling), primary $\alpha$-phase surrounded by transformed $\beta$-phase (needle-like, due to moderate cooling) and acicular $\alpha$-phase in the primary $\alpha$ - $\beta$ phase (due to rapid cooling), respectively. The wear track images of the various specimens are as shown in Fig. 18. The water and air-cooled specimens consisted of the retained protective oxide layer formed on the surface. This characteristic was identified only with those samples which were rapid cooled ensuing heat treatment. The argument was also confirmed based on the EDS analysis, which showed a higher percentage of oxygen content for the specimens. The shot-peened specimens were identified to have enhanced iron content on the surface due to the adhesion and transfer of material from the steel shots. Moreover, the quenched samples were found to have comparatively higher hardness, attributed to the formation of acicular $\left(\alpha^{\prime}\right)$ martensite phase. The hardness of the processed Ti64 specimens was in the increasing order of asreceived (311 VHN), air-cooled and aged (340 VHN), furnace quenched and aged (351 VHN), water quenched and aged (380 VHN) and shot-peened (380 VHN).

The wear behavior of the as-received Ti64 in comparison to the heat treated-cooled and shot-peened specimens is as depicted in Fig. 19. The wear rate $\left(\mathrm{m}^{3} / \mathrm{min}\right)$ was notified to be the highest for the (a)

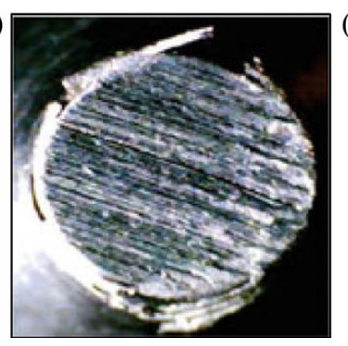

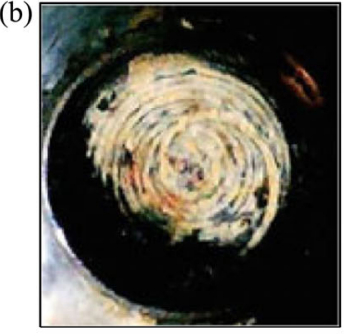

(e)

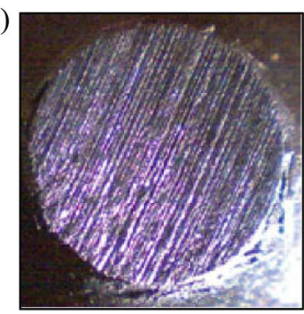

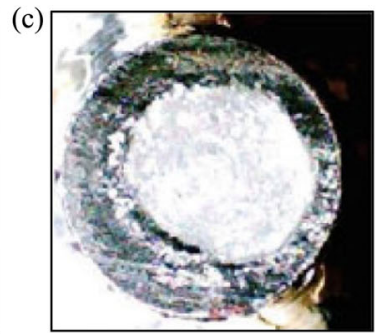

(f)

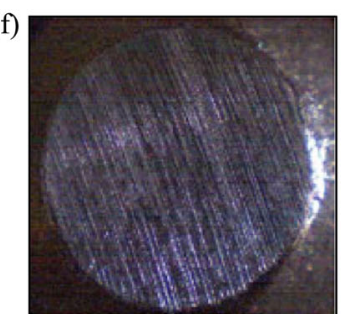

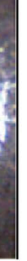

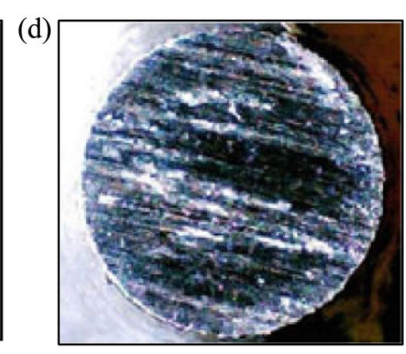

Fig. 18 Wear track images of the processed Ti64 test specimens (magnification:20×): (a) as-received; (b) water cooled; (c) air cooled; (d) furnace cooled (e) shot peened (3.5 bar) (f) shot peened (4.5 bar). Reproduced with permission from Ref. [3]. Copyright Springer Nature, 2012.
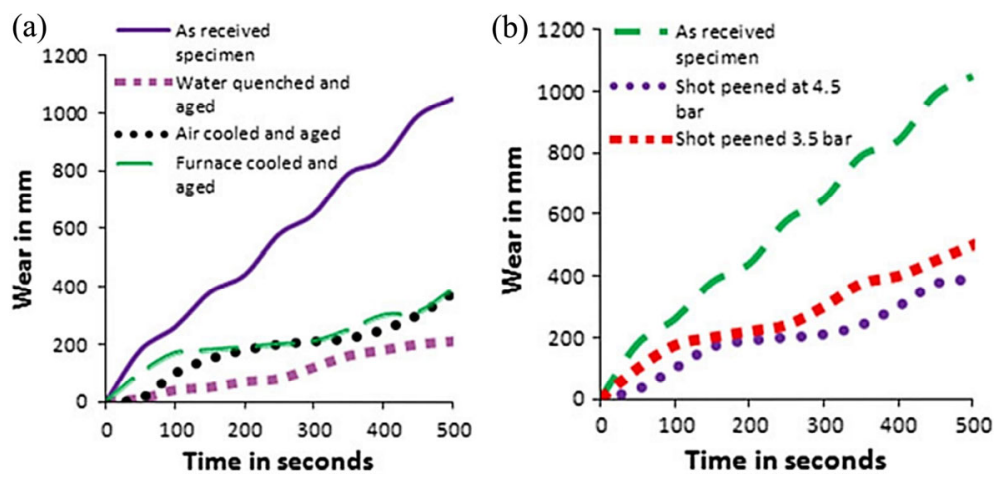

Fig. 19 Wear characteristics of Ti64 in comparison to the processed specimens: (a) heat treated; (b) shot peened. Reproduced with permission from Ref. [3]. Copyright Springer Nature, 2012. 
as-received samples, followed by shot-peened and furnace cooled-aged samples. Hence, the formation of fully lamellar microstructure although observed to have comparable hardness does not impart sufficient wear resistance in contrast to the other discrete phases, viz., transformed $\beta$ ( $\alpha^{\prime}$-phase) or acicular $\alpha$-phase, as observed to be formed in air-cooled and waterquenched specimens. The shot-peened samples were also found to have reduced wear rate, intermediate to the as-received and heat treated-cooled test samples. Although it got reported that the quenched samples correlated well with that of the Archard's law, the argument was recognized to be inaccurate in the case of furnace-cooled and aged to that of the air-cooled and aged specimens. The hardness was higher for the former; nevertheless, the wear resistance was not found to be better in comparison to the latter. Moreover, the shot-peened specimens with peak hardness values of all the samples considered in the investigation were identified to have a high wear rate only second to that of the as-received Ti64 samples. Hence, it got inferred that the significance of hardness comes only secondary to the role of microstructures in controlling the wear characteristics of Ti64 specimens. Furthermore, for the as-received Ti64 samples, the dominant wear mechanism at low sliding speed $\left(1 \mathrm{~m} \cdot \mathrm{s}^{-1}\right)$ was identified to be due to surface oxidation (oxidative wear) which got shifted to delamination with increment in sliding speed $\left(2 \mathrm{~m} \cdot \mathrm{s}^{-1}\right)$. The enhancement in microhardness (350-450 HV) was also notified with progressive sliding at high speed due to plastic deformation assisted work hardening of the material surfaces. This state is reached by the increment in interface temperature of the tribo-pair, due to FH. Further, the rise in temperature contributes to a considerable reduction in yield strength of the material, progressively $[3,90]$.

\subsection{AISI 52100 steel}

Li et al. [106] evaluated the influence of sliding velocity on the formation of tribo-oxides and the corresponding wear behavior of Ti64 alloy. The material initially got annealed (at $760{ }^{\circ} \mathrm{C}, 2 \mathrm{~h}$ ) to be cooled in air. Moreover, the counter-body was subject to austenitization (at $850{ }^{\circ} \mathrm{C}$ ) to be oil quenched, followed by tempering (at $400{ }^{\circ} \mathrm{C}, 2 \mathrm{~h}$ ). The variation in tribo-characteristics of the alloy with sliding velocity is as shown in Fig. 20.

The sliding velocities of 0.75 and $4 \mathrm{~m} \cdot \mathrm{s}^{-1}$, marked the lowest wear rate of the alloy at dry sliding conditions. The peak wear was reported to have occurred at a velocity of $2.68 \mathrm{~m} \cdot \mathrm{s}^{-1}$. The trend got based on the variation in the percentage of oxygen and presence of distinct oxides developed on the sample surfaces at $0.75 \mathrm{~m} \cdot \mathrm{s}^{-1}\left(20.56 \%\right.$, traces of $\mathrm{TiO}$ ), $2.68 \mathrm{~m} \cdot \mathrm{s}^{-1}$ (no oxides) and $4 \mathrm{~m} \cdot \mathrm{s}^{-1}\left(37.48 \%\right.$, minimal presence of $\mathrm{TiO}, \mathrm{TiO}_{2}$, $\mathrm{Fe}_{2} \mathrm{O}_{3}$ ). Moreover, the oxidative color observed from the macro-metallographic images confirmed the above argument with small areas of dark and larger areas of grey regions, bright regions with metallic lustre and fully covered dark regions at low, medium and high-speed conditions, respectively. It is significant to note that the frictional coefficient followed a similar trend to that of wear in variation with sliding velocity, albeit with acceptable tolerances. The SEM metallographic images of the worn-pin surfaces at distinct sliding conditions are as shown in Fig. 21. It was reported based on the observations that the dominant wear mechanisms at sliding speeds of $0.75,2.68$, and $4 \mathrm{~m} \cdot \mathrm{s}^{-1}$ are composite wear (oxidative
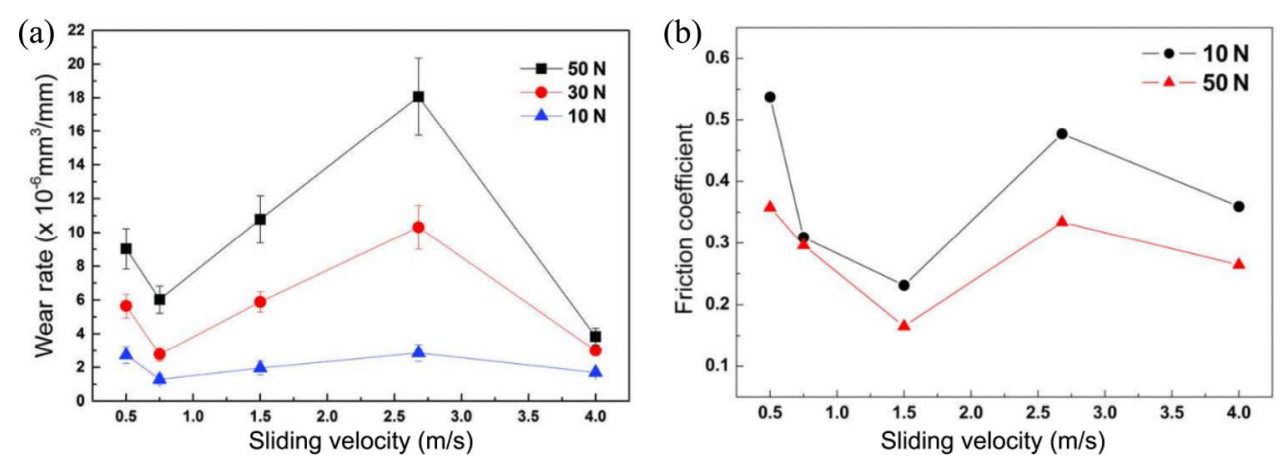

Fig. 20 Tribo-behavior of Ti64: (a) variation in wear rate with sliding velocity; (b) variation in frictional coefficient with increment in sliding velocity. Reproduced with permission from Ref. [106]. Copyright Elsevier, 2015. 

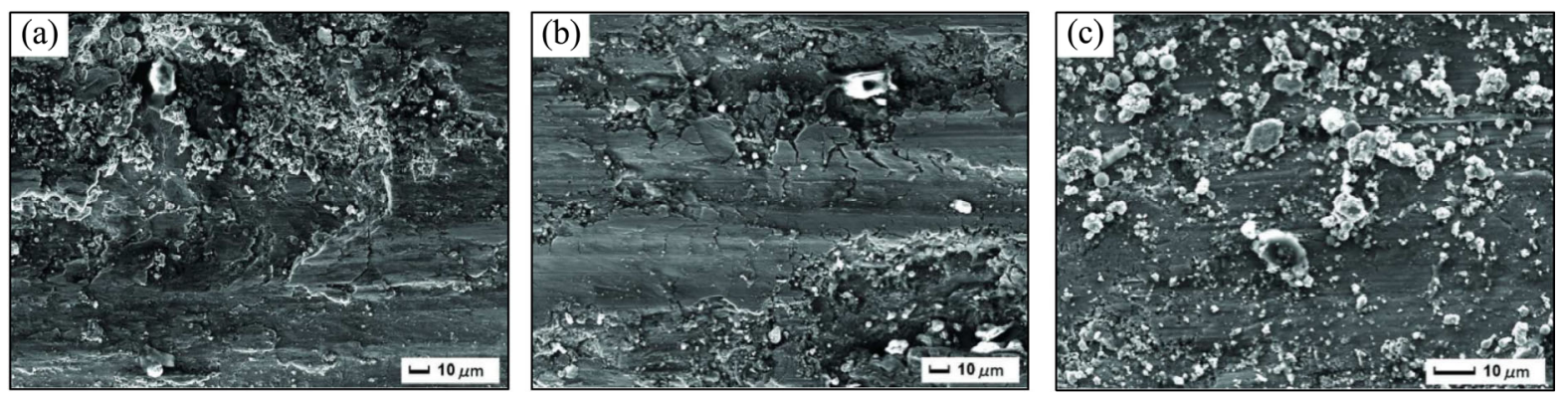

Fig. 21 SEM metallographic images of worn-pin surfaces pertinent to Ti64 specimens at distinct dry sliding speeds: (a) $0.75 \mathrm{~m} \cdot \mathrm{s}^{-1}$; (b) $2.68 \mathrm{~m} \cdot \mathrm{s}^{-1}$; (c) $4 \mathrm{~m} \cdot \mathrm{s}^{-1}$. Reproduced with permission from Ref. [106]. Copyright Elsevier, 2015.

and delamination), metallic wear and oxidative wear, respectively [106].

\subsection{AISI M2 steel}

Straffelini and Molinari [29], evaluated the dry sliding wear behavior of Ti64 (cold rolled bar) interacting with similar and AISI M2 steel (quenched and tempered) counter-bodies, respectively. The wear behavior of the alloy as test and counter-face materials is as depicted in Fig. 22. For the tribo-pair Ti64/Ti64, the wear rate initially reduced to a minimum and henceforth improved. At applied loads of 50, 100, and $200 \mathrm{~N}$ the least value of wear rate was identified with sliding velocities of $0.6,0.5$, and $0.4 \mathrm{~m} \cdot \mathrm{s}^{-1}$, respectively. Moreover, the Ti64 counter-face underwent significant wear (above the maximum limit of mild wear rate; $10-3 \mathrm{~mm}^{3} / \mathrm{m}$ ) [149]. Although at loads of 50 and $100 \mathrm{~N}$, the Ti64 counter-face was nearly unaffected by wear at elevated sliding velocities, the surface underwent drastic increment in wear rate during interaction at $200 \mathrm{~N}$. Contrarily, for Ti64/AISI M2 mating surfaces, the wear rate followed a decremental trend for all considered sliding conditions and the counter-face was devoid of appreciable material removal. The analysis of wear debris has shown that for both the distinct counterbody interactions, the size of the fragmented plate-like structures keeps on increasing in dimensions $(0.5-4 \mu \mathrm{m}$ to $200 \mu \mathrm{m}$ ), with the sliding velocity. The exception in the case of the percentage of oxides (TiO) produced was reported to be higher in the case of Ti64/AISI M2 interactions. The worn-pin and counter-body surface morphologies ensuing dry sliding at 0.3 and $0.8 \mathrm{~m} \cdot \mathrm{s}^{-1}$ at a load of $100 \mathrm{~N}$ are as shown in Fig. 23. At low sliding velocities, the characteristic of Ti64 worn-pin surfaces is the presence of smooth and compact layers affected by brittle fracture. Whereas, plastically deformed layers and abrasive grooves dominated the surface at peak sliding velocities. The AISI M2 steel surface demonstrated the existence of small particles and large adherent transfer layer (Ti64) at 0.3 and $0.5 \mathrm{~m} \cdot \mathrm{s}^{-1}$ sliding velocities, respectively. The plastically deformed layer and strain hardened subsurface region exists for sliding at distinct velocities and loads. The oxide scales formed at low sliding speeds $\left(0.2-0.5 \mathrm{~m} \cdot \mathrm{s}^{-1}\right)$ were
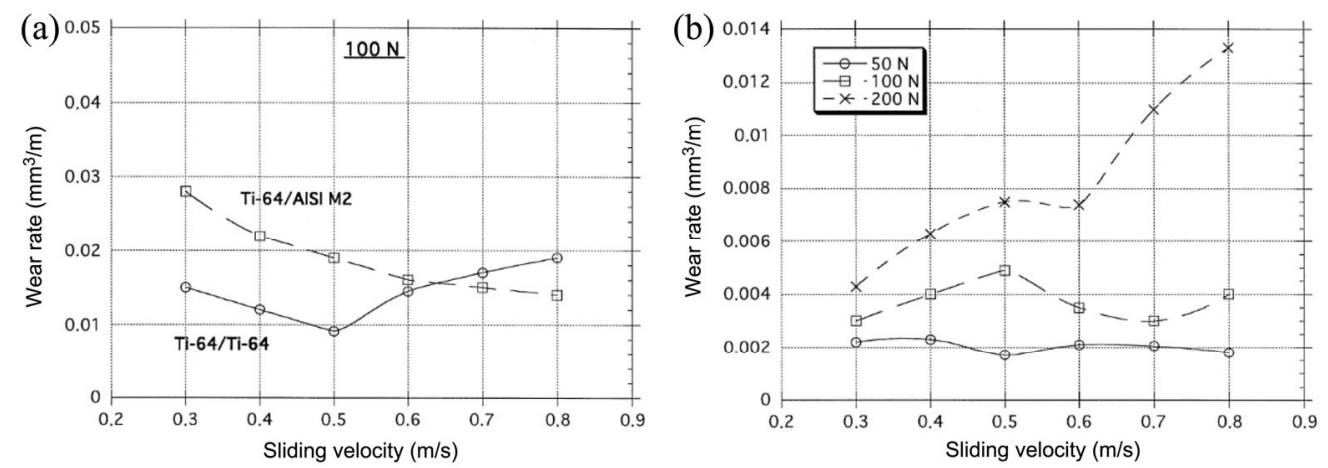

Fig. 22 Wear behavior of Ti64 sliding against similar and AISI M2 steel counter-body surfaces at varying sliding velocities: (a) Ti64 test specimen during Ti64/Ti64 and Ti64/AISI M2 steel interactions (load = $100 \mathrm{~N}$ ); (b) Ti64 counter-face during Ti64/Ti64 interaction $($ load $=50,100$ and $200 \mathrm{~N})$. Reproduced with permission from Ref. [29]. Copyright Elsevier, 1999. 

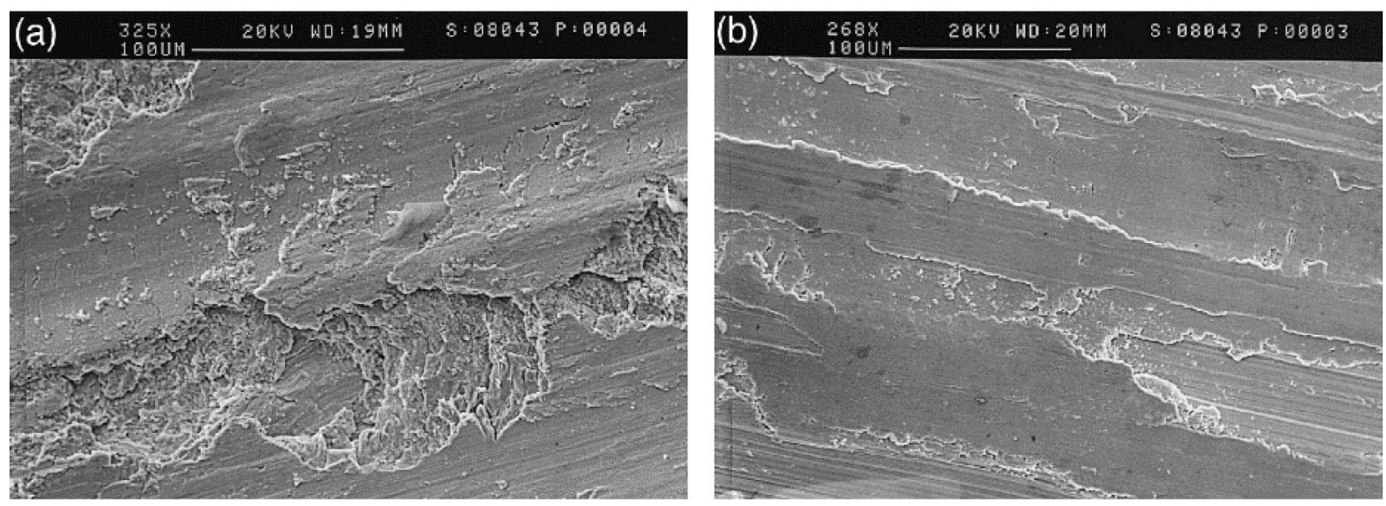

Fig. 23 Worn-out surfaces of Ti64 test specimen slid against AISI M2 steel counter-body at varying sliding velocities (load = $100 \mathrm{~N}$ ): (a) Ti64 pin surface ensuing sliding at $0.3 \mathrm{~m} \cdot \mathrm{s}^{-1}$; (b) Ti64 pin surface ensuing sliding at $0.8 \mathrm{~m} \cdot \mathrm{s}^{-1}$. Reproduced with permission from Ref. [29]. Copyright Elsevier, 1999.

reported to be brittle and gets fragmented, being unstable and does not receive amble support from the strain hardened subsurface regions [29].

\subsection{Ti6Al4V}

Molinari et al. [25] carried out the tribo-characteristic evaluation of Ti64 (cut from cold rolled bars) sliding against the same material counter-face at varying speed and load conditions. The variation in wear volumes as a function of speed and load conditions is as shown in Fig. 24. Wear volume was increased with applied load and never demonstrated a transition in wear mechanism, whereas a minimum wear point exists at intermediate points for each distinct sliding speed test condition. The thickness of the plastically deformed layers and the surface scales was identified to be increased with applied load and was independent of the sliding conditions. At distinct sliding speeds, the morphology and composition of the wear debris produced were notified to be different. During nteractions at $0.3,0.5$, and $0.8 \mathrm{~m} \cdot \mathrm{s}^{-1}$, the morphology of the debris emanating from the mating surfaces, differed from being fine powders to plate-like (medium) and plate-like (large). The particle composition consisted of $\mathrm{TiO}$ (prevailing) and $\alpha-\mathrm{Ti}, \mathrm{TiO}$ and $\alpha-\mathrm{Ti}$, and $\alpha-\mathrm{Ti}$ (prevailing) at low, medium, and high speeds, respectively. Qualitative representation of wear to represent the domains of the occurring wear mechanisms (oxidative and delamination) is as shown in Fig. 25. It was hypothesized based on the results that the oxidative and delamination wear dominated at low and medium sliding speeds. Further, there may exist a region within the oxidative wear region, where plastic deformation occurs leading to the formation of appendage layers which can be a matrix of metallic debris and oxide particles. Based on the detailed review carried out in the above sections, this type of layer got referred to as the MML. Further, the point of
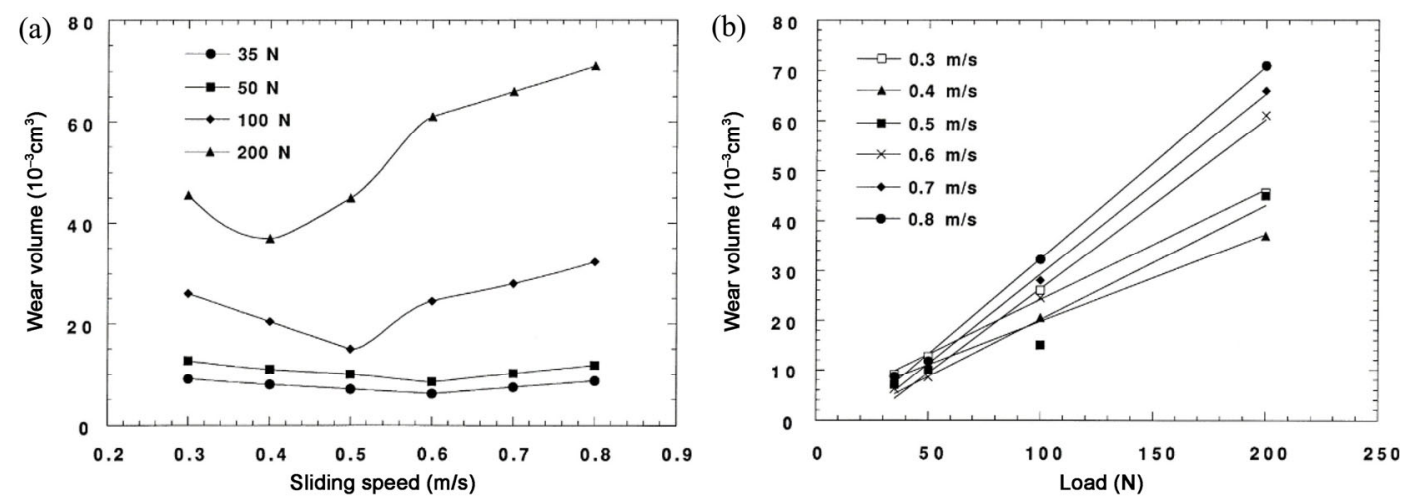

Fig. 24 Wear behavior of Ti64/Ti64 sliding pair: (a) variation in wear volume with increment in sliding speed; (b) variation in wear volume with increment in load. Reproduced with permission from Ref. [25]. Copyright Elsevier, 1997. 


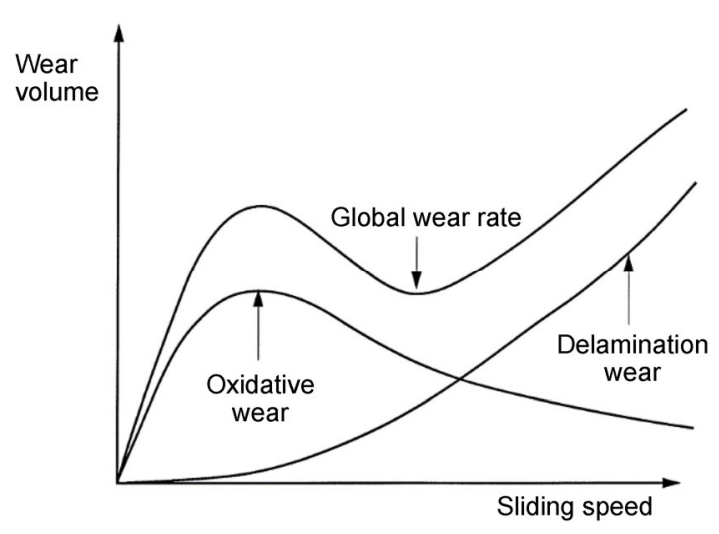

Fig. 25 Qualitative representation of variation in wear volume with increment in sliding speed (representing the domains of the occurring wear mechanisms). Reproduced with permission from Ref. [25]. Copyright Elsevier, 1997.

minimum wear rate got suggested to be the transition node from the oxidative to delamination, the value of which decreases with the applied load [25].

\subsection{Maraging steel}

Long and Rack [31] investigated on the reciprocated dry sliding characteristics of different grades of titanium alloy namely $\mathrm{Ti}-35 \mathrm{Nb}-8 \mathrm{Zr}-5 \mathrm{Ta}$ (without oxygen (TNZT) and with oxygen (TNZTO)), metastable- $\beta$ (21 SRX) and Ti64 (orthopaedic grade). The wear mechanisms pertinent to the Ti-alloys were characterized by plastic deformation, galling, adhesion, micro-plowing, material migration, and mechanical alloying. The notable shear deformation and material transfer associated with 21 SRX was much more prominent than that of Ti64, and hence the greater surface smearing and flaking. The worn surfaces (Fig. 26) produced ensuing the sliding test varied distinctively based on the contact stresses, amount of material migration, surfaces roughness, and the various wear mechanisms. The wear mechanisms associated with Ti64 and the steel counter-body surfaces were micro-plowing, although in minuscule levels for the latter. The existence of $\alpha$-Ti (FCC), $\alpha^{\prime \prime}$-Ti (FCC, martensite, orthorhombic), and $\alpha$-Fe (BCC) got confirmed from the wear debris analysis. Although the quantum of wear debris produced got increased with the rise of contact stresses nevertheless, the Ti64 produced the least amount, comparatively. Hence, the material transfer was proclaimed to be minimum for the alloys leading to micro-plowing, contrary to the other discrete Ti-alloys favoring Ti-Ti interaction (due to the formation of Ti migrated layer over the counter-face). At steady-state conditions, the dynamic frictional response due to the interaction between BCC structured Ti-alloys was identified to be lower as compared to that in the case of FCC [150, 151]. The interaction of Ti alloys $(\alpha$ and $\alpha+\beta)$ against similar counter-bodies, respectively can produce low dynamic friction coefficient compared to $\beta$-Ti [150]. The influence of surface oxides on the frictional behavior pertinent to the present state of sliding was notified to be negligible due to the absence of oxygen content. Finally, the peak interfacial temperature of $200-350{ }^{\circ} \mathrm{C}$ achieved under-considered sliding conditions got proposed as inadequate for $\mathrm{TO}$, and its possible influence on the sliding mechanisms [31].

\section{Summary}

This manuscript was a determined effort to review the tribological aspects of Ti64, in the context of
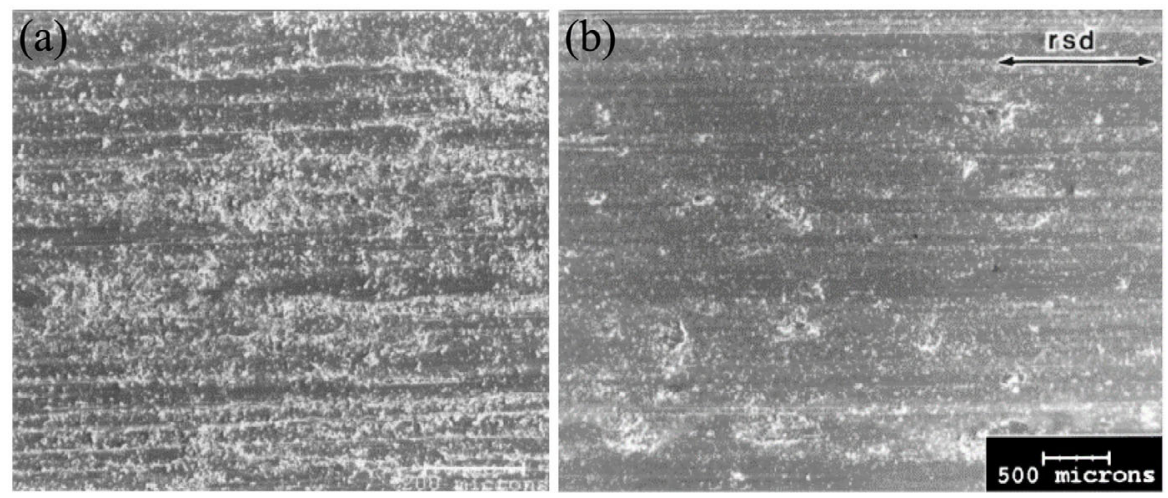

Fig. 26 SEM images of worn surfaces ensuing reciprocated sliding at $5 \mathrm{MPa}$ and after 20,000 cycles: (a) Ti64 (pin); (b) steel counter-face (plate). Reproduced with permission from Ref. [31]. Copyright Elsevier, 2001. 
microstructural variations, factors affecting the tribobehavior and tribo-response at distinct sliding conditions of the alloy. The salient points of the initiative summarized in the crisp form are as detailed below.

- The significance and role of TL on the wear behavior of Ti64 alloy depend on the stability of the developed appendage layers, the nature of which is governed by distinct sliding conditions. The two major categories of TL include MML and TOL; the former existed at all sliding states of the tribo-pairs. The corresponding capacity to impart protective action was primarily governed by the formation/presence of TO and its capability to be in adherence with the substrate to exist as TOL. Hence, the TL will probably impart protective action if the MML and TOL remain in coexistence, thereby contributing mutual support for resistance against wear.

- The hardness of MML and TOL got enhanced with increment in concentration of the induced oxygen content. In the context of $\mathrm{TO}$, this is a case of multi-mechanism occurrence. The scenario can be deduced to the maxim that although higher oxidation rate can impart enhanced tribo-behavior, there exists a limit beyond which internal stresses get developed between the substrate and the appendage layer which leads to its spalling aiding to severe wear.

- Although the factors affecting tribo-behavior of Ti64 were individually specified in terms of ThO, TO, MML, ASB, SRR, FS, DRX, EH, FH, and TS, they are correlated to each other. Precisely, SRR and $\mathrm{EH} / \mathrm{FH}$ can be recognized to possess a superior control on the process; nonetheless, they are not mutually exclusive. While SRR can regulate the occurrence of ASB, FS, and DRX, EH/FH can govern the impact range of the factors, viz., TO, MML, ASB, and TS due to the temperature effect. Overall, EH and cooling methods which can predominantly vary the microstructure of the Ti64 will thereby, diversify the tribo-response of the material.

- At combined low load (50-100 N) and temperature $\left(25-200{ }^{\circ} \mathrm{C}\right)$ conditions, the role of TOL is found to be negligible. The material removal directed by the mechanism of adhesion progressively shifted to abrasion and delamination. Although, some researchers have reported the development of thin layers during such a state of sliding, contradicting results obtained by a few proposed against it. Conversely, at high load (100-200 N) coupled with high temperature $\left(200-500{ }^{\circ} \mathrm{C}\right)$ conditions, TOL was identified to be formed with appreciable thickness and compactness, to impart protective action. The oxidative wear was the only recognized mechanism causing surface damage during tribo-interaction.

- The integrity of the Ti64 surfaces in the context of tribo-behavior was found to degrade with ST, quenching, and aging. The underlying reasons include: (i) the HCP structured materials possessing low work hardenability, (ii) phase transformation leading to the shift in surface characteristics from being ductile to more brittle, and (iii) transition induced stresses or strains. The characteristic wear behaviors associated with the as-received and quench-aged Ti64 samples are micro-plowing, grooving and wedge formation for the former and micro-cutting assisted micro-chip development for the latter.

- The transition in wear mechanism at incremental sliding conditions is notified to be independent of the distinction in microstructures (lamellar, bi-modal or equiaxed), pertinent to the Ti64 specimen. The general trend is that at low sliding speed $\left(0.3 \mathrm{~m} \cdot \mathrm{s}^{-1}\right)$, oxidative wear dominates the material removal process. With the increment in sliding speed $\left(0.6 \mathrm{~m} \cdot \mathrm{s}^{-1}\right)$, there is a shift in wear mechanism from oxidative to delamination. Further, at peak velocity sliding of the pin $\left(0.9 \mathrm{~m} \cdot \mathrm{s}^{-1}\right)$, metallic delamination commands the counter-body interaction assisted wear.

- Finally, the utilization of distinct counter-body surfaces affects the tribo-behavior of the alloy in terms of the type, composition and percentage of the developed surface oxides $\left(\mathrm{TiO}, \mathrm{TiO}_{2}, \mathrm{Ti}_{8} \mathrm{O}_{15}\right.$, $\mathrm{V}_{2} \mathrm{O}_{3}, \mathrm{Fe}_{2} \mathrm{O}_{3}$ ), the existence and severity of the various wear mechanisms (oxidative, delamination or composite) and the nature of the TL (stability, thickness and compactness) at discrete sliding conditions. Regardless, the general trend was that the oxidative wear prevailed at low-velocity, low load and high-temperature interactions and delamination wear dominated at medium velocity sliding, peak load, and low-temperature conditions. For all other states of sliding, the composite wear (a combination of oxidative and delamination wear) demonstrated a significant role. 
Henceforth, from a future perspective, the detailed overview of tribological aspects pertinent to the heavily utilized Ti-alloy (Ti64) covered in this manuscript can eliminate the problems faced in perceiving the vital points. This can extend a unique edge while formulating solutions for surface characteristic enhancement or developing/implementing modification techniques, to improve the interactive behavior of the Ti64 alloy.

\section{Acknowledgements}

The authors extend their humble obligations to the Science and Engineering Research Board (SERB), Department of Science and Technology (DST), Government of India for the research grant sanctioned for the project (Ref. No. ECR/2016/001929) through the aid of which this initiative was undertaken.

Open Access: This article is licensed under a Creative Commons Attribution 4.0 International License, which permits use, sharing, adaptation, distribution and reproduction in any medium or format, as long as you give appropriate credit to the original author(s) and the source, provide a link to the Creative Commons licence, and indicate if changes were made.

The images or other third party material in this article are included in the article's Creative Commons licence, unless indicated otherwise in a credit line to the material. If material is not included in the article's Creative Commons licence and your intended use is not permitted by statutory regulation or exceeds the permitted use, you will need to obtain permission directly from the copyright holder.

To view a copy of this licence, visit http:// creativecommons.org/licenses/by/4.0/.

\section{References}

[1] Raj J A, Pottirayil A, Kailas S V. Dry sliding wear behavior of Ti-6Al-4V Pin against SS316L disk at constant contact pressure. J Tribol 139(2): 021603 (2017)

[2] Mao Y S, Wang L, Chen K M, Wang S Q, Cui X H. Tribolayer and its role in dry sliding wear of Ti-6 Al-4V alloy. Wear 297(1-2): 1032-1039 (2013)

[3] Ganesh B K C, Ramanaih N, Chandrasekhar Rao P V. Dry sliding wear behavior of Ti-6Al-4V implant alloy subjected to various surface treatments. Trans Indian Inst Met 65(5): 425-434 (2012)
[4] Geetha M, Singh A K, Asokamani R, Gogia A K. Ti based biomaterials, the ultimate choice for orthopaedic implants A review. Prog Mater Sci 54(3): 397-425 (2009)

[5] Blau P J, Jolly B C, Qu J, Peter W H, Blue C A. Tribological investigation of titanium-based materials for brakes. Wear 263(7-12): 1202-1211 (2007)

[6] Hasçalık A, Çaydaş U. Electrical discharge machining of titanium alloy (Ti-6Al-4V). Appl Surf Sci 253(22): 90079016 (2007)

[7] Yerramareddy S, Bahadur S. The effect of laser surface treatments on the tribological behavior of Ti-6Al-4V. Wear 157(2): 245-262 (1992)

[8] Buckley D H, Miyoshi K. Friction and wear of ceramics. Wear 100(1-3): 333-353 (1984)

[9] Budinski K G. Tribological properties of titanium alloys. Wear 151(2): 203-217 (1991)

[10] Miller P D, Holladay J W. Friction and wear properties of titanium. Wear 2(2): 133-140 (1958)

[11] Liao S C, Duffy J. Adiabatic shear bands in a TI-6Al-4V titanium alloy. J Mech Phys Solids 46(11): 2201-2231 (1998)

[12] Timothy S P, Hutchings I M. The structure of adiabatic shear bands in a titanium alloy. Acta Metall 33(4): 667-676 (1985)

[13] Shahan A R, Taheri A K. Adiabatic shear bands in titanium and titanium alloys: A critical review. Mater Des 14(4): 243-250 (1993)

[14] Hussein M A, Mohammed A A, Al-Aqeeli N. Wear characteristics of metallic biomaterials: A review. Materials (Basel) 8(5): 2749-2768 (2015)

[15] Niinomi M. Mechanical biocompatibilities of titanium alloys for biomedical applications. $J$ Mech Behav Biomed Mater 1(1): 30-42 (2008)

[16] Blau P J, Erdman III D L, Ohriner E, Jolly B C. Hightemperature galling characteristics of TI-6AL-4V with and without surface treatments. Tribol Trans 54(2): 192-200 (2011)

[17] Guleryuz H, Cimenoglu H. Surface modification of a Ti-6Al-4V alloy by thermal oxidation. Surf Coat Technol 192(2-3): 164-170 (2005)

[18] Mantry S, Jha B B, Mandal A, Mishra D K, Mishra B K, Chakraborty M. Influence of in-flight particle state diagnostics on properties of plasma sprayed $\mathrm{YSZ}-\mathrm{CeO}_{2}$ nanocomposite coatings. Int J Smart Nano Mater 5(3): 207-216 (2014)

[19] Feng C, Khan T I. The effect of quenching medium on the wear behaviour of a Ti-6Al-4V alloy. J Mater Sci 43(2): 788-792 (2008)

[20] Cvijović-Alagić I, Mitrović S, Cvijović Z, Veljović ĐĐ, Babić M, Rakin M. Influence of the heat treatment on the tribological characteristics of the Ti-based alloy for biomedical applications. Tribol Ind 31(3-4): 17-22 (2009) 
[21] Sahoo R, Jha B B, Sahoo T K. Dry sliding wear behaviour of Ti-6Al-4V alloy consisting of bimodal microstructure. Trans Indian Inst Met 67(2): 239-245 (2014)

[22] Zhecheva A, Sha W, Malinov S, Long A. Enhancing the microstructure and properties of titanium alloys through nitriding and other surface engineering methods. Surf Coat Technol 200(7): 2192-2207 (2005)

[23] Johns S M, Bell T, Samandi M, Collins G A. Wear resistance of plasma immersion ion implanted Ti6Al4V. Surf Coat Technol 85(1-2): 7-14 (1996)

[24] Roliński E. Isothermal and cyclic plasma nitriding of titanium alloys. Surf Eng 2(1): 35-42 (1986)

[25] Molinari A, Straffelini G, Tesi B, Bacci T. Dry sliding wear mechanisms of the Ti6Al4V alloy. Wear 208(1-2): 105-112 (1997)

[26] Borgioli F, Galvanetto E, Iozzelli F, Pradelli G. Improvement of wear resistance of Ti-6Al-4V alloy by means of thermal oxidation. Mater Lett 59(17): 2159-2162 (2005)

[27] Bhattacharyya D, Viswanathan G B, Vogel S C, Williams D J, Venkatesh V, Fraser H L. A study of the mechanism of $\alpha$ to $\beta$ phase transformation by tracking texture evolution with temperature in Ti-6Al-4V using neutron diffraction. $\mathrm{Scr}$ Mater 54(2): 231-236 (2006)

[28] Chiou S T, Tsai H L, Lee W S. Effects of strain rate and temperature on the deformation and fracture behaviour of titanium alloy. Mater Trans 48(9): 2525-2533 (2007)

[29] Straffelini G, Molinari A. Dry sliding wear of Ti-6Al-4V alloy as influenced by the counterface and sliding conditions. Wear 236(1-2): 328-338 (1999)

[30] Dong H, Bell T. Enhanced wear resistance of titanium surfaces by a new thermal oxidation treatment. Wear 238(2): 131-137 (2000)

[31] Long M, Rack H J. Friction and surface behavior of selected titanium alloys during reciprocating-sliding motion. Wear 249(1-2): 157-167 (2001)

[32] Lin N M, Zhang H Y, Zou J J, Tang B. Recent developments in improving tribological performance of TC4 titanium alloy via double glow plasma surface alloying in China: A literature review. Rev Adv Mater Sci 38: 61-74 (2014).

[33] Łępicka M, Grądzka-Dahlke M. Surface modification of ti6al4v titanium alloy for biomedical applications and its effect on tribological performance-a review. Rev Adv Mater Sci 46: 86-103 (2016).

[34] Lim S C, Ashby M F. Overview no. 55 Wear-Mechanism maps. Acta Metall 35(1): 1-24 (1987)

[35] Stachowiak G W, Batchelor A W. Engineering Tribology. Amsterdam (The Netherlands): Elsevier, 1993.

[36] Wilson J E, Stott F H, Wood G C. The development of wearprotective oxides and their influence on sliding friction. Proc
Roy Soc A Math Phys Eng Sci 369(1739): 557-574 (1980)

[37] Welsh N C. Frictional heating and its influence on the wear of steel. J Appl Phys 28(9): 960-968 (1957)

[38] Quinn T F J, Rowson D M, Sullivan J L. Application of the oxidational theory of mild wear to the sliding wear of low alloy steel. Wear 65(1): 1-20 (1980)

[39] Zhang J, Alpas A T. Transition between mild and severe wear in aluminium alloys. Acta Mater 45(2): 513-528 (1997)

[40] Donachie Jr M J. Titanium: A Technical Guide. 2nd ed. Metals Park, OH (USA): ASM International, 2000.

[41] Verlinden B, Driver J, Samajdar I, Doherty R D. ThermoMechanical Processing of Metallic Materials. Amsterdam (The Netherlands): Elsevier, 2007.

[42] Humphreys F J, Hatherly M. Recrystallization and Related Annealing Phenomena. 2nd ed. Amsterdam (The Netherlands): Elsevier, 2004.

[43] Bhattacharyya D, Viswanathan G B, Denkenberger R, Furrer D, Fraser H L. The role of crystallographic and geometrical relationships between $\alpha$ and $\beta$ phases in an $\alpha / \beta$ titanium alloy. Acta Mater 51(16): 4679-4691 (2003)

[44] Lütjering G. Influence of processing on microstructure and mechanical properties of $(\alpha+\beta)$ titanium alloys. Mater $S c i$ Eng A 243(1-2): 32-45 (1998)

[45] Lütjering G. Property optimization through microstructural control in titanium and aluminum alloys. Mater Sci Eng A 263(2): 117-126 (1999)

[46] Rack H J, Qazi J I. Titanium alloys for biomedical applications. Mater Sci Eng C 26(8): 1269-1277 (2006)

[47] Leyens C, Peters M. Titanium and Titanium Alloys: Fundamentals and Applications. Weinheim (UK): John Wiley \& Sons, 2003.

[48] Filip R, Kubiak K, Ziaja W, Sieniawski J. The effect of microstructure on the mechanical properties of two-phase titanium alloys. J Mater Process Technol 133(1-2): 84-89 (2003)

[49] Huang J Y, Zhu Y T, Liao X Z, Beyerlein I J, Bourke M A, Mitchell T E. Microstructure of cryogenic treated M2 tool steel. Mater Sci Eng A 339(1-2): 241-244 (2003)

[50] Sahoo R, Jha B B, Sahoo T K, Sahoo D. Effect of microstructural variation on dry sliding wear behavior of Ti-6Al-4V alloy. J Mater Eng Perform 23(6): 2092-2102 (2014)

[51] Lütjering G, Williams J C. Titanium. 2nd ed. Berlin Heidelberg (Germany): Springer, 2007.

[52] Tarín P, Gualo A, Simón A G, Piris N M, Badía J M. Study of alpha-beta transformation in Ti-6Al-4V-ELI. Mechanical and microstructural characteristics. Mater Sci Forum 638-642: 712-717 (2010)

[53] Yang J J, Yu H C, Yin J, Gao M, Wang Z M, Zeng X Y. Formation and control of martensite in Ti-6Al-4V alloy 
produced by selective laser melting. Mater Des 108: 308-318 (2016)

[54] Mantani Y, Tajima M. Phase transformation of quenched $\alpha^{\prime \prime}$ martensite by aging in Ti-Nb alloys. Mater Sci Eng $A$ 438-440: 315-319 (2006)

[55] Ahmed T, Rack H J. Phase transformations during cooling in $\alpha+\beta$ titanium alloys. Mater Sci Eng A 243(1-2): 206-211 (1998)

[56] Ding R, Guo Z X, Wilson A. Microstructural evolution of a Ti-6Al-4V alloy during thermomechanical processing. Mater Sci Eng A 327(2): 233-245 (2002)

[57] Kherrouba N, Bouabdallah M, Badji R, Carron D, Amir M. Beta to alpha transformation kinetics and microstructure of Ti-6Al-4V alloy during continuous cooling. Mater Chem Phys 181: 462-469 (2016)

[58] Sukumar G, Singh B B, Bhattacharjee A, Sivakumar K, Gogia A K. Effect of Heat treatment on mechanical properties and ballistic performance of Ti-4Al-2.3V-1.9Fe alloy. Mater Today Proc 2(4-5): 1102-1108 (2015)

[59] Tan X P, Kok Y, Toh W Q, Tan Y J, Descoins M, Mangelinck D, Tor S B, Leong K F, Chua C K. Revealing martensitic transformation and $\alpha / \beta$ interface evolution in electron beam melting three-dimensional-printed Ti-6Al-4V. Sci Rep 6: 26039 (2016)

[60] Ankem S, Greene C A. Recent developments in microstructure/ property relationships of beta titanium alloys. Mater Sci Eng A 263(2): 127-131 (1999)

[61] Hadke S, Khatirkar R K, Shekhawat S K, Jain S, Sapate S G. Microstructure evolution and abrasive wear behavior of Ti-6Al-4V alloy. J Mater Eng Perform 24(10): 3969-3981 (2015)

[62] Assadi A T K, Flower H M, West D R F. Microstructure and strength of alloys of the Ti-Al-Zr-Mo-Si system. Met Technol 6(1): 8-15 (1979)

[63] Banerjee D, Muraleedharan K, Strudel J L. Substructure in titanium alloy martensite. Philos Mag A 77(2): 299-323 (1998)

[64] Bendersky L A, Roytburd A, Boettinger W J. Phase transformations in the (Ti, Al)3 Nb section of the Ti-Al-Nb system-I. Microstructural predictions based on a subgroup relation between phases. Acta Metall Mater 42(7): 2323-2335 (1994)

[65] Borradaile J B, Jeal R H. Mechanical Properties of Titanium Alloys. Derby (UK): Rolls Royce Ltd, 1981.

[66] Pinke P, Čaplovič L, Kovacs T. The influence of heat treatment on the microstructure of the casted Ti6Al4V titanium alloy. Bratislava: Slovak University, 2011.

[67] Dąbrowski R. The kinetics of phase transformations during continuous cooling of the Ti6A14V alloy from the singlephase $\beta$ range. Arch Metall Mater 56(3): 703-707 (2011)

[68] Charles C. Modelling microstructure evolution of weld deposited Ti-6Al-4V. Ph.D Thesis. Luleå (Sweden): Luleå University of Technology, 2008.

[69] Gammon L M, Briggs R D, Packard J M, Batson K W, Boyer R, Domby C W. Metallography and microstructures of titanium and its alloys. In Metallography and Microstructures. McCall J L, Olson D L, LeMay I, Eds. Metals Park, OH: ASM International, 2004: 899-917

[70] Bhadeshia H, Honeycombe R. Steels: Microstructure and Properties. 4th ed. Oxford (UK): Butterworth-Heinemann, 2017.

[71] Ungár T. Microstructural parameters from X-ray diffraction peak broadening. Scr Mater 51(8): 777-781 (2004)

[72] Khatirkar R K, Yadav P, Sapate S G. Structural and wear characterization of heat treated En24 steel. ISIJ Int 52(7): 1370-1376 (2012)

[73] Khatirkar R K, Murty B S. Structural changes in iron powder during ball milling. Mater Chem Phys 123(1): 247-253 (2010)

[74] Williamson G, Hall W H. X-ray line broadening from filed aluminium and wolfram. Acta Metall 1(1): 22-31 (1953)

[75] Burgers W G. On the process of transition of the cubicbody-centered modification into the hexagonal-close-packed modification of zirconium. Physica 1(7-12): 561-586 (1934)

[76] Germain L, Gey N, Humbert M, Vo P, Jahazi M, Bocher P. Texture heterogeneities induced by subtransus processing of near $\alpha$ titanium alloys. Acta Mater 56(16): 4298-4308 (2008)

[77] Germain L, Gey N, Humbert M. Reliability of reconstructed $\beta$-orientation maps in titanium alloys. Ultramicroscopy 107(12): 1129-1135 (2007)

[78] Tylczak J H. Abrasive wear. In Frict Lubr. Wear Technology. ASM International, 1992: 184-190.

[79] Hutchings I, Shipway P. Tribology: Friction and Wear of Engineering Materials. 2nd ed. Oxford (UK): ButterworthHeinemann, 2017.

[80] Xu Z C, Kriegel H P. The martensitic transformation in Ti-6Al-4V. Mater Sci Forum 914: 140-148 (2018)

[81] Rigney D A. Some thoughts on sliding wear. Wear 152(1): 187-192 (1992)

[82] Wang L, Li X X, Zhou Y, Zhang Q Y, Chen K M, Wang S Q. Relations of counterface materials with stability of tribo-oxide layer and wear behavior of Ti-6.5Al-3.5Mo1.5Zr-0.3Si alloy. Tribol Int 91: 246-257 (2015)

[83] Wilson S, Alpas A T. Thermal effects on mild wear transitions in dry sliding of an aluminum alloy. Wear 225-229: 440-449 (1999) 
[84] Dwivedi D K. Sliding temperature and wear behaviour of cast Al-Si-Mg alloys. Mater Sci Eng A 382(1-2): 328-334 (2004)

[85] Jin T, Rowe W B, McCormack D. Temperatures in deep grinding of finite workpieces. Int J Mach Tools Manuf 42(1): 53-59 (2002)

[86] Komanduri R, Hou Z B. Analysis of heat partition and temperature distribution in sliding systems. Wear 251(1-12): 925-938 (2001)

[87] Wilson S, Alpas A T. Wear mechanism maps for metal matrix composites. Wear 212(1): 41-49 (1997)

[88] Pürçek G, Savaşkan T, Küçükömeroğlu T, Murphy S. Dry sliding friction and wear properties of zinc-based alloys. Wear 252(11-12): 894-901 (2002)

[89] Hsu S M, Shen M C, Ruff A W. Wear prediction for metals. Tribol Int 30(5): 377-383 (1997)

[90] Alam M O, Haseeb A S M A. Response of Ti-6Al-4V and Ti-24Al-11 Nb alloys to dry sliding wear against hardened steel. Tribol Int 35(6): 357-362 (2002)

[91] Ghaednia H, Jackson R L. The effect of nanoparticles on the real area of contact, friction, and wear. $J$ Tribol 135(4): 041603 (2013)

[92] Krishna D S R, Brama Y L, Sun Y. Thick rutile layer on titanium for tribological applications. Tribol Int 40(2): 329-334 (2007)

[93] Dong H, Li X Y. Oxygen boost diffusion for the deep-case hardening of titanium alloys. Mater Sci Eng A 280(2): 303-310 (2000)

[94] Yazdanian M M, Edrisy A, Alpas A T. Vacuum sliding behaviour of thermally oxidized Ti-6Al-4V alloy. Surf Coat Technol 202(4-7): 1182-1188 (2007)

[95] Frangini S, Mignone A, De Riccardis F Various aspects of the air oxidation behaviour of a Ti6Al4V alloy at temperatures in the range $600-700{ }^{\circ} \mathrm{C} . J$ Mater Sci 29(3): 714-720 (1994)

[96] Chaze A M, Coddet C. The role of nitrogen in the oxidation behaviour of titanium and some binary alloys. J Less Common Met 124(1-2): 73-84 (1986)

[97] Borgioli F, Galvanetto E, Fossati A, Pradelli G. Glowdischarge and furnace treatments of Ti-6Al-4V. Surf Coat Technol 184(2-3): 255-262 (2004)

[98] Mushiake M, Asano K, Miyamura N, Nagano S. Development of titanium alloy valve spring retainers. SAE Transactions. SAE, 1991: 475-483.

[99] Bertrand G, Jarraya K, Chaix J M. Morphology of oxide scales formed on titanium. Oxid Met 21(1-2): 1-19 (1984)

[100] Qin Y X, Lu W J, Zhang D, Qin J N, Ji B. Oxidation of in situ synthesized $\mathrm{TiC}$ particle-reinforced titanium matrix composites. Mater Sci Eng A 404(1-2): 42-48 (2005)
[101] Dong H, Bloyce A, Morton P H, Bell T. Surface engineering to improve tribological performance of Ti-6Al-4V. Surf Eng 13(5): 402-406 (1997)

[102] Dearnley P A, Dahm K L, Çimenoğlu H. The corrosion-wear behaviour of thermally oxidised CP-Ti and Ti-6Al-4V. Wear 256(5): 469-479 (2004)

[103] Güleryüz H, Çimenoğlu H. Effect of thermal oxidation on corrosion and corrosion-wear behaviour of a $\mathrm{Ti}-6 \mathrm{Al}-4 \mathrm{~V}$ alloy. Biomaterials 25(16): 3325-3333 (2004)

[104] Glaeser W A. Wear experiments in the scanning electron microscope. Wear 73(2): 371-386 (1981)

[105] Buckley D H, Pepper S V. Elemental analysis of a friction and wear surface during sliding using auger spectroscopy. A S L E Trans 15(4): 252-260 (1972)

[106] Li X X, Zhou Y, Ji X L, Li Y X, Wang S Q. Effects of sliding velocity on tribo-oxides and wear behavior of Ti-6Al-4V alloy. Tribol Int 91: 228-234 (2015)

[107] Pauschitz A, Roy M, Franek F. Mechanisms of sliding wear of metals and alloys at elevated temperatures. Tribol Int 41(7): 584-602 (2008)

[108] Coddet C, Craze A M, Beranger G. Measurements of the adhesion of thermal oxide films: Application to the oxidation of titanium. J Mater Sci 22(8): 2969-2974 (1987)

[109] Stott F H, Glascott J, Wood G C. Models for the generation of oxides during sliding wear. Proc Roy Soc A Math Phys Eng Sci 402(1822): 167-186 (1985)

[110] Sullivan J L, Hodgson S G. A study of mild oxidational wear for conditions of low load and speed. Wear 121(1): 95-106 (1988)

[111] Ludema K. Friction, Wear, Lubrication: A Textbook in Tribology. Boca Raton (USA): CRC Press, 1996

[112] Collings E W. The Physical Metallurgy of Titanium Alloys. Metals Park Ohio (USA): America Society for Metals, 1984.

[113] Cui X H, Mao Y S, Wei M X, Wang S Q. Wear characteristics of Ti-6Al-4V alloy at $20-400{ }^{\circ}$ C. Tribol Trans 55(2): 185-190 (2012)

[114] Ming Q, Zhang Y Z, Yang J H, Zhu J. Microstructure and tribological characteristics of $\mathrm{Ti}-6 \mathrm{Al}-4 \mathrm{~V}$ alloy against GCr15 under high speed and dry sliding. Mater Sci Eng A 434(1-2): 71-75 (2006)

[115] Du H L, Datta P K, Lewis D B, Burnell-Gray J S. Enhancement of oxidation/sulphidation resistance of $\mathrm{Ti}$ and Ti-6Al-4V alloy by HfN coating. Mater Sci Eng $A$ 205(1-2): 199-208 (1996)

[116] Wang L, Zhang Q Y, Li X X, Cui X H, Wang S Q. Severe-to-mild wear transition of titanium alloys as a function of temperature. Tribol Lett 53(3): 511-520 (2014) 
[117] Wang L, Zhang Q Y, Li X X, Cui X H, Wang S Q. Dry sliding wear behavior of Ti-6.5Al-3.5Mo-1.5Zr-0.3Si alloy. Metall Mater Trans A 45(4): 2284-2296 (2014)

[118] Rigney D A. Fundamentals of Friction and Wear of Materials. Metals Park, Ohio (USA): American Society of Metallurgy, 1981.

[119] Rigney D. Transfer and its effects during unlubricated sliding. In Metal Transfer and Galling in Metallic Systems. Bhansali K, Merchant H D, Eds. Warrendale: Metallurgical Society, 1987: 87-102.

[120] Rigney D. Microstructural evolution during sliding. In Wear Eng Mater. 1998: 3-12.

[121] Kailas S V, Biswas S K. Sliding wear of copper against alumina. J Tribol 121(4): 795-801 (1999)

[122] Kailas S V, Biswas S K. The role of strain rate response in plane strain abrasion of metals. Wear 181-183: 648-657 (1995)

[123] Biswas S K, Kailas S V. Strain rate response and wear of metals. Tribol Int 30(5): 369-375 (1997)

[124] Prasad Y V R K, Gegel H L, Doraivelu S M, Malas J C, Morgan J T, Lark K A, Barker D R. Modeling of dynamic material behavior in hot deformation: Forging of Ti-6242. Metall Trans A 15(10): 1883-1892 (1984)

[125] Prasad Y V R K, Seshacharyulu T. Modelling of hot deformation for microstructural control. Int Mater Rev 43(6): 243-258 (1998)

[126] Chelliah N, Kailas S V. Synergy between tribo-oxidation and strain rate response on governing the dry sliding wear behavior of titanium. Wear 266(7-8): 704-712 (2009)

[127] Nemat-Nasser S, Guo W G, Nesterenko V F, Indrakanti S $\mathrm{S}, \mathrm{Gu} \mathrm{Y}$ B. Dynamic response of conventional and hot isostatically pressed Ti-6Al-4V alloys: Experiments and modeling. Mech Mater 33(8): 425-439 (2001)

[128] Rittel D, Wang Z G. Thermo-mechanical aspects of adiabatic shear failure of AM50 and Ti6A14V alloys. Mech Mater 40(8): 629-635 (2008)

[129] Kailas S V, Prasad Y V R K, Biswas S K. Flow Instabilities and fracture in Ti-6Al-4V deformed in compression at 298 K to 673 K. Metall Mater Trans A 25(10): 2173-2179 (1994)

[130] Ramirez A C. Microstructural properties associated with adiabatic shear bands in titanium-aluminum-vanadium deformed by ballistic impact. El Paso (USA): The University of Texas at El Paso, 2008.

[131] Me-Bar Y, Shechtman D. On the adiabatic shear of Ti-6Al-4V ballistic targets. Mater Sci Eng 58(2): 181-188 (1983)

[132] Alpas A T, Hu H, Zhang J. Plastic deformation and damage accumulation below the worn surfaces. Wear 162-164: 188-195 (1993)

[133] Osovski S, Rittel D, Venkert A. The respective influence of microstructural and thermal softening on adiabatic shear localization. Mech Mater 56: 11-22 (2013)

[134] Johnson G R, Cook W H. A constitutive model and data for metals subjected to large strains, high strain rates and high temperatures. In Proceedings of the 7th International Symposium on Ballistics, The Hague, The Netherlands, 1983: 541-547.

[135] Biswas C P. Strain hardening of titanium by severe plastic deformation. Ph.D Thesis. Cambridge (USA): Massachusetts Institute of Technology, 1973.

[136] Laird C. Strain rate sensitivity effects in cyclic deformation and fatigue crack. In Proceedings of the 1st International Conference on Corros. Fatigue up to Ultrason. Freq, 1982.

[137] Hager Jr C H, Sanders J H, Sharma S. Effect of high temperature on the characterization of fretting wear regimes at Ti6Al4V interfaces. Wear 260(4-5): 493-508 (2006)

[138] Ming Q, Zhang Y Z, Zhu J, Yang J H. Correlation between the characteristics of the thermo-mechanical mixed layer and wear behaviour of Ti-6Al-4V alloy. Tribol Lett 22(3): 227-231 (2006)

[139] Suh N P. The delamination theory of wear. Wear 25(1): 111-124 (1973)

[140] Venkataraman B, Sundararajan G. The sliding wear behaviour of Al-SiC particulate composites-II. The characterization of subsurface deformation and correlation with wear behaviour. Acta Mater 44(2): 461-473 (1996)

[141] Biswas S K. Wear of metals: A material approach. In Wear-Materials, Mechanisms and Practice. Stachowiak G W, Ed. Chichester: John Wiley \& Sons, 2005: 21-36.

[142] Kailas S V, Biswas S K. Sliding wear of titanium. J Tribol 119(1): 31-35 (1997)

[143] Gil F J, Planell J A. Behaviour of normal grain growth kinetics in single phase titanium and titanium alloys. Mater Sci Eng A 283(1-2): 17-24 (2000)

[144] Mercer A P, Hutchings I M. The influence of atmospheric composition on the abrasive wear of titanium and Ti-6Al-4V. Wear 124(2): 165-176 (1988)

[145] Kumar J, Eswara Prasad N, Kumar V. Damage micromechanisms in IMI-834 titanium alloy: Stress triaxiality effects. Trans Indian Inst Met 61(5): 415-417 (2008)

[146] Kumar J, Punnose S, Mukhopadhyay C K, Jayakumar T, Kumar V. Acoustic emission during tensile deformation of smooth and notched specimens of near alpha titanium alloy. Res Nondestruct Eval 23(1): 17-31 (2012).

[147] Sahoo R, Mantry S, Sahoo T K, Mishra S, Jha B B. Effect 
of microstructural variation on erosion wear behavior of Ti-6Al-4V alloy. Tribol Trans 56(4): 555-560 (2013)

[148] Singh J, Alpas A T. High-temperature wear and deformation processes in metal matrix composites. Metall Mater Trans A 27(10): 3135-3148 (1996)

[149] Venkatesan S, Rigney D A. Sliding friction and wear of

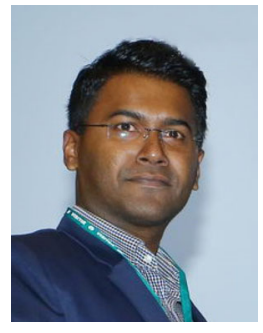

Jibin T PHILIP. He received his bachelor degree in mechanical engineering and master degree in machine design with affiliation from Mahatma Gandhi University, Kerala, India and APJ Abdul Kalam Technological University, Kerala, India, respectively. Presently, he is serving as senior

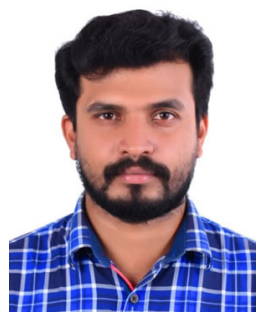

Basil KURIACHEN. $\mathrm{He}$ is an assistant professor in the Department of Mechanical Engineering, National Institute of Technology Mizoram, Aizawl, Mizoram, India. His vivacity and dexterity towards abiding commitment to sublime work ethic conferred him with the Ph.D. and M. Tech degree from plain carbon steels in air and vacuum. Wear 153(1): 163-178 (1992)

[150] Fayeulle S, Blanchard P, Vincent L. Fretting behavior of titanium alloys. Tribol Trans 36(2): 267-275 (1993)

[151] Rigney D A, Hirth J P. Plastic deformation and sliding friction of metals. Wear 53(2): 345-370 (1979)

research fellow (SRF) for a DST-SERB Project, funded by the Government of India and Research Scholar in the Department of Mechanical Engineering at National Institute of Technology Mizoram, Aizawl, Mizoram, India. His primary research interests are in the fields of tribology, nano-tribology, surface coatings, nanolubricants, advanced manufacturing, and surface characterization.

NIT Calicut (2015) and Mahatma Gandhi University, Kottayam (2011), respectively. His resolute research niches are in the field of micro- and nano-machining processes, precision and ultra-precision machining, and modeling and analysis in machining of "difficult to machine" materials. He has to his credit, 45 research publications in international referred journals and conferences alongside with two filed patents. 